\title{
SISTEMÁTICA, FILOGENIA Y FILOGEOGRAFÍA DE LAS RANAS PATAGÓNICAS ATELOGNATHUS PATAGONICUS Y ATELOGNATHUS PRAEBASALTICUS
}

\section{Lic. Liza Beatriz Martinazzo Giménez}

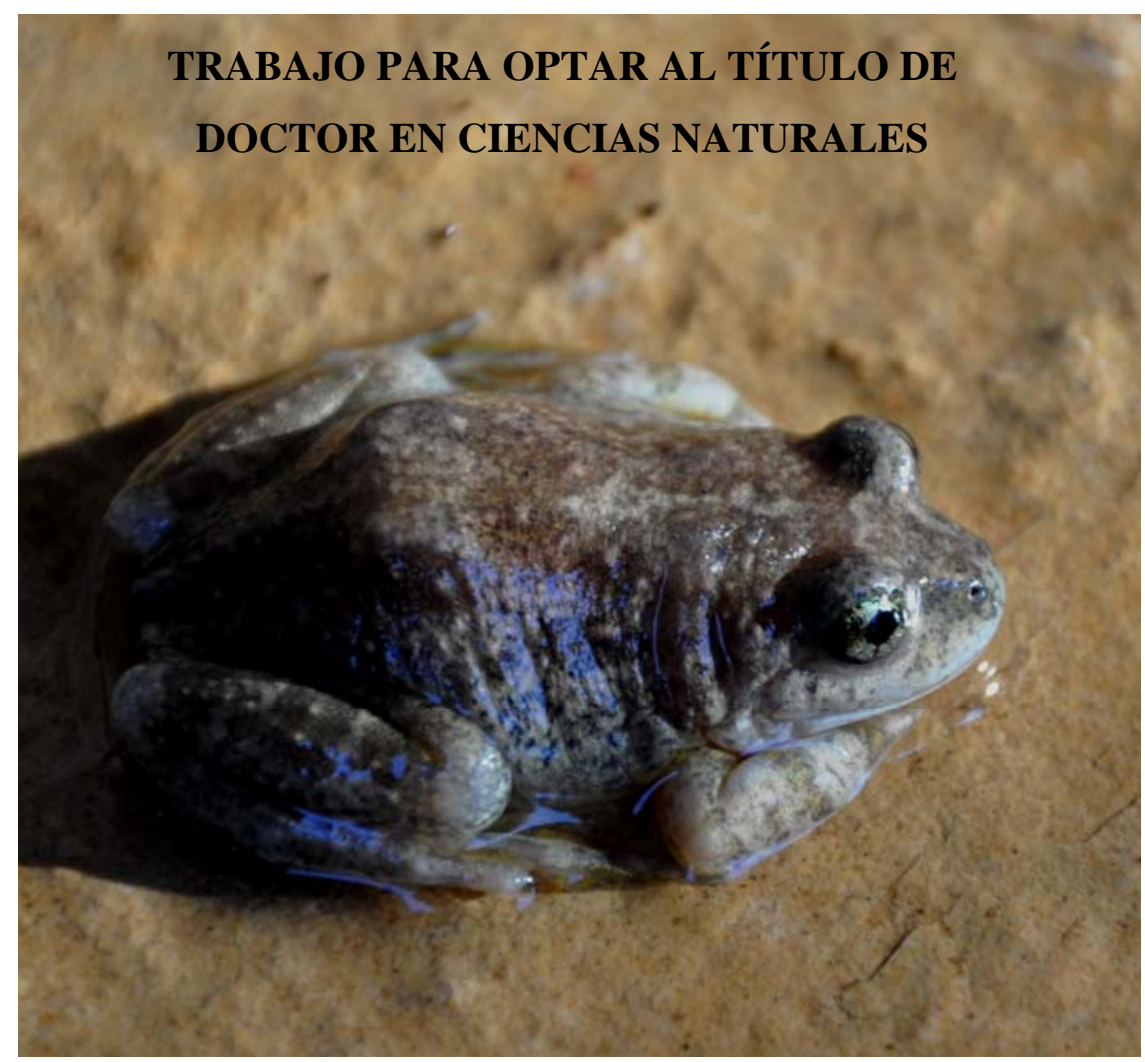

Director: Néstor Guillermo Basso Co-Director: Hugo Luis López

Facultad de Ciencias Naturales y Museo. Universidad Nacional de La Plata (UNLP) 
Con mucho amor y cariño esta Tesis la dedico a Sergio, a Zoe y a todos ustedes.

Debes amar el tiempo de los intentos debes amar la hora que nunca brilla y si no, no pretendas tocar lo cierto.

Silvio Rodríguez 
Agradecimientos

En este tiempo he tenido la enorme suerte y satisfacción de conocer y de trabajar con personas que me han ayudado -de una forma u otra- en la consecución de un esfuerzo de investigación, que se recoge en el presente documento de tesis doctoral y a las que les estoy profundamente agradecida. Aunque el hecho de exponer una lista de personas siempre supone el riesgo de olvidar a alguna de ellas, sí quisiera hacer una especial mención de agradecimiento para las siguientes.

En primer lugar quisiera mencionar al Dr. Néstor G. Basso por aceptarme para realizar esta tesis doctoral bajo su dirección. Su apoyo y confianza en mi trabajo han sido un aporte invaluable en el desarrollo de esta tesis. Le agradezco también el haberme facilitado siempre los medios suficientes para llevar a cabo todas las actividades propuestas durante el desarrollo de esta tesis. También quisiera agradecer al Dr. Hugo López por haber aceptado ser mi co-director, y al que me gustaría agradecerle la confianza que ha depositado en mí en el decurso de esta tesis doctoral.

A mis compañeros: mi infinito agradecimiento al Lic. Luciano Real quien además de brindarme sus conocimientos, experiencias profesionales, colaboración en las actividades de laboratorio- desde el primer momento me ha permitido considerarlo un amigo, con el que siempre pude contar. Quisiera también agradecer a Marcela Iglesias, por su ayuda en las tareas de laboratorio y por sus mates. A Berenice Trovant, por su apoyo y su capacidad de servicio.

Agradezco muy especialmente a la Dra. Carmen A. Úbeda y a la Lic. María Marta Bunge por su gran aporte a la realización de este trabajo.

También quisiera mencionar a la Dra. Carla Riva Rossi, quien me ha ayudado muchísimo en distintos momentos durante estos cuatro años, aportándome conocimientos, ideas, emociones y dedicándome horas cuando las he necesitado. 
Quisiera agradecer a la Dra. Mariana Morando por su ayuda en cada consulta que le he hecho y por la revisión del manuscrito en la última etapa.

A la Administración de Parques Nacionales por su autorización a realizar trabajos de campo en el Parque Nacional Laguna Blanca, a la Facultad de Ciencias Naturales y Museo (UNLP) por haberme permitido realizar mi doctorado, al CONICET por las becas que me otorgó para poder realizar este trabajo y al Centro Nacional Patagónico (CENPAT) por haberme dado lugar de trabajo durante estos cuatro años.

Quiero expresar también mi agradecimiento a mis amigas que me han dado fuerzas y ayudado siempre y todas las personas que de una u otra manera han hecho posible este trabajo.

Finalmente -a los que están en mi corazón y son mi vida- quiero agradecer profundamente a mi esposo, Sergio Saba y a mi hija Zoe. Me brindaron su apoyo, me comprendieron, tuvieron tolerancia e infinita paciencia y cedieron su tiempo para que "Mamá trabaje", para permitir así llevar adelante un proyecto que pasó de ser una meta personal a un emprendimiento más de familia. A ellos, mi eterno amor y gratitud. Además, un agradecimiento y un reconocimiento especial a mis padres, Laura y Raúl, por su ejemplo de lucha y honestidad; a mi hermana Luchi por su luz, por su tenacidad y por su superación; a mi hermano Andrés por su paciencia, inteligencia y generosidad y a mi hermano Rogelio por ser un ejemplo de valentía, capacidad y superación.

...por ellos y para ellos! 
Índice

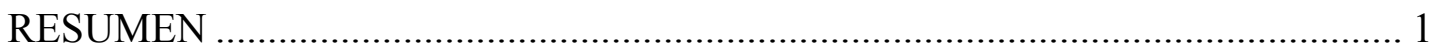

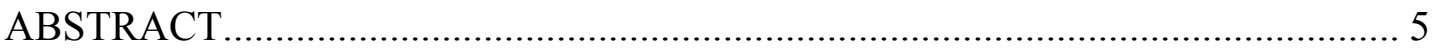

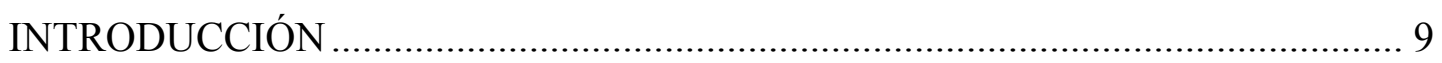

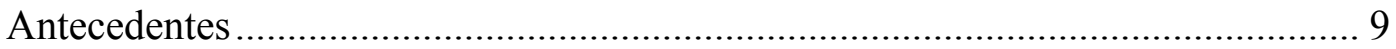

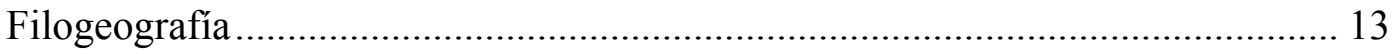

Teoría de la Coalescencia: teoría subyacente de la filogeografía......................... 22

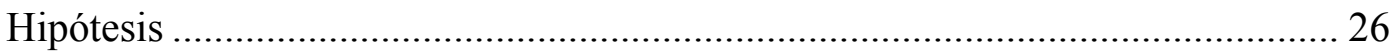

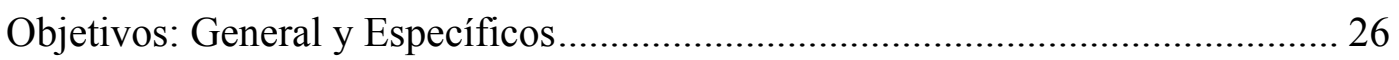

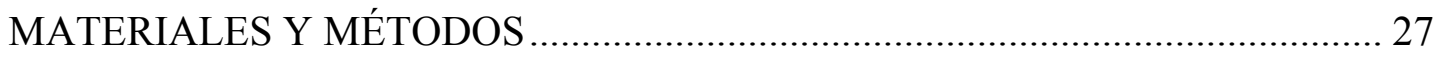

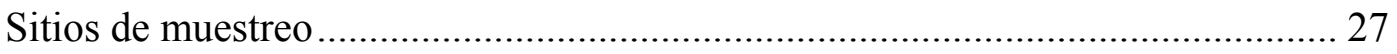

Captura y preservación del material colectado .................................................. 42

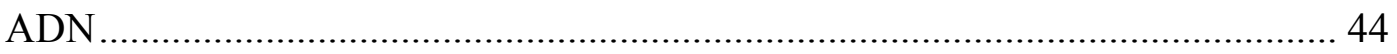

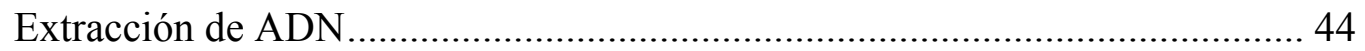

Amplificación y secuenciación del ADN …................................................. 44

Edición y alineamiento de secuencias ................................................................ 45

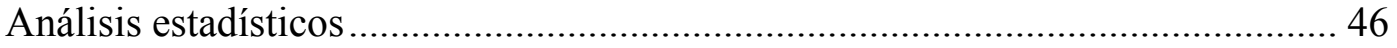

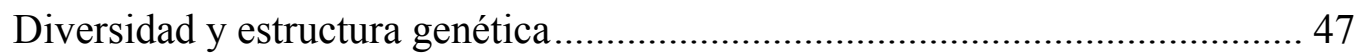

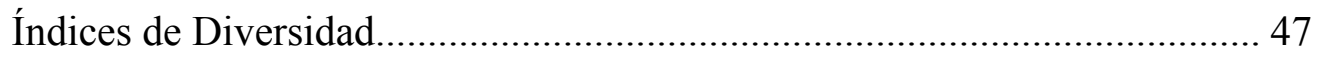

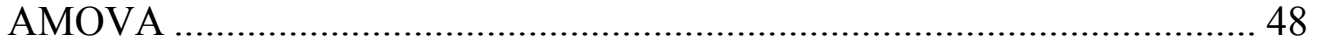

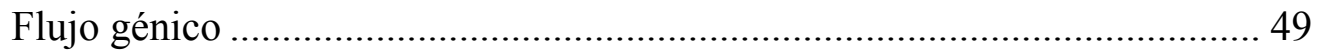

Prueba de Mantel ................................................................................. 51

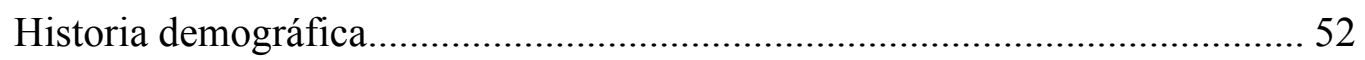

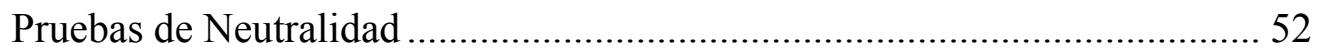

Distribución de diferencias pareadas (mismatch distributions) .................... 53

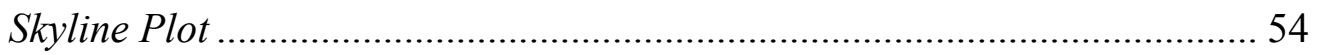

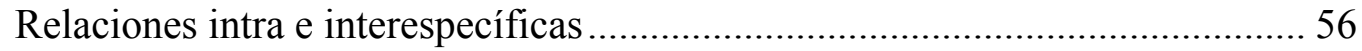




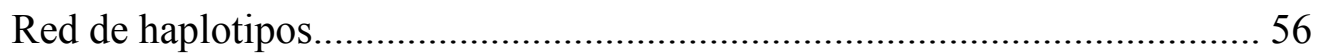

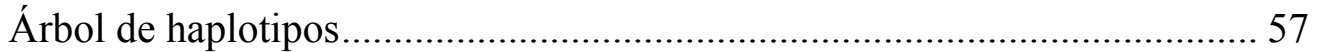

Distancias genéticas en el género Atelognathus ........................................ 58

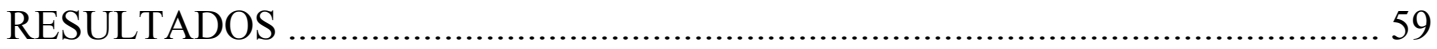

El problema de las formas "acuática" y "litoral” de Atelognathus patagonicus ... 59

Diversidad y estructura genética del complejo patagonicus-praebasalticus ........ 61

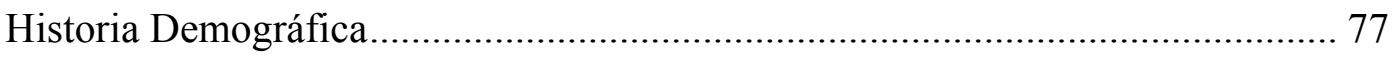

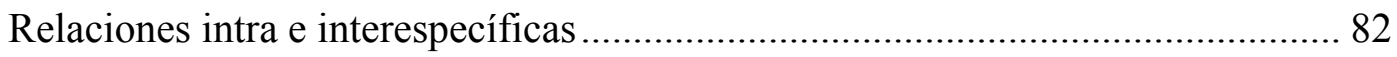

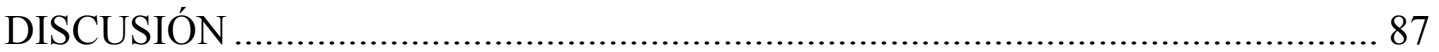

Formas acuática y litoral de Atelognathus patagonicus ...................................... 87

Diversidad y estructura genética del complejo patagonicus-praebasalticus ........ 89

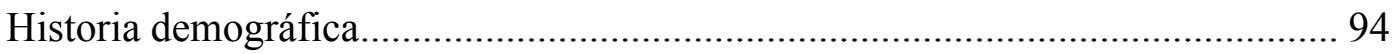

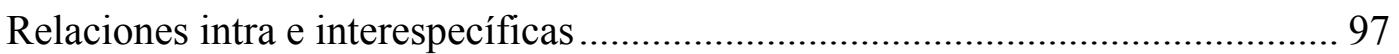

Estado de Conservación del complejo patagonicus-praebasalticus...................... 99

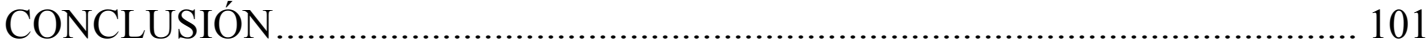

REFERENCIAS BIBLIOGRÁFICAS …........................................................... 102

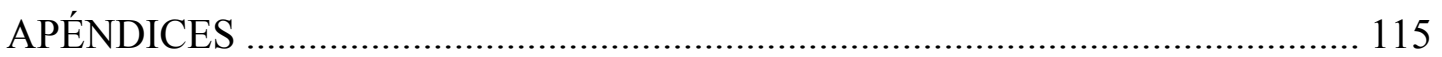

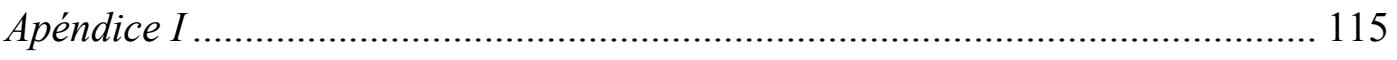

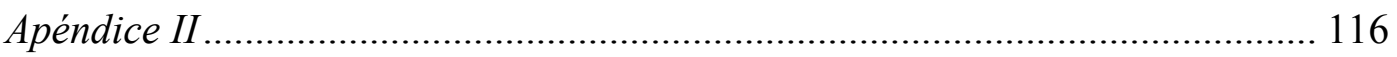

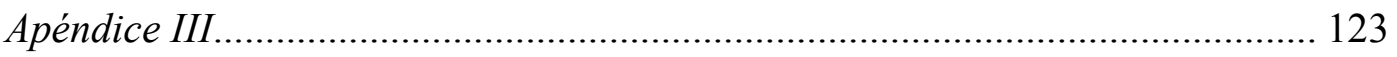




\section{RESUMEN}

Entre las ranas patagónicas del género Atelognathus se han descripto dos especies con estrecha relación filética y ecológica que exhiben diferencias morfológicas poco evidentes: A. patagonicus y A. praebasalticus. Ambas son especies endémicas de pequeñas lagunas endorreicas con aportes de aguas de filtración basálticas que se extienden al suroeste de Zapala (Neuquén, Argentina), a saber: Jabón, Antiñir, del Hoyo, del Molle, Verde, La Batea, del Overo, de Los Flamencos, del Tero y Del Burro - todas ellas pertenecientes al Sistema Laguna Blanca (Sistema LB) - y las lagunas Honda, Casa de Piedra, Overa y del Piojo, distribuidas al sur del Sistema LB.

Para la especie A. patagonicus se describieron dos formas claramente definidas morfológica y ecológicamente: morfotipo acuático y morfotipo litoral. Estos morfotipos fueron considerados alternativamente variantes polimórficas de una única especie, especies diferentes o el resultado de plasticidad fenotípica. Para $A$. praebasalticus se describieron cuatro subespecies: A. p. praebasalticus, A. p. agilis, A. p. luisi y A. p. dobeslawi. Las diferencias morfológicas entre individuos con morfotipo litoral de $A$. patagonicus e individuos de algunas de las subespecies de $A$. praebasalticus (A. p. praebasalticus, A. p. agilis) son poco evidentes, lo cual dificulta la asignación de éstos a una u otra especie.

El objetivo de esta tesis fue evaluar el estatus sistemático de las especies Atelognathus patagonicus y Atelognathus praebasalticus, incluyendo sus formas y subespecies descriptas, con el fin de delimitar genéticamente sus poblaciones y establecer sus relaciones intra e interespecíficas en el marco de un análisis filogenético y filogeográfico. Para ello se evaluó la variación genética secuenciando un total de 1.200 pares de bases de los genes Citocromo b (Cit-b) y Región Control $(R C)$ del ADN mitocondrial a partir de 185 ejemplares del complejo patagonicuspraebasalticus colectados en catorce localidades a lo largo de todo el rango de sus distribuciones. Se realizaron estudios de diversidad genética a partir de distintos estadísticos; de estructura genética mediante AMOVA; e historia demográfica por medio de pruebas de aislamiento por distancia, pruebas de neutralidad (Fu y Tajima) y distribuciones de diferencias pareadas. Las relaciones entre los haplotipos fueron 
inferidas a través de análisis de máxima parsimonia y redes de haplotipos; las relaciones interespecíficas se estimaron utilizando la proporción de sitios variables entre secuencias ( $p$-distance), incluyéndose ejemplares de otras especies del género Atelognathus y de los géneros Batrachyla, Hylorina y Chaltenobatrachus.

Las poblaciones del complejo patagonicus-praebasalticus distribuidas en distintas lagunas del noroeste y centro-oeste de la provincia del Neuquén mostraron diferentes valores de variación genética. Tanto para $C i t-b$ como para $R C$ se observó un único haplotipo más frecuente y ampliamente distribuido, compartido (en ambos casos) por individuos determinados a priori como A. patagonicus y a dos subespecies de A. praebasalticus (A. p. agilis y A. p. praebasalticus). Las comparaciones pareadas de los valores de $\phi_{S T}$ mostraron que no existen diferencias genéticas significativas entre las poblaciones de $A$. patagonicus y $A$. $p$. praebasalticus. Estos resultados nos permiten inferir que estas poblaciones pertenecen a una misma especie. Complementariamente, esta afirmación se sostiene en los altísimos valores de flujo génico calculados al comparar poblaciones de $A$. $p$. praebasalticus con distintas poblaciones de A. patagonicus. Los individuos provenientes de la laguna de Casa de Piedra, algunos atribuibles a priori a $A$. patagonicus y otros a A. p. agilis, resultaron indiferenciables genéticamente, evidenciando altísimos valores de flujo génico y presentando haplotipos compartidos.

Las ranas muestreadas en la laguna Honda fueron originariamente determinadas como A. patagonicus. Sin embargo, en este trabajo se pone en evidencia que estos anuros son genéticamente diferentes a los A. patagonicus pertenecientes a las otras poblaciones analizadas. Aunque con resultados que pueden parecer en principio contradictorios, de acuerdo a con cuál de los dos genes utilizados como herramienta de comparación se elabore una conclusión, no habrían diferencias genéticas significativas entre la población de la laguna Honda y la población de A. p. luisi de la laguna Overa.

La población de la laguna del Piojo es genéticamente discernible de casi todas las poblaciones estudiadas aquí. La excepción la constituye la población de $A$. $p$. agilis de la laguna de Casa de Piedra analizada a partir de la variabilidad de la $R C$, 
con la cual las ranas la laguna del Piojo comparten un haplotipo. Sin embargo, los niveles de flujo génico entre estas ranas y el resto de las poblaciones estudiadas fueron menores a 1 .

El análisis de la varianza molecular (AMOVA) evidenció una clara estructuración poblacional del complejo patagonicus-praebasalticus, la cual estaría asociada a la distribución geográfica, según los resultados obtenidos a partir de las pruebas de Mantel.

Los resultados obtenidos al evaluar la historia demográfica de estas poblaciones son en algunos casos también contradictorios: a nivel local, en algunas poblaciones del Sistema LB se registraron índices significativamente negativos de Tajima (prueba de neutralidad) lo que estaría indicando eventos de expansión y/o cuello de botella; sin embargo se trataría de fenómenos muy focalizados geográficamente, dado que el mismo análisis realizado a nivel regional indica que tales procesos demográficos no han tenido lugar en el Sistema LB. Aunque, al analizar este sistema (al igual que el grupo de Casa de Piedra) a partir de la distribución de las diferencias pareadas (mismatch distributions) no se puede rechazar la hipótesis nula de expansión poblacional, si bien la curva resultante del análisis es bimodal (curva típica de poblaciones estables). Por otro lado, los índices de las pruebas de neutralidad no fueron significativos para el grupo Honda/Overa, resultado que estaría indicando que no hubo desviaciones respecto a la neutralidad. No obstante, con la prueba de distribución de las diferencias pareadas (mismatch distributions), no se pudo rechazar la hipótesis nula de expansión poblacional, evidenciada por una curva unimodal con buen ajuste al modelo de expansión poblacional. La población de la laguna del Piojo no presentó variabilidad como para estudiar su historia demográfica. Probablemente se trate de un sitio colonizado en un pasado muy reciente a partir de unos pocos individuos provenientes de Casa de Piedra, con quienes comparten un haplotipo revelado en la red de haplotipos obtenida a partir de las secuencias de Región Control.

Los árboles de haplotipos recuperaron un clado bien soportado que incluye a todos los individuos de las lagunas Honda y Overa. Los análisis realizados a partir del método skyline plot no evidenció, en ningún caso a ningún nivel, cambios en los 
tamaños poblacionales. Probablemente estas contradicciones sean producto de cambios muy recientes en la estructura y distribución de una única población ancestral que ocupaba parte (reforzando la idea de expansiones poblacionales locales) o toda (abonando la teoría de cuellos de botellas y aislamiento) la distribución actual. Esta hipótesis se ve reforzada al comparar los valores de distancias genéticas obtenidos entre los haplotipos de las especies estudiadas en esta tesis - que no superaron el 0,8\% - y los valores de distancia genética que existen entre distintas especies del género Atelognathus, obtenidos con secuencias de Cit-b, que resultaron en la mayoría de las comparaciones mayor al $1 \%$.

En conclusión, los análisis genético-moleculares realizados en el complejo patagonicus-praebasalticus evidencian la existencia de una única especie con un alto grado de estructuración genética asociada a la distribución geográfica. Los resultados obtenidos se corresponden con un proceso de aislamiento geográfico reciente, resultando en la diferenciación incipiente de las poblaciones presentes en las lagunas Honda y Overa por un lado y del Piojo por otro. Dada la ausencia de evidencia que apoye la validez de dos especies en el área de estudio, se propone considerar a Atelognathus praebasalticus (Cei \& Roig, 1968), incluyendo a todas sus subespecies nominadas, como sinónimo junior de Atelognathus patagonicus (Gallardo, 1962).

Los resultados obtenidos en este trabajo sugieren que es imprescindible realizar enfoques multigénicos en este tipo de estudios, dado que las conclusiones que puedan surgir a partir del estudio de la variabilidad de un único gen pueden ser erróneas, derivándose esta confusión en la eventual toma de decisiones de manejo desafortunadas para la conservación de las especies involucradas. El hallazgo de un significativo flujo génico entre todas las poblaciones examinadas en este estudio es auspicioso para la conservación de estos anuros, pero se recomienda en forma inexcusable la supresión de nuevas introducciones de especies de peces en las lagunas que aun no han sufrido estas alteraciones antrópicas. Se recomienda la realización de estudios genéticos y morfológicos complementarios para establecer más ajustadamente la diversidad de las ranas nordpatagónicas del género Atelognathus. 


\section{ABSTRACT}

Among the Patagonian frogs of the genus Atelognathus, the closely related species A. patagonicus and A. praebasalticus exhibit a barely morphological differentiation. Both species are endemic of small endorheic lagoons with input from basaltic filtration waters stretching southwest of Zapala (Neuquén, Argentina), namely: Jabón, Antiñir, del Hoyo, del Molle, Verde, La Batea, del Overo, de Los Flamencos, del Tero y Del Burro - all members of the Laguna Blanca System (LB System) - and Honda, Casa de Piedra, Overa and del Piojo lagoons, distributed South of LB System.

For the species A. patagonicus, two clearly morphologically and ecologically defined forms were described: aquatic morphotype and littoral morphotype. These morphotypes were alternatively considered polymorphic variants of a single species, different species, or the result of phenotypic plasticity. For A. praebasalticus, four subspecies were described: A. p. praebasalticus, A. p. agilis, A. p. luisi and A. p. dobeslawi. Morphological differences between individuals with littoral morphotype of $A$. patagonicus and individuals of some of the subspecies of $A$. praebasalticus ( $A$. p. praebasalticus, A. P. agilis) are little evident, thus hindering the allocation of them to one or another species.

The objective of this Thesis was to evaluate the systematic status of the species Atelognathus patagonicus and Atelognathus praebasalticus, including its described forms and subspecies, in order to genetically delimit their populations and establish intra and interspecific relationships within the framework of a phylogenetic and phylogeographic analysis. This genetic variation was assessed by sequencing a total of 1,200 base pairs of cytochrome b $(C y t-b)$ and control region $(C R)$ genes of the mitochondrial DNA from 185 specimens of the patagonicus-praebasalticus complex, collected in fourteen localities throughout the entire range of their distributions. Studies of genetic diversity were performed from different statistical analyses; genetic structure by AMOVA; demographic history through isolation by distance test, neutrality tests ( $\mathrm{Fu}$ and Tajima) and mismatch distributions. Relationships among haplotypes were inferred by maximum parsimony analysis and haplotype networks. Interspecific relationships were estimated using the proportion 
of variable sites between sequences (p-distance), including in the analysis specimens of other representatives of the genus Atelognathus and the genera Batrachyla, Hylorina and Chaltenobatrachus.

The patagonicus-praebasalticus complex populations distributed over different lagoons in the northwest and west-central Neuquén Province showed different values of genetic variation. Both $C y t-b$ and $R C$ genes showed a single most frequent and widely distributed haplotype, shared for individuals determined a priori as A. patagonicus and for two subspecies of A. praebasalticus (A. p. agilis and A. p. praebasalticus). Paired comparisons of $\phi_{S T}$ values showed no significant genetic differences between the populations of A. patagonicus and A.p.praebasalticus. These results allow us to infer that these populations belong to the same species. Additionally, this assertion holds in the very high gene flow values calculated by comparing populations of $A$. p praebasalticus with different populations of $A$. patagonicus. The individuals from the Casa de Piedra lagoon some a priori attributed to $A$. patagonicus and to A. p. agilis, were genetically indistinguishable, showing very high values of gene flow and presenting shared haplotypes.

The frogs sampled at Honda lagoon were originally identified as $A$. patagonicus. However, in this work becomes evident that these frogs are genetically different from the A. patagonicus belonging to the other analyzed populations. Although results may at first seem contradictory, according to which of the two genes used as a tool for comparison is drawn a conclusion, would not have significant genetic differences between the Honda lagoon population and the population of $A$. p. luisi from Overa lagoon.

The population of Piojo lagoon is genetically distinguishable from almost all populations studied here. The only exception is the population of $A$. p. agilis Casa de Piedra lagoon analyzed by $R C$, with which the Piojo population share one haplotype. However, the levels of gene flow between these frogs and the rest of the populations studied were smaller than 1 .

The analysis of molecular variance (AMOVA) showed a clear population structure in the praebasalticus-patagonicus complex, which would be associated to their geographic distribution, based on the results obtained from Mantel tests. 
The results obtained by evaluating the demographic history of these populations are, in some cases, locally contradictory; in some populations of the LB System were recorded significantly negative Tajima values (test of neutrality), which would indicate events of expansion and / or bottleneck, but it would a be very focused geographical phenomena, since the same analysis at regional level suggests that these demographic processes have not taken place in the LB system. While analyzing this system (like the Casa de Piedra group) by mismatch distributions we cannot reject the null hypothesis of population expansion, although the resulting curve is bimodal (typical curve of stable populations). On the other hand, the values of neutrality tests were not significant for the group Honda/Overa, a result that would indicate that there were no deviations from neutrality. However, using mismatch distributions, we could not reject the null hypothesis of population expansion, as evidenced by a unimodal curve with good fit to the model of population expansion. The population of Piojo lagoon showed no variability, so, the study of its demographic history is not possible. It is probably a site recently colonized from a few individuals from Casa de Piedra, with whom they share one haplotype, as can be seen in the haplotype network obtained with $C R$ sequences.

The haplotype trees recovered a well-supported clade that includes all the individuals of the Honda and Overa lagoons. Analyses from the skyline plot method did not show in any case at any level, changes in population sizes. These contradictions are probably a product of very recent changes in the structure and distribution of a single ancestral population that occupied part (reinforcing the idea of local population expansions) or all (supporting the theory of bottlenecks and isolation) the current distribution. This hypothesis is reinforced by comparing the obtained values of genetic distances between haplotypes of the species studied in this thesis - which not exceed $0.8 \%$ - and the values of genetic distance between different species of the genus Atelognathus, obtained with Cit-b sequences, which were in most comparisons greater than $1 \%$.

In conclusion, molecular genetic analysis performed in the praebasalticuspatagonicus complex show the existence of a single species with a high degree of genetic structure associated with their distribution. The results are consistent with a 
recent geographic isolation process, resulting in the incipient differentiation of the populations present in the Honda and Overa lagoons on one side, and the Piojo lagoon on the other. Given the absence of evidence to support the validity of two species in the study area, we propose to consider Atelognathus praebasalticus (Cei \& Roig, 1968), including all its nominated subspecies, as junior synonym of Atelognathus patagonicus (Gallardo, 1962).

The results obtained in this work suggest that it is essential to use multigenic approaches in this type of studies, given that the conclusions arising from the study of the variability of a single gene may be erroneous, and the wrong conclusions may be translated to eventual management decisions for the conservation of the species involved. The finding of a significant gene flow among all populations examined in this study are promising for the conservation of these anurans, but is recommended the suppression of new introductions of fishes in the lagoons that have not experienced these anthropogenic disturbances.

It is recommended to conduct additional genetic and morphological studies to establish more accurately the diversity of the north Patagonian frogs of the genus Atelognathus. 


\section{INTRODUCCIÓN}

\section{Antecedentes}

La Patagonia comprende un extenso territorio situado en el extremo sur de América del Sur, cuyo límite norte en la pendiente atlántica coincide aproximadamente con el curso del río Colorado, desde los $36^{\circ} \mathrm{S}$ en la cordillera de los Andes hasta los $40^{\circ} \mathrm{S}$ en su desembocadura en el océano Atlántico. Su diversidad biológica se encuentra en gran medida desconocida debido a que presenta áreas ampliamente inexploradas o poco relevadas para la mayoría de los grupos taxonómicos.

A partir del último levantamiento de los Andes en el Terciario tardío, es posible reconocer en la Patagonia dos grandes biomas: el bosque templado, en ambas pendientes de la cordillera de los Andes (con una precipitación anual superior a los $3.000 \mathrm{~mm}$ ) y la estepa, una extensa zona predominantemente árida situada al este de los Andes. Estos extensos biomas, a la vez, albergan diferentes tipos de macro y microhábitats que dotan a la región en su conjunto de una vasta heterogeneidad ambiental.

La existencia de una antigua biota austral se refleja particularmente en la fauna de anfibios. La singularidad de la batracofauna patagónica no radica en el número de especies (aproximadamente 50 especies de anuros descriptas, Frost, 2011), sino en la diversidad expresada en la cantidad de géneros endémicos (11), muchos de ellos monotípicos o poco especiosos (Calyptocephalella, Hylorina, Insuetophrynus, Rhinoderma, Somuncuria, Telmatobufo, Chaltenobatrachus). Sólo el género Alsodes comprende un número significativo de especies (18). Del total de especies reconocidas, aproximadamente el $82 \%$ constituyen endemismos patagónicos (Lavilla et al., 2000).

El género de ranas patagónicas Atelognathus (Lynch, 1978) comprende ocho especies adaptadas tanto a ambientes extremadamente xéricos de la Patagonia extraandina (A. patagonicus, A. preaebasalticus, A. solitarius, A. reverberii) como a 
ambientes de bosques templado-húmedos de hayas australes del género Nothophagus (A. nitoi, A. salai, A. ceii, A. grandisonae). Pese a la diversidad de ambientes en que habita, el género es claramente monofilético, diagnosticado por las siguientes sinapomorfías: presencia de una amplia fontanela frontoparietal, huesos palatinos cortos, nasales amplios y ausencias de cuadradojugal, columela, anillo timpánico y cavidad timpánica (Lynch, 1978, Basso, 1998).

Tradicionalmente, Atelognathus fue considerado un representante de la subfamilia Telmatobiinae, de la familia “Leptodactylidae” sensu lato (Lynch, 1971, 1978; Cei, 1980). Frost et al. (2006), en un análisis de las relaciones cladísticas de los anfibios actuales, ubican al género Atelognathus dentro de la familia Ceratophryidae, conjuntamente con los géneros Batrachyla, Ceratophrys, Chacophrys, Lepidobatrachus, Insuetophrynus y Telmatobius. Posteriormente, en ese mismo año, Grant et al. (2006) proponen se nomine la subfamilia Batrachylinae para el clado que incluye a Atelognathus y Batrachyla (Ceratophryidae). Basso et al. (2011) incluyen al recientemente descripto género Chaltenobatrachus en la subfamilia Batrachylinae, constituyendo el grupo hermano de Atelognathus. En un estudio reciente, Pyron \& Wiens (2011), en el marco de un amplio análisis filogenético de los anfibios utilizando secuencias de ADN tomadas de GenBank, elevan al clado compuesto por Batrachyla y Atelognathus al rango de familia (Batrachylidae).

Atelognathus patagonicus, descripta originalmente por Gallardo (1962) como Batrachophrynus pagatonicus, para la localidad tipo Laguna Blanca (Parque Nacional Laguna Blanca, Neuquén), es una de las especies de Atelognathus más ampliamente distribuidas de la meseta patagónica, sin por ello dejar de representar un microendemismo bien definido, con varias poblaciones identificadas en diferentes áreas del sistema de lagunas del Parque Nacional Laguna Blanca (Neuquén) y cuerpos de agua cercanos (Cei \& Roig, 1968). Si bien la especie fue descripta en el año 1962, se conocen registros de estos anuros desde 1948 (Cei \& Roig, 1968).

Atelognathus patagonicus se ha extinguido en la Laguna Blanca, donde originalmente fue descrita, a causa de la introducción de percas (Percichthys colhuapiensis) y otros peces (Oncorhynchus mykiss y Salmo trutta) (Cuello et al., 
2009), y por lo tanto sus restantes poblaciones han sido consideradas en peligro de extinción en la Categorización de los Anfibios y Reptiles de la República Argentina (Lavilla et al., 2000).

Cei \& Roig (1968) describieron dos formas de A. patagonicus, a las que denominaron "forma acuática" y "forma litoral". La primera vive asociada a rocas bajo el agua y presenta membranas interdigitales muy desarrolladas, piel fuertemente vascularizada formando pliegues ondulantes en la región lateral y ventral del tronco y sobre los fémures (bagginess) y coloración ventral amarillo-anaranjada. La forma litoral ha sido encontrada a 70-80 m de la orilla de la laguna La Batea (Cuello et al., 2006) en un ambiente comparativamente más árido bajo roquedales volcánicos.

Presenta membranas interdigitales escotadas, carece de bagginess y la coloración ventral es blanco-grisácea. La condición de simpatría conjuntamente con las diferencias morfológicas (estadísticamente significativa) y los distintos nichos ecológicos ocupados por estas formas, podrían hacer pensar en la existencia de especies crípticas (Cei \& Roig, 1968). Sin embargo, un estudio inmunológico sobre proteínas séricas realizado por Cei (1972) resalta que ambas formas (acuática y litoral) son probablemente coespecíficas, y las diferencias morfológicas sólo reflejan la existencia de un conjunto de caracteres genéticamente determinados, en equilibrio poblacional en el mismo nicho ambiental (polimorfismos balanceados). Cuello y colaboradores (2008), a partir de un estudio ecomorfológico, observaron que existe una asociación entre las formas acuática y litoral y algunas variables ambientales (nivel del agua y condiciones limnológicas de la laguna), y en base a esto proponen una explicación alternativa, en la que sugieren que los dos morfotipos descriptos son el resultado de una transición de la forma acuática a la litoral, y viceversa, siendo $A$. patagonicus capaz de cambiar en respuesta a fluctuaciones ambientales (plasticidad fenotípica).

Si bien es más frecuente en la literatura la descripción de casos de plasticidad fenotípica con cambios irreversibles, existen antecedentes que revelan el fenómeno de cambio reversible en el fenotipo en algunas especies de anuros. Por ejemplo, durante la época reproductiva, los machos adultos de Tricobatrachus robustus desarrollan filamentos tegumentarios que actúan como branquias, incrementando la 
superficie de absorción de oxígeno durante la fase reproductiva acuática (Noble, 1925; Zippel, 1997). Otro caso de cambio reversible ha sido observado en larvas de Hyla versicolor, las cuales responden a la presencia de depredadores cambiando el tamaño del cuerpo, la altura de las aletas caudales, el comportamiento de ocultamiento y su nivel de actividad (Relyea, 2003).

En estrecha relación filética y ecológica con A. patagonicus se encuentra la especie A. praebasalticus (Cei \& Roig, 1968), que fue subdividida en cuatro subespecies por Cei (1972): A. praebasalticus praebasalticus (Parque Nacional Laguna Blanca y lagunas cercanas); A. praebasalticus agilis (lagunas de la barda circular de la Meseta de Casa de Piedra); A. praebasalticus luisi (laguna Overa en el sistema de Catán Lil); y A. praebasalticus dobeslawi (laguna del Piojo, en la Barda de Santo Tomás).

Es difícil distinguir entre individuos con morfotipo litoral de $A$. patagonicus e individuos de algunas de las subespecies de A.praebasalticus (A. p. praebasalticus, A. p. agilis), debido a que las diferencias morfológicas que existen entre ellos son poco evidentes (Apéndice II): lo que dificulta su asignación a una u otra especie. Esta semejanza morfológica podría ser el resultado de una convergencia evolutiva producto de presiones selectivas semejantes, o alternativamente, podría deberse a un escaso conocimiento de los límites específicos del complejo patagonicuspraebasalticus.

Desde el punto de vista genético, las investigaciones en $A$. patagonicus y en A. praebasalticus han estado restringidas a estudios de compatibilidad genética entre especies del grupo Atelognathus (Cei, 1972). Un análisis poblacional de la variabilidad genética en el complejo patagonicus-praebasalticus permitiría delimitar sus poblaciones genéticamente y establecer sus relaciones intra e interespecíficas en el marco de un análisis filogenético y filogeográfico. 


\section{Filogeografía}

El término filogeografía fue acuñado a finales de los años ochenta por John Avise y colaboradores para referirse al "estudio de los principios y procesos que determinan la distribución geográfica de los linajes genealógicos, especialmente dentro y entre taxa cercanamente emparentados" (Avise et al., 1987). Esta disciplina trabaja con los componentes históricos o filogenéticos de la distribución espacial de linajes de genes y considera como ejes al tiempo y al espacio. Idealmente entre estos ejes se mapean las genealogías de estudio, permitiendo identificar de este modo patrones que señalen la existencia de antiguas barreras geográficas o ambientales que oportunamente limitaron el flujo génico entre las poblaciones (Roderick, 1996; Avise, 2000). Los estudios filogeográficos tienen en cuenta el flujo génico histórico y la fragmentación poblacional en un contexto filogenético. Por ejemplo, cuando se interrumpe el flujo génico entre dos poblaciones, éstas comenzarán a diferenciarse genéticamente hasta que todos los alelos dentro de cada población lleguen a tener un ancestro común más cercano entre sí que con los alelos de otra población. A este estado se lo denomina 'monofilia recíproca' (Figura 1) y se alcanza luego de que los alelos han transitado por estados previos de parafiletismo y polifiletismo (Avise, 2000). Si se hacen inferencias sobre el pasado histórico de las poblaciones cuando éstas todavía no alcanzaron el estado de monofilia, es posible hallar todavía variación alélica ancestral que puede ser interpretada erróneamente como debida a flujo génico interpoblacional (Schaal \& Olsen, 2000).

En un árbol de genes y en términos de una genealogía matrilineal dentro de poblaciones o especies hermanas (A y B), que derivan de la misma población ancestral se pueden reconocer tres categorías filogenéticas (Avise, 2000):

I)- Monofilia recíproca: todas las matrilíneas de una población están más estrechamente relacionadas entre sí que con respecto a la otra población.

II)- Polifilia: algunas matrilíneas de la población A (pero no todas) tienen un ancestro en común más cercano con las matrilíneas de la población B que con las de su propia población. 
III)- Parafilia: todas las matrilíneas de una población forman un grupo monofilético anidado dentro de una historia matrilineal mayor de una segunda población.

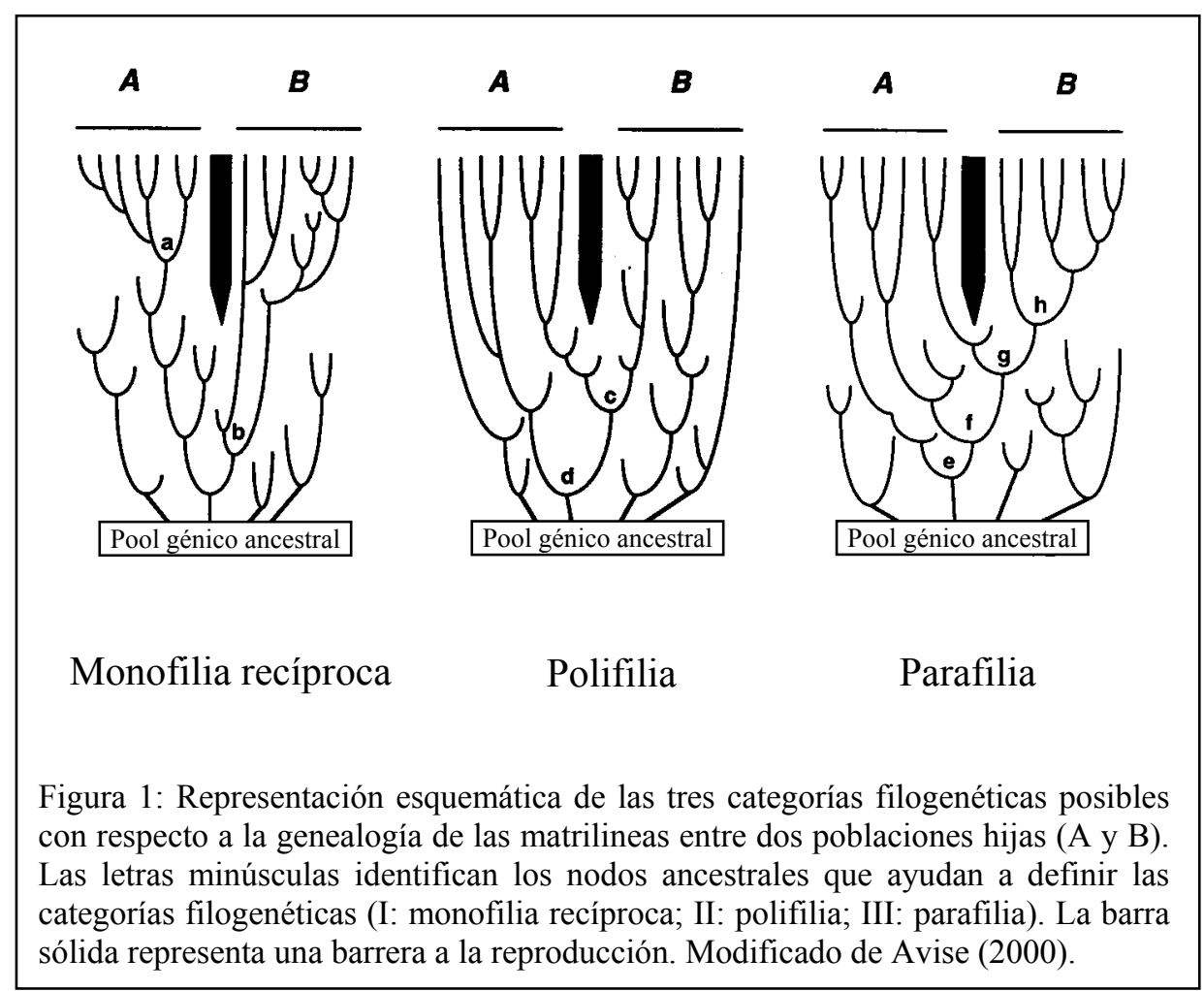


Las categorías II y III ilustran cómo la topología de las ramas del árbol de genes puede diferir con respecto al patrón de ramas observado para el árbol de especies. Esta discordancia es a raíz de que muchas de las separaciones en el árbol de genes preceden a la especiación.

Estas tres categorías filogenéticas frecuentemente se manifiestan entre pares de poblaciones hermanas en diferentes tiempos desde su separación de la población original. Esto ocurre debido a que la distribución de los linajes (lineage sorting) convierte cualquier situación genealógica de polifilia original en estado de parafilia y eventualmente de monofilia recíproca a medida que pasa el tiempo (Avise, 2000).

La filogenia intraespecífica superpuesta en un mapa geográfico puede reflejar diferentes tipos de patrones filogeográficos. Avise y colaboradores (1987) resumen cinco posibles categorías filogeográficas y sus interpretaciones para los diferentes patrones de distribución geográfica observados en estudios de ADN mitocondrial (ADNmt) (Figura 2). La categoría filogeográfica tipo I consiste en árboles genéticos con divergencia antigua (linajes alopátricos), con haplogrupos restringidos a un área geográfica determinada, separados por distancias genéticas relativamente grandes. La subestructura espacial también puede estar presente entre los linajes más cercanamente relacionados dentro de las regiones. Esta categoría comúnmente aparece en las investigaciones filogeográficas realizadas con ADNmt. La categoría filogeográfica tipo II se caracteriza por un árbol génico con bifurcaciones profundas en algunas de sus ramas, cuyos linajes principales son simpátricos a lo largo de una amplia área geográfica. Hay diferentes escenarios hipotéticos que podrían dar lugar a este patrón filogeográfico; sin embargo, en la mayoría de los casos reales documentados, la evidencia apunta hacia una zona de contacto secundario y mezcla de linajes que divergieron históricamente en alopatría. La categoría filogeográfica tipo III se manifiesta en un árbol genético con divergencia reciente de linajes alopátricos. La mayoría de los haplotipos están cercanamente relacionados y están localizados geográficamente cada uno por separado. Esta categoría permite evidenciar poblaciones que han mantenido un contacto reciente entre grupos inicialmente alopátricos, que divergieron genéticamente ya sea por efectos de la 
deriva genética al azar y el arreglo de linajes, o bien por selección natural. Esto implica que las poblaciones deben haber mantenido un bajo flujo génico relativo a su tamaño efectivo poblacional para permitir la divergencia entre poblaciones. $L a$ categoría filogeográfica tipo $I V$ también se caracteriza por una genealogía poco profunda, pero con linajes simpátricos. Este patrón corresponde a especies con altos niveles de flujo génico y tamaños efectivos poblacionales moderados o pequeños, cuyas poblaciones no han sido divididas por barreras filogeográficas de largo plazo. La categoría filogeográfica tipo $V$, intermedia entre la de tipo III y la de tipo IV, se caracteriza por genealogías superficiales en las que existen linajes comunes ampliamente distribuidos junto con linajes cercanamente relacionados que son exclusivos de localidades cercanas. Este patrón se asocia a niveles bajos a moderados de flujo génico contemporáneo entre poblaciones que habrían sufrido una expansión geográfica relativamente reciente. En este caso, los haplotipos comunes suelen ser los ancestrales mientras que los exclusivos se suponen derivados o apomórficos.

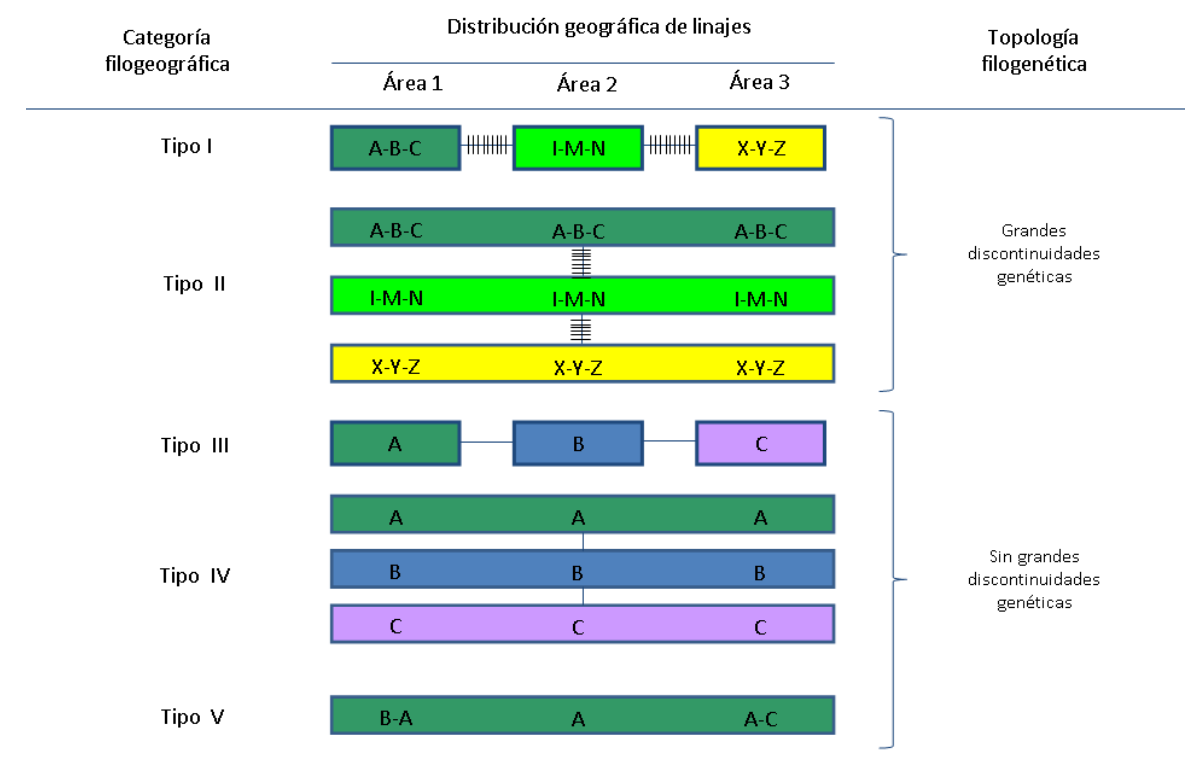

Figura 2: Categorías filogeográficas basadas en la distribución geográfica de linajes filogenéticos (óvalos) y sus niveles de divergencia genética. Las grandes discontinuidades se muestran con varias líneas. El nivel de similitud genética está codificado por la similitud en colores. Modificado de Avise (2000). 
Parte de la historia del surgimiento de la filogeografía se debió no sólo al desarrollo de técnicas moleculares, sino también al avance en el conocimiento de la molécula de ADNmt, que posee varias características muy peculiares, que la hacen particularmente útil en estudios evolutivos (Avise et al., 1987). Estas características evolutivas dan pie a que las genealogías mitocondriales resulten en árboles bifurcantes que representan la transmisión vertical del ADNmt de madres a hijas (Piñero, 2008).

\section{ADN mitocondrial}

La mitocondria posee un genoma que se caracteriza por su replicación autónoma dentro del orgánulo. El genoma mitocondrial está constituido por un ADN de doble cadena, circular y covalentemente cerrado, con un tamaño relativamente constante en todas las especies animales estudiadas de alrededor de $16.000 \mathrm{pb}$. El ADNmt codifica para 3 subunidades de la proteína citocromo c oxidasa (COI, COII y COIII), 7 subunidades de la NADH deshidrogenasa (ND1 a ND6 y ND4L), el citocromo b de la citocromo c reductasa $(c i t-b)$ y las subunidades 6 y 8 del componente $\mathrm{F}_{0}$ de la ATP sintetasa (ATPasa 6 y 8). Además, contiene la información necesaria para la síntesis de 22 tRNAs y 2 rRNAs (12S y 16S) implicados en la traducción de los mensajeros expresados por el genoma mitocondrial (Anderson et al., 1981; Chomyn et al., 1985). El resto de las proteínas presentes en la mitocondria (DNA y RNA polimerasas, aminoacil-tUNA sintetasas, las proteínas ribosomales, y las enzimas de la matriz, las membranas mitocondriales y el espacio intermembranal) son codificadas por el genoma nuclear. Con la excepción de la región de control, que contiene el denominado bucle de desplazamiento (D-loop), existen muy pocos nucleótidos no codificantes y aparentemente ningún intrón (Anderson et al., 1981; Bibb et al., 1981).

Dentro de los vertebrados superiores se conocen las secuencias completas del ADNmt de nueve mamíferos: el hombre Homo sapiens (Anderson et al., 1981), el ratón doméstico Mus domesticus (Bibb et al., 1981), la vaca Bos taurus (Anderson et 
al., 1982), la rata noruega Rattus norvegicus (Gadaleta et al., 1989), el rorcual común Balaenoptera physalus (Arnason et al., 1991), la foca común Phoca vitulina (Arnason \& Johnsson, 1992), la foca gris Halichoerus grypus (Arnason et al., 1993), rorcual azul Balaenoptera musculus (Arnason, 1993) y la comadreja americana Didelphis virginiana (Janke et al., 1994); un anfibio, Xenopus laevis (Roe et al., 1985); dos teleósteos, Crossostoma lacustre (Tzeng et al., 1992) y la carpa Cyprinus carpio (Chang \& Huang, 1994) y un ave, el pollo Gallus gallus (Desjardins \& Morais, 1990). De todas ellas, con excepción de la del pollo, se deduce una organización genómica idéntica (Figura 3).

El genoma mitocondrial presenta varias características peculiares que hacen que esta molécula sea particularmente útil en estudios evolutivos (Avise et al., 1987). Entre éstas se destacan:

a) es una molécula que se encuentra ampliamente distribuida en el árbol evolutivo, lo que permite hacer estudios comparativos dentro de una vasta gama de organismos.

b) es una molécula fácil de aislar y se presenta en múltiples copias por célula.

c) presenta un modo de transmisión genética matrilineal, es decir sólo se hereda vía materna sin recombinación u otro reordenamiento genético.

d) presenta una estructura genética simple: ausencias de ADN repetitivo, elementos transponibles, pseudogenes e intrones.

e) posee alta tasa de evolución (sustitución) a nivel de secuencias de nucleótidos: la evolución a nivel de las secuencias nucleotídicas es entre una a diez veces mayor que cualquier copia simple del ADN nuclear (Brown et al., 1979; Vawter \& Brown, 1986). 


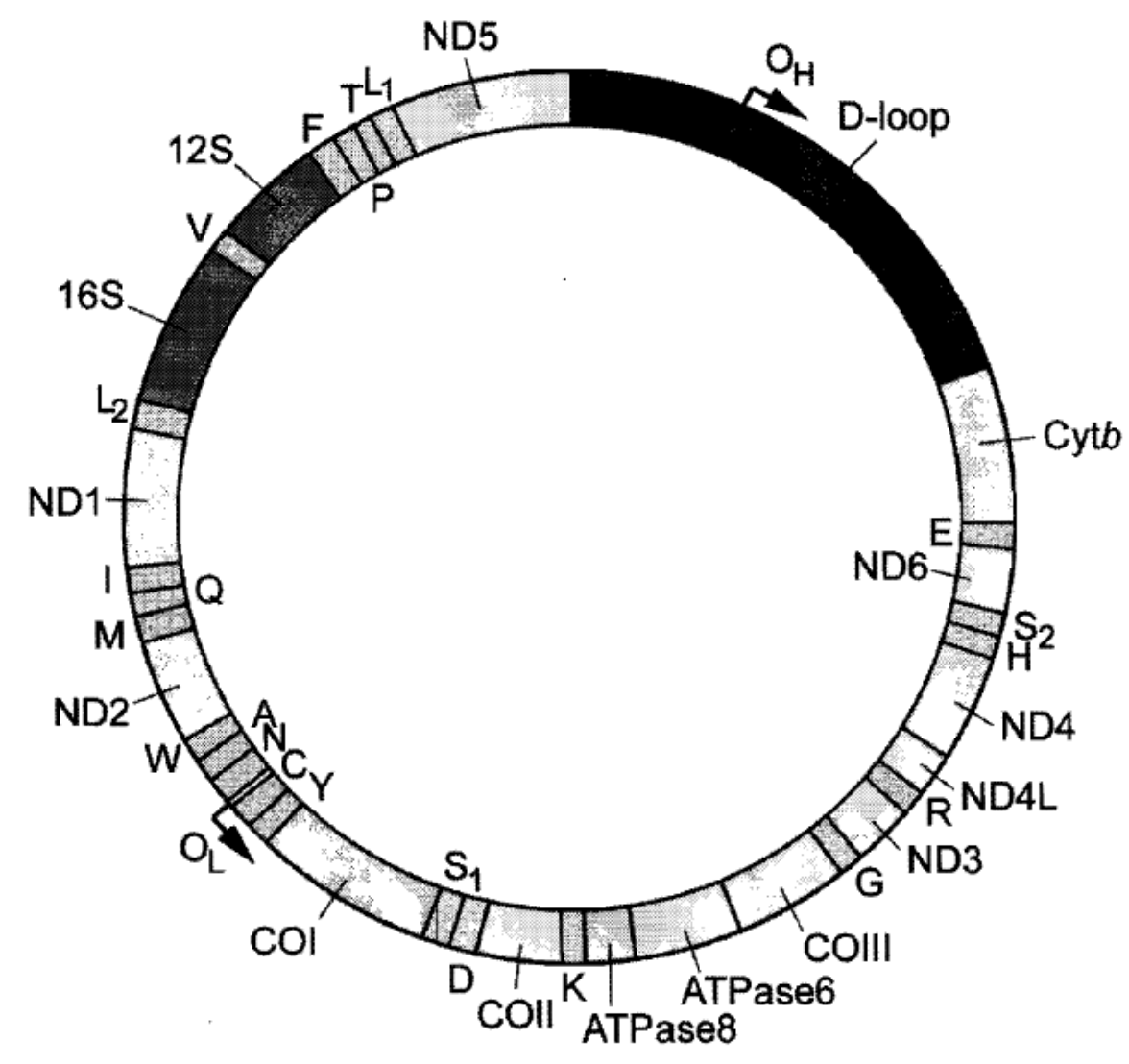

Figura 3: Esquema del genoma mitocondrial de anfibios. Modificado de Plötner et al., 2007. 
Diferentes regiones y genes presentan tasas de evolución variadas dentro de un linaje. Por ejemplo, la Región Control $(R C)$ ha sido particularmente útil para análisis filogeográficos en escalas muy pequeñas de tiempo evolutivo (e.g. miles o cientos de miles de años), ya que tiene una tasa excepcionalmente alta de sustitución de nucleótidos y altos niveles de polimorfismo intraespecífico (Lunt et al., 1998). La región que codifica para Citocromo b, en cambio, comúnmente se utiliza para determinar relaciones interespecíficas, debido a que es un poco menos variable que la $R C$. La organización y estructura de esta región es similar en todos los organismos. De acuerdo a la distribución de las posiciones de nucleótidos variables y según la frecuencia de diferentes nucleótidos en distintas partes de la misma, Brown et al. (1986) y Sbisà et al. (1997) postulan la existencia de tres dominios en esta región (Figura 4). El dominio I (o dominio ETAS: Extended Termination Associated Sequences), el dominio II (o CD: Central Domain) y el dominio III (o CSB:

Conserved Sequence Bloks). Los dominios I y III son ricos en nucleótidos de adenina y son los dominios donde se encuentra la mayor parte de la variación (originada en sustituciones e inserciones / deleciones), mientras que el dominio II o central posee baja frecuencia de adenina y un gran incremento en el nucleótido de guanina, siendo un dominio altamente conservado. Este último dominio es el que tendría la función reguladora de la replicación y de la transcripción del ADNmt. Así mismo existen pequeños segmentos de ADN conservados dentro de uno de los dominios variables (Taberlet, 1996). 


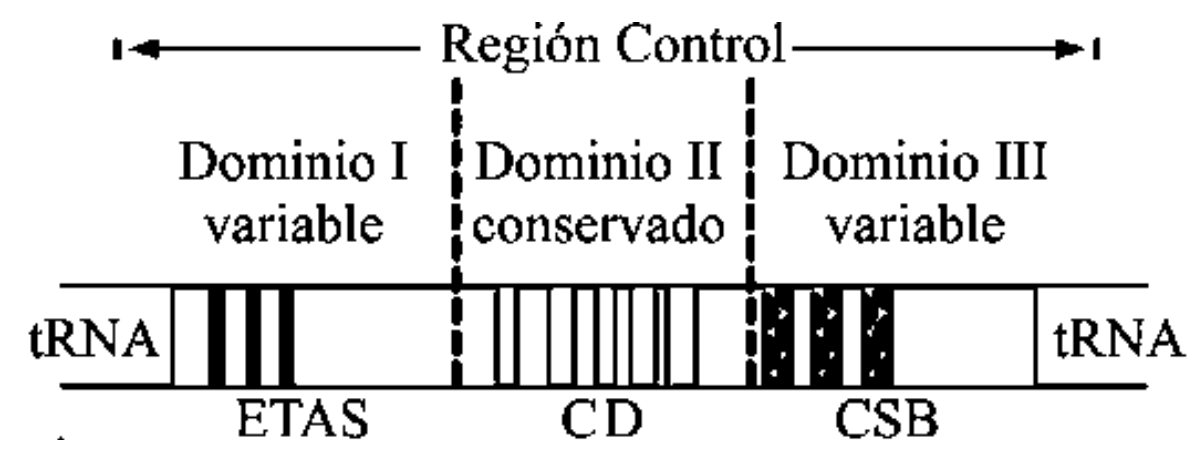

Figura 4: Estructura general de la Región Control mitocondrial de vertebrados. ETAS (Extended Termination Associated Sequences); CD (Central Domain); CSB (Conserved Sequence Bloks). Dentro de cada dominio se muestran también los bloques de secuencias conservadas. Modificado de Ochoa Hein (2008). 
Teoría de la Coalescencia: teoría subyacente de la filogeografía

La teoría coalescente representa un análisis matemático formal y tratamiento estadístico para analizar las genealogías génicas dentro y entre especies relacionadas (Avise, 2000). El concepto de coalescencia fue desarrollado principalmente por Kingman (1982) quien demostró que la unión de linajes hacia un ancestro común se describe por un proceso matemático que denominó $n$-coalescent. La idea básica subyacente al coalescente es que, en ausencia de selección, se puede ver cómo diferentes linajes observados en una muestra de la población se relacionan y convergen hacia atrás en el tiempo con sus linajes ancestrales. Esta teoría es un modelo retrospectivo basado en la genealogía de los alelos, un modelo de separación de linajes y deriva genética que se retrotrae en el tiempo hasta un ancestro común (Harding, 1996). Usa un modelo básico (normalmente el modelo Wright-Fisher en el que sólo hay estocasticidad en la reproducción) para describir la dinámica de la unión de los linajes hasta un ancestro común. Surge como una extensión natural de la genética de poblaciones clásica, tomando también algunas características e ideas seminales de la filogenia y de la teoría neutral de la evolución molecular (Hein et al., 2005). La genética de poblaciones describe las fuerzas responsables de la variación genética, como la mutación, la deriva genética y la selección natural. Por su parte, la filogenia converge con la teoría de coalescencia en el uso y la descripción de árboles que relacionan unidades evolutivas. Finalmente, la teoría neutral propuesta por Motoo Kimura en 1968 (teoría subyacente, que considera que las mutaciones neutras se acumulan a lo largo del tiempo en las ramas de los árboles que representan las genealogías génicas) provee, por un lado, un marco teórico para estudiar la evolución en el nivel molecular y, por otro, un modelo nulo con el cual contrastar escenarios más complejos de evolución (Futuyma, 2009).

A partir de datos moleculares es posible calcular el tiempo de divergencia entre alelos dentro de una población usando como base la teoría de coalescencia. Con estos análisis se puede determinar la genealogía de los alelos, el tiempo hacia el 
pasado en que divergieron de un único alelo y parámetros demográficos como el tamaño efectivo histórico de la población (Furlong \& Brookfield, 2001).

El esquema de la figura 5 representa una población en ausencia de selección, a lo largo de varias generaciones y en la que en forma permanente surgen nuevos alelos por mutación y se pierden otros por deriva genética, de tal forma que todos los alelos de un gen en una generación derivan de (o coalescen hacia) un único alelo ancestral. De esta forma el coalescente describe el linaje genético de una muestra de alelos en una población y utiliza esta información para hacer predicciones sobre patrones de variación genética. Este linaje genético de una muestra, referido como “genealogía de genes", registra la historia matrilineal de eventos mutacionales de las variantes (secuencias) de ADNmt, conocidas como haplotipos, los cuales podrán ser conectados de un modo filogenético y expresado en un "árbol de genes" (Avise, 2000, 2009; Wakeley, 2007). El concepto de árbol de genes y el procesos coalescente han sido centrales en el surgimiento de la filogeografía como subdisciplina de la biogeografía (Avise, 2009). 


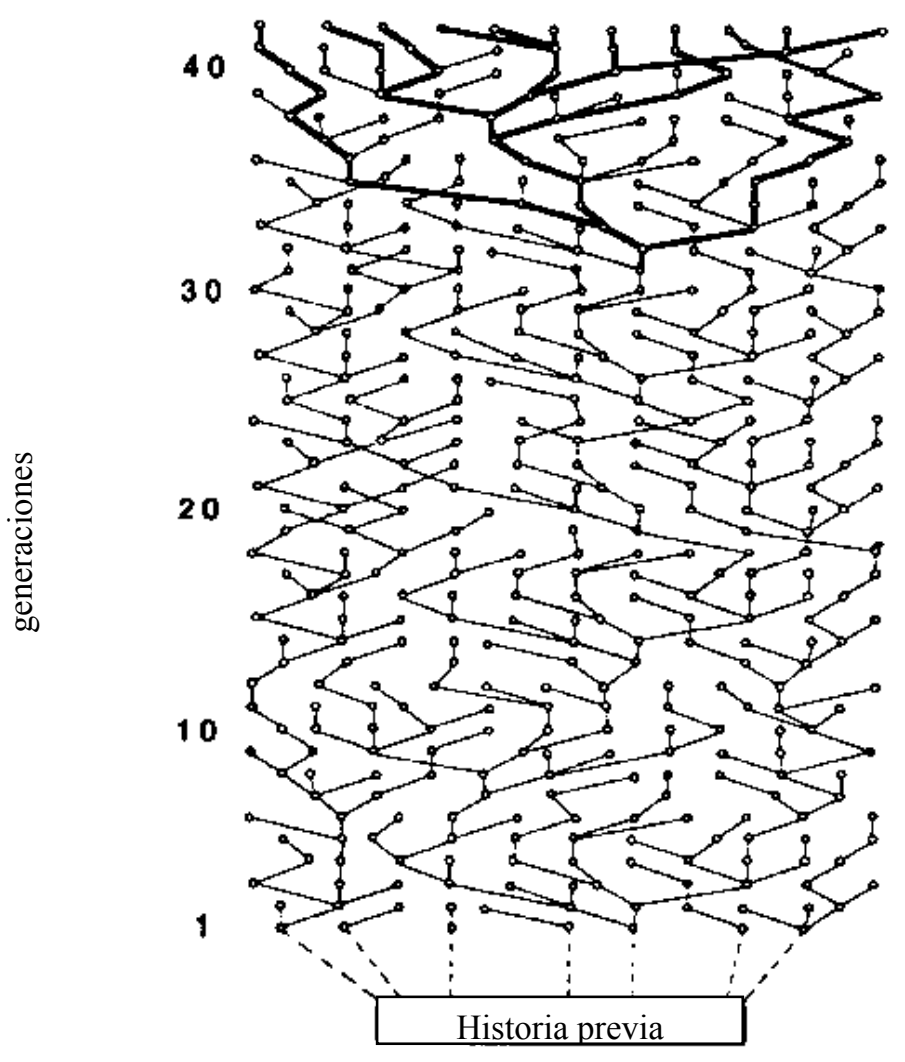

Figura 5: Separación de linajes génicos de ADNmt dentro de una población, durante 40 generaciones, conectando madres e hijas. Los linajes que llegan a la actualidad "coalescen" en una hembra común, en la generación 30. Las líneas negras más gruesas ilustran la jerarquía que se refleja en el ADN mitocondrial. (Modificado de Avise 2000).

La implementación de la teoría de coalescencia tiene varias vertientes. Por un lado, están los llamados estadísticos resumen, que sintetizan la información contenida en la muestra comparándola con lo que se esperaría obtener bajo un modelo nulo o neutro, como las poblaciones ideales de Wright-Fisher (Fisher 1932; Wright 1931, 1951). Algunos de los estadísticos resumen más comunes son la $D$ de Tajima (1989) y la distribución de las diferencias pareadas (Rogers \& Harpending 1992). La coalescencia permite no sólo detectar los procesos evolutivos que afectaron a la muestra sino que, además, infiere parámetros relacionados con estos procesos que pudieron dar lugar a la misma (tasa de mutación poblacional, número 
de migrantes por generación entre $n$ poblaciones, tasa de crecimiento poblacional, tiempo desde el ancestro común más reciente de la muestra, tiempo de divergencia entre dos poblaciones) (Avise, 2000; Piñero, 2008). 
Hipótesis

En esta Tesis Doctoral se plantean las siguientes hipótesis: 1) Atelognathus patagonicus constituye una única especie con una marcada estructuración genética debido a un escaso flujo génico entre sus poblaciones. 2) Las formas litoral y acuática de $A$. patagonicus, descriptas en la literatura representan un caso de plasticidad fenotípica. 3) Ciertas subespecies de Atelognathus praebasalticus constituyen especies plenas, conformando un complejo de especies claramente diferenciadas genéticamente.

\section{Objetivos: General y Específicos}

Objetivo general

Evaluar el estatus sistemático de las especies de ranas endémicas patagónicas Atelognathus patagonicus y Atelognathus praebasalticus con el fin de delimitar sus poblaciones genéticamente y establecer sus relaciones intra e interespecíficas en el marco de un análisis filogenético y filogeográfico.

Objetivos específicos

1. Examinar los patrones de variación genética interpoblacional del complejo patagonicus-praebasalticus, sobre la base de secuencias de nucleótidos de los genes Citocromo b y Región Control del ADN mitocondrial y evaluar la posible existencia de un complejo de especies.

2. Determinar si los patrones genéticos de variación intrapoblacional del complejo patagonicus-praebasalticus son consistentes con la geografía.

3. Delimitar unidades taxonómicas evolutivas de significancia para el establecimiento de políticas de conservación. 


\section{MATERIALES Y MÉTODOS}

\section{Sitios de muestreo}

Para este estudio se analizaron un total de 185 ejemplares del complejo patagonicus-praebasalticus, provenientes de 14 localidades (Figura 6) pertenecientes a un sistema de pequeñas cuencas endorreicas con aportes de aguas de filtración basálticas, distribuidas irregularmente a lo largo de planicies neuquinas. Se trata de pequeños cuerpos lacustres, de profundidad no superior a los 15 metros, con aguas alcalinas (PH, 7,2 - 8,9) y de escasa salinidad con rangos que van desde 0,103gr./1 a 0,886 gr./1 (Cei \& Roig 1966 y 1968). Las lagunas están rodeadas por roquedales volcánicos (basaltos olivínicos y augíticos), cubiertos por grandes capas de calcita microcristalina de origen hidrotermal. Estos cuerpos de agua tienen diámetros variables, desde los 2-5 km. hasta apenas unos centenares de metros. Su régimen hídrico está fuertemente condicionado por variaciones periódicas o arrítmicas de las precipitaciones lluviosas o nivales (Cei \& Roig, 1968). La amplitud térmica a la que están expuestas esta agua son notables, dado que se congelan en el invierno y en primavera-verano en la superficie se registran temperaturas superiores a $\operatorname{los} 20^{\circ} \mathrm{C}$ (Cuello et al., 2008). La presencia de sistemas endorreicos de tal naturaleza es un elemento hidrológico regional de notable importancia y sus influencias microclimáticas en un paisaje de mesetas erosionadas, áridas o semiáridas, se traduce en condiciones particulares de equilibrio de las asociaciones biocenóticas locales, vegetales y animales. El régimen permanente o temporario de los cuerpos de agua oligohalinos o hipohalinos mencionados determina la composición del plancton y la predominancia estacional de sus elementos característicos (Ringuelet, 1958). Este sistema que se extiende al suroeste de Zapala (Neuquén) con altitudes medias de 1.200-1.300 msnm, se encuentra inmerso en la Región Biogeográfica Neotropical. Desde un punto de vista fitogeográfico 
corresponde a la Provincia Patagónica (Cabrera, 1976) y, según el panorama zoogeográfico de Argentina dado por Ringuelet (1961), se encuentra dentro de la Subregión Andino-Patagónica en el Dominio Patagónico. El principal cuerpo lacustre del área de estudio es Laguna Blanca, incluida en el Parque Nacional homónimo (PNLB). Otros cuerpos de agua menores pertenecientes al mismo sistema son las lagunas Jabón, Antiñir, del Hoyo, del Molle, Verde, la Batea y del Overo (dentro del PNLB, Figuras 10, 12, 13 y 14); de los Flamencos, del Tero, del Burro, Honda, Casa de Piedra, Overa y del Piojo (fuera del PNLB, Figuras 7, 8, 9, 11, 15, 16 y 17 ) (Tabla 1) (Cei 1972; Cuello et al., 2009).

La asociación de hidrófitas que representa la base fundamental de existencia de toda comunidad en las lagunas, está formada por abundantes algas Nostocaceas del género Nostoc, las que forman masas gelatinosas ovoides entre los guijarros y escombros volcánicos costeros, y por dos fanerógamas de distribución cosmopolita, Miriophylum brasiliense y Zannichellia palustres. La primera es más abundante y se deposita en rollos tupidos a lo largo de la costa. Sobre sus tallos y en inferiores fondo formado por lajas basálticas, viven colonias de anfípodos del género Hyalella y diminutas sanguijuelas (gen. Helobdella). Estos invertebrados junto con otros pequeños artrópodos y con las algas Nostocaceae, representan los componentes principales de la alimentación adulta y aun larvaria de estos anuros (Cei \& Roig, 1968).

Los ambientes que rodean las lagunas son áridos, alternando roquedales y pedregales de rocas eruptivas en destrucción, con espacios arenosos provistos de vegetación de hierbas, arbustos y sufrútices, caracterizada por elementos patagónicos como Mulinum, pero probablemente con fissonomía propia y especializada (Ruíz Leal, 1966). 


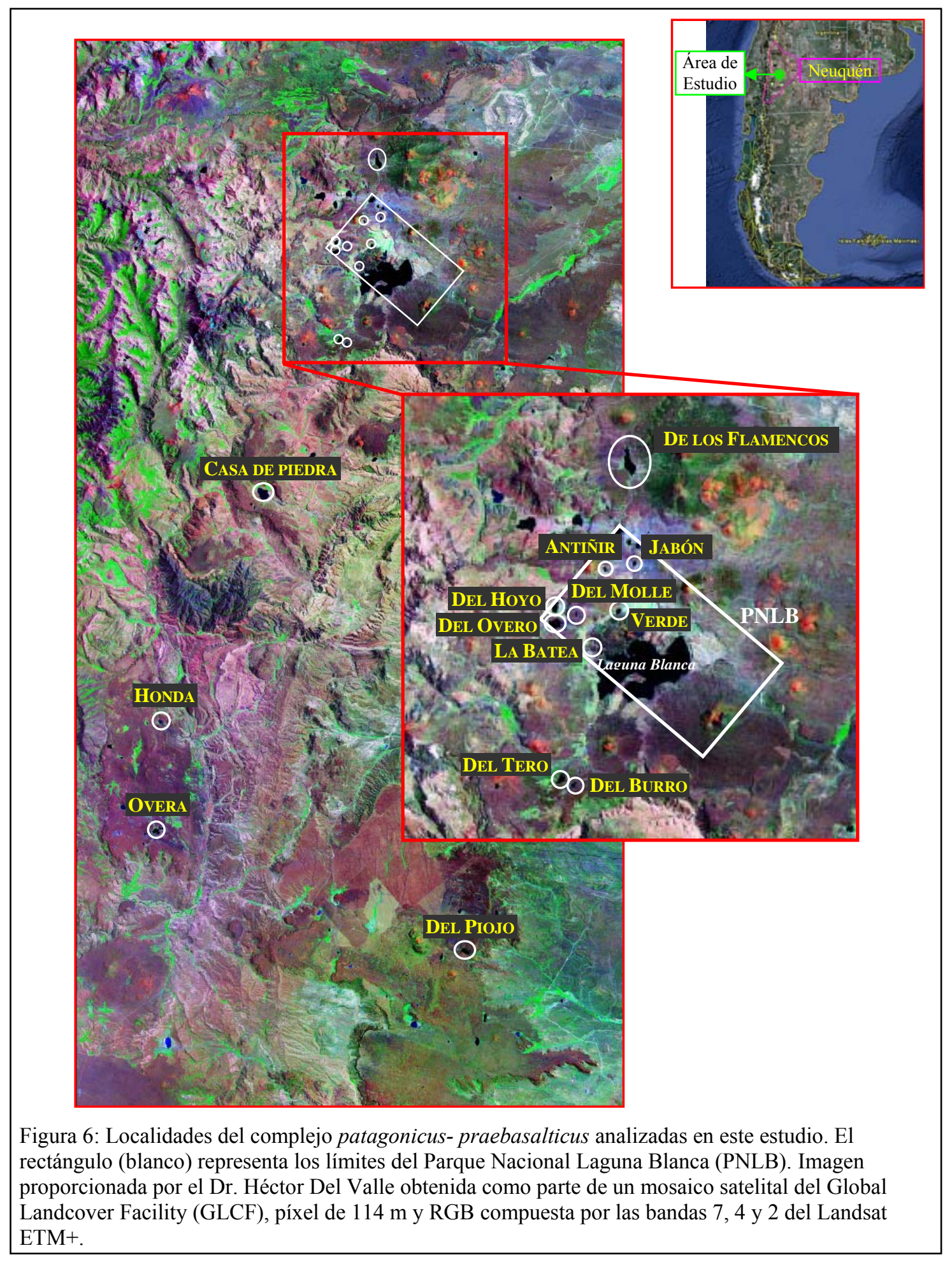


Tabla 1: Localidades (lagunas) concentradas en cuatro grupos regionales. Sistema LB: lagunas ubicadas dentro del Sistema Laguna Blanca, comprendiendo todas las lagunas localizadas dentro del Parque Nacional Laguna Blanca (del Molle, del Hoyo, del Overo, Jabón, Antiñir, Verde y La Batea) y lagunas cercanas (fuera de los límites del PNLB como del Burro, del Tero y de los Flamencos). Casa de Piedra: poblaciones de la laguna de Casa de Piedra. Honda/Overa: poblaciones de las lagunas Honda y Overa. Piojo: población de la laguna del Piojo. Se muestran coordenadas geográficas y número de individuos analizados con citocromo b (Cit-b) y Región Control (RC).

\begin{tabular}{|c|c|c|c|c|c|}
\hline Grupo & Lagunas & \multicolumn{2}{|c|}{ Coordenadas } & $\mathrm{N}_{C i t-b}$ & $\mathrm{~N}_{R C}$ \\
\hline \multirow{10}{*}{ Sistema LB } & Burro & $39^{\circ} 06^{\prime} 51,00^{\prime \prime S}$ & $70^{\circ} 24^{\prime} 42,90^{\prime \prime} \mathrm{O}$ & 13 & 9 \\
\hline & Molle & $39^{\circ} 00^{\prime} 48,60^{\prime \prime S}$ & $70^{\circ} 24^{\prime} 58,10^{\prime \prime} \mathrm{O}$ & 11 & 8 \\
\hline & Ноуо & $39^{\circ} 00^{\prime} 41,90^{\prime \prime} \mathrm{S}$ & $70^{\circ} 25^{\prime} 54,30^{\prime \prime} \mathrm{O}$ & 16 & 12 \\
\hline & Overo & $39^{\circ} 01^{\prime} 05,30^{\prime \prime} \mathrm{S}$ & $70^{\circ} 25^{\prime} 43,90^{\prime \prime} \mathrm{O}$ & 9 & 9 \\
\hline & Jabón & $38^{\circ} 58^{\prime} 51,90^{\prime \prime} \mathrm{S}$ & $70^{\circ} 22^{\prime} 14,70^{\prime \prime} \mathrm{O}$ & 13 & 10 \\
\hline & Antiñir & $38^{\circ} 59^{\prime} 08,60^{\prime \prime} \mathrm{S}$ & $70^{\circ} 23^{\prime} 50,40^{\prime \prime} \mathrm{O}$ & 3 & 2 \\
\hline & Verde & $39^{\circ} 00^{\prime} 27,50^{\prime \prime} \mathrm{S}$ & $70^{\circ} 23^{\prime} 06,90^{\prime \prime} \mathrm{O}$ & 7 & 6 \\
\hline & Batea & $39^{\circ} 02^{\prime} 02,90^{\prime \prime S}$ & $70^{\circ} 24^{\prime} 36,00^{\prime \prime} \mathrm{O}$ & 16 & 10 \\
\hline & Flamencos & $38^{\circ} 54^{\prime} 28,70^{\prime \prime S}$ & $70^{\circ} 23^{\prime} 10,10^{\prime \prime O}$ & 5 & 4 \\
\hline & Tero & $39^{\circ} 06^{\prime} 50,60^{\prime \prime} \mathrm{S}$ & $70^{\circ} 25^{\prime} 09,30^{\prime \prime} \mathrm{O}$ & 4 & 2 \\
\hline Casa de Piedra & Casa de Piedra & $39^{\circ} 14^{\prime} 29,70^{\prime \prime S}$ & $70^{\circ} 27^{\prime} 28,50^{\prime \prime O}$ & 27 & 17 \\
\hline \multirow{2}{*}{ Honda/Overa } & Honda & $39^{\circ} 32^{\prime} 11,00^{\prime \prime S}$ & $70^{\circ} 38^{\prime} 40,10^{\prime \prime O}$ & 19 & 13 \\
\hline & Overa & $39^{\circ} 39^{\prime} 08,90 " \mathrm{~S}$ & $70^{\circ} 38^{\prime} 49,00^{\prime \prime} \mathrm{O}$ & 19 & 8 \\
\hline \multirow[t]{2}{*}{ Piojo } & Piojo & $39^{\circ} 45^{\prime} 55,70^{\prime \prime} \mathrm{S}$ & $70^{\circ} 12^{\prime} 39,20^{\prime \prime O}$ & 18 & 9 \\
\hline & Total & & & 180 & 119 \\
\hline
\end{tabular}




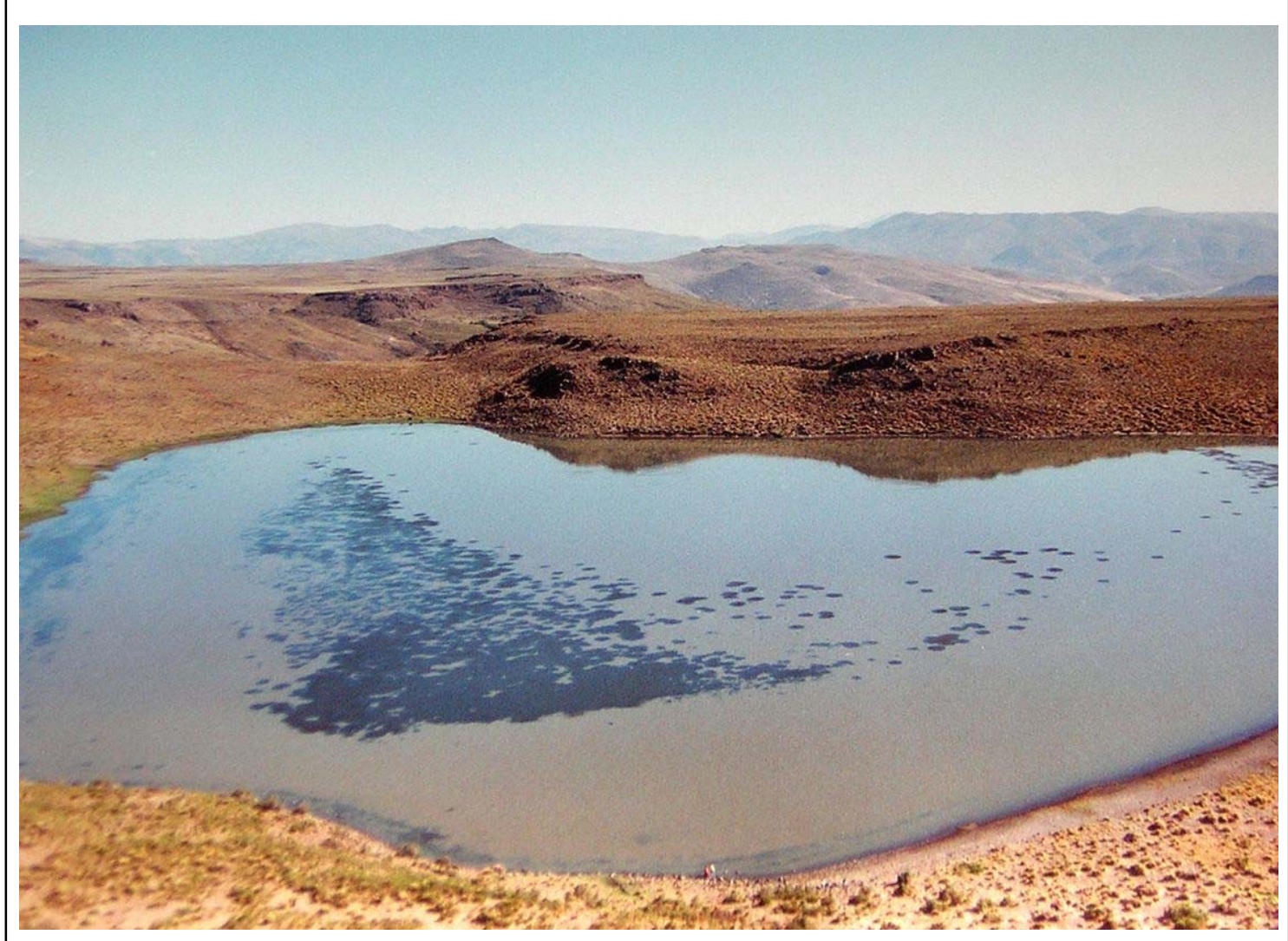

Figura 7: Laguna Honda en el Sistema de Catan Lil o Las Coloradas (Neuquén). Ambiente natural patagónico de Atelognathus patagonicus. 


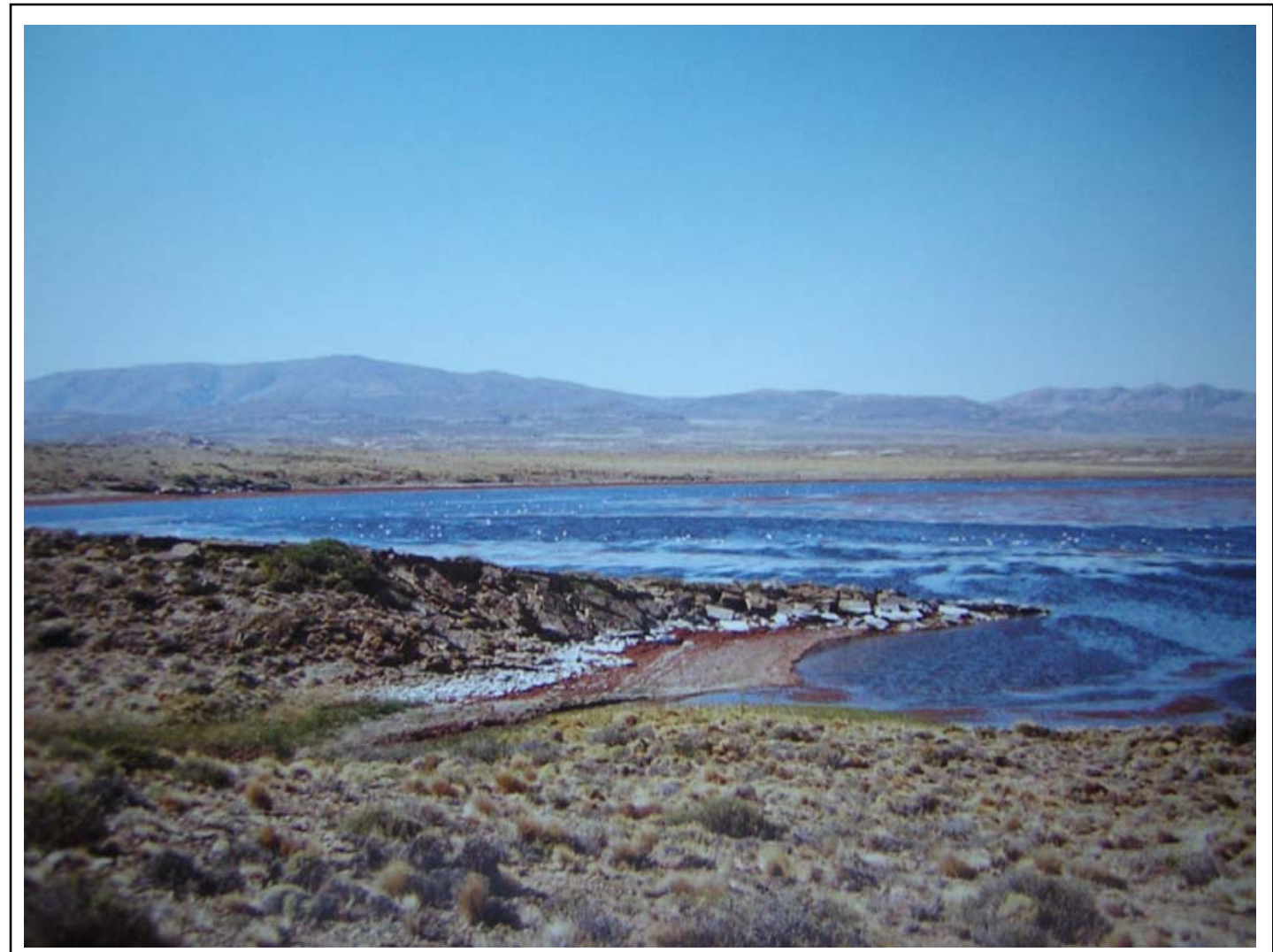

Figura 8: Laguna de Casa de Piedra en la barda circular de Casa de Piedra (Neuquén). Ambiente natural patagónico de Atelognathus patagonicus y de Atelognathus praebasalticus agilis. 


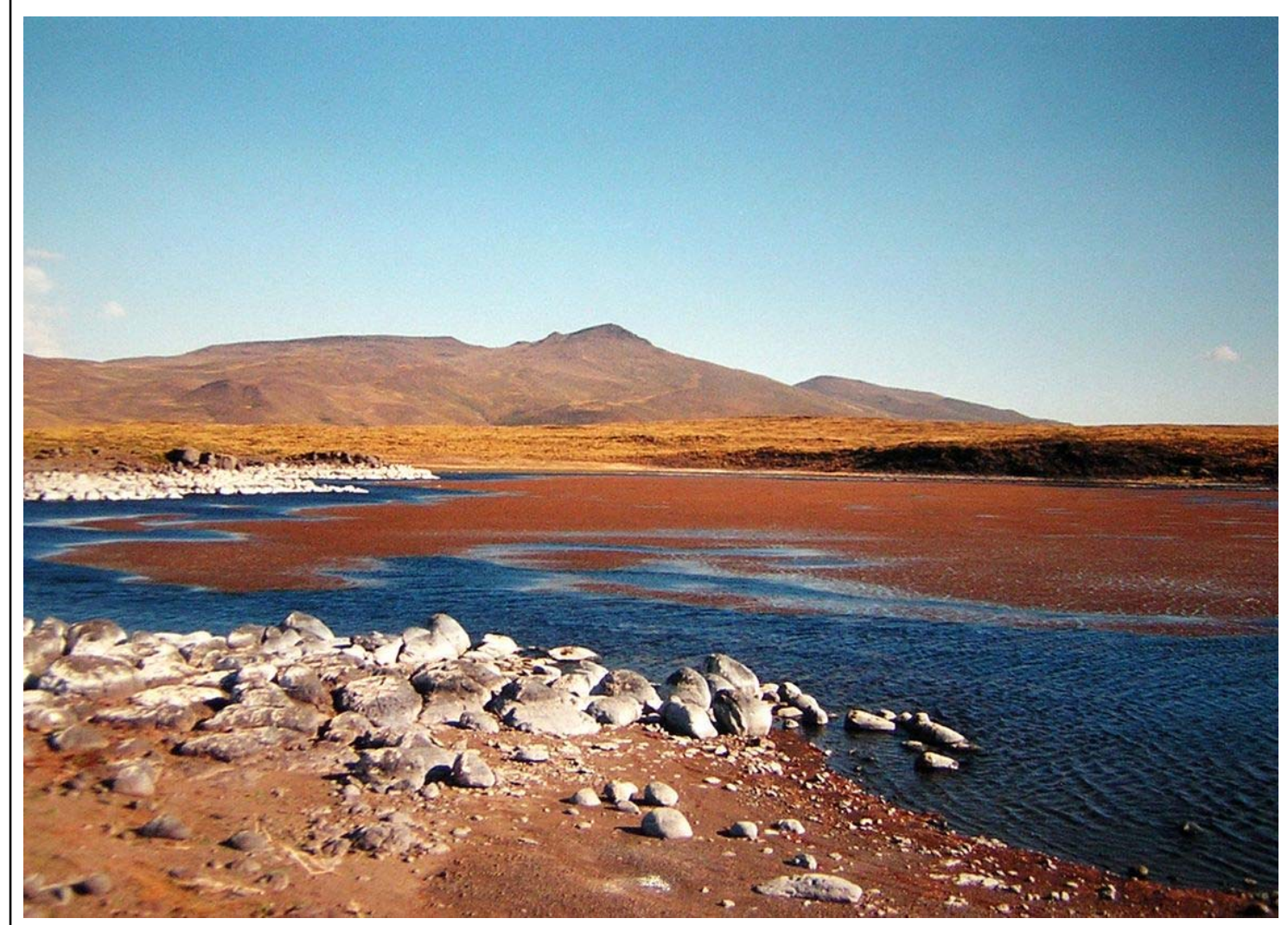

Figura 9: Laguna del Burro (Neuquén). Ambiente natural patagónico de Atelognathus patagonicus y de Atelognathus praebasalticus preaebasalticus. 


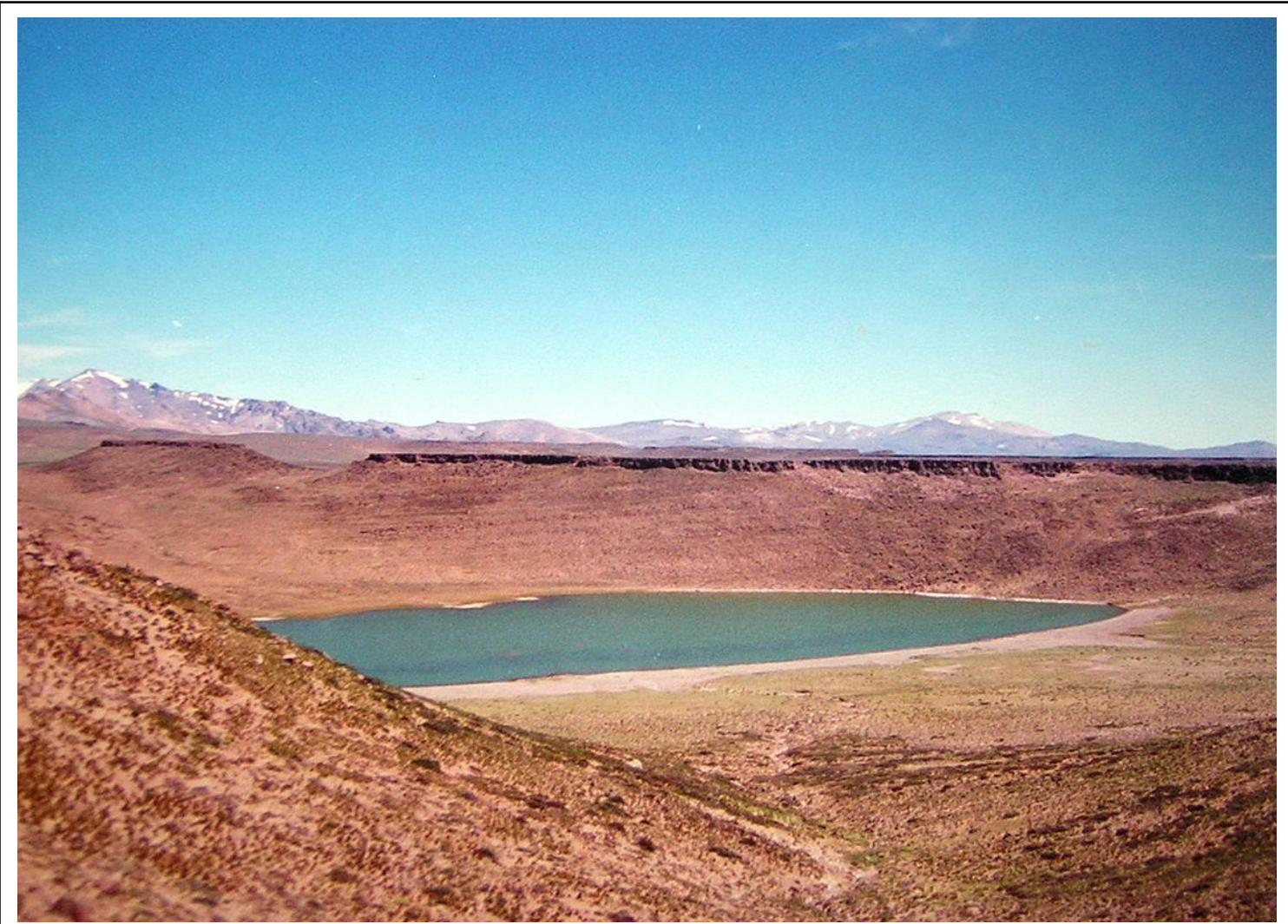

Figura 10: Laguna del Hoyo, dentro del Parque Nacional Laguna Blanca (Neuquén). Ambiente natural patagónico de Atelognathus patagonicus. 


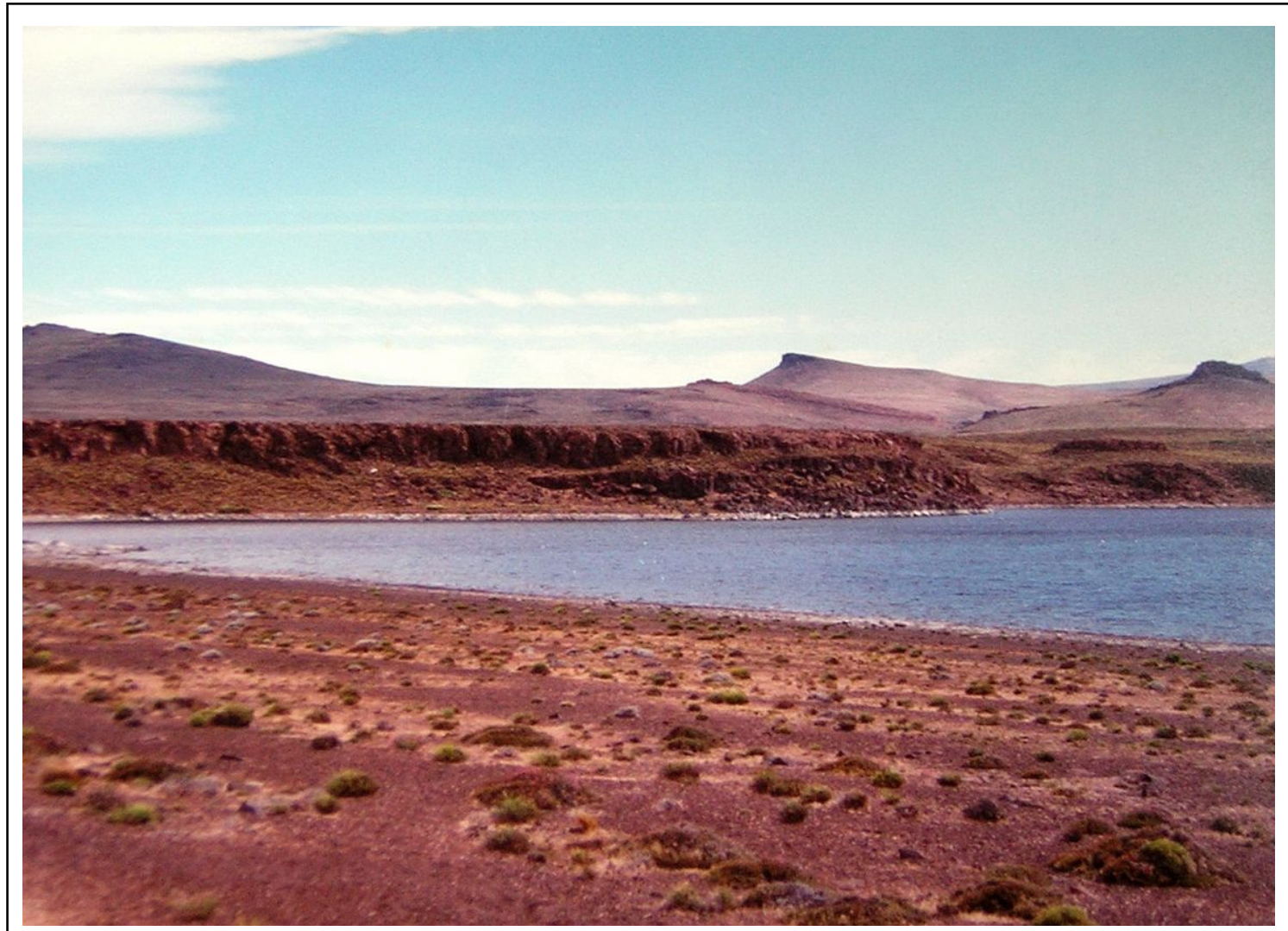

Figura 11: Laguna del Overo, dentro del Parque Nacional Laguna Blanca (Neuquén). Ambiente natural patagónico de Atelognathus patagonicus. 


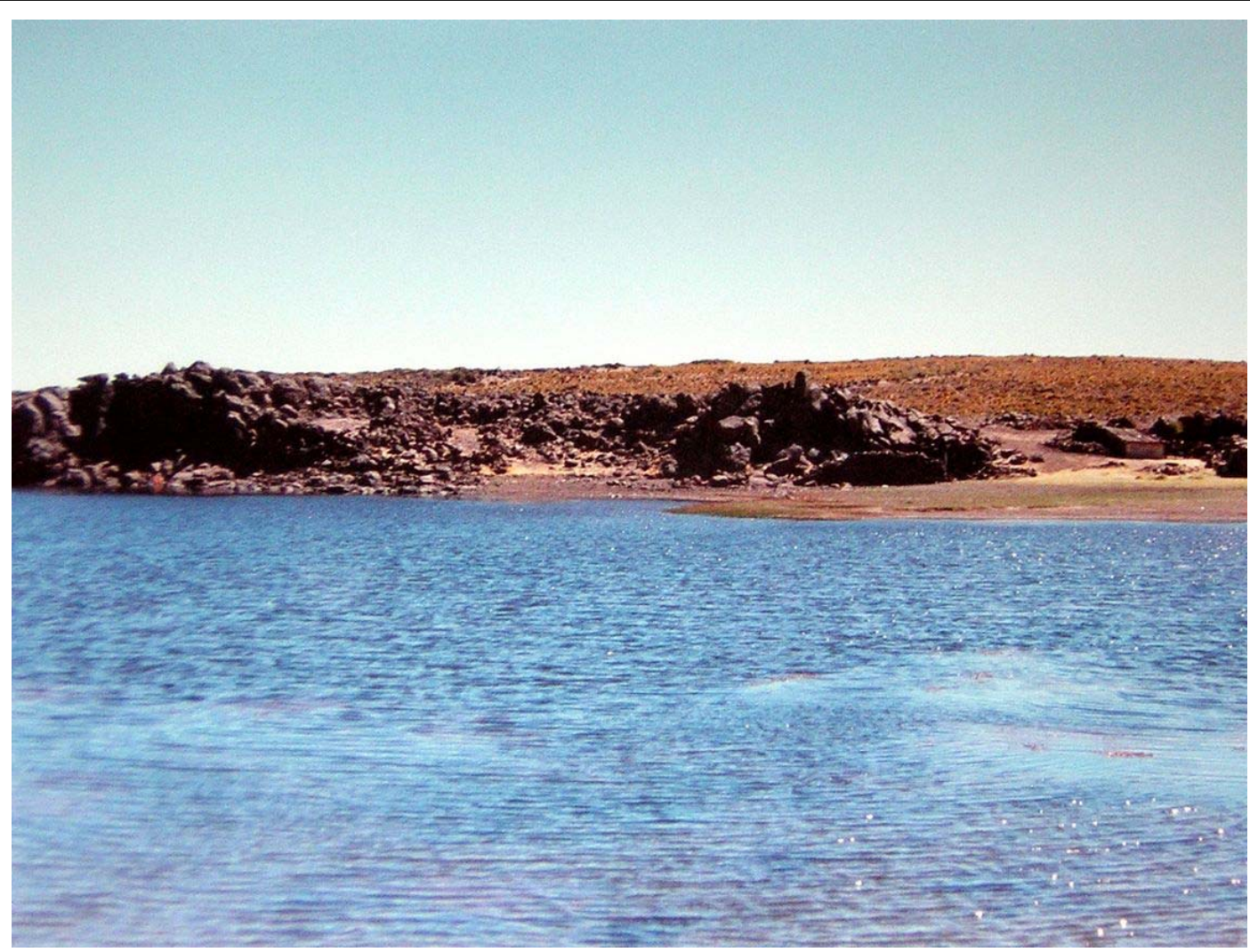

Figura 12: Laguna Jabón, dentro del Parque Nacional Laguna Blanca (Neuquén). Ambiente natural patagónico de Atelognathus patagonicus. 


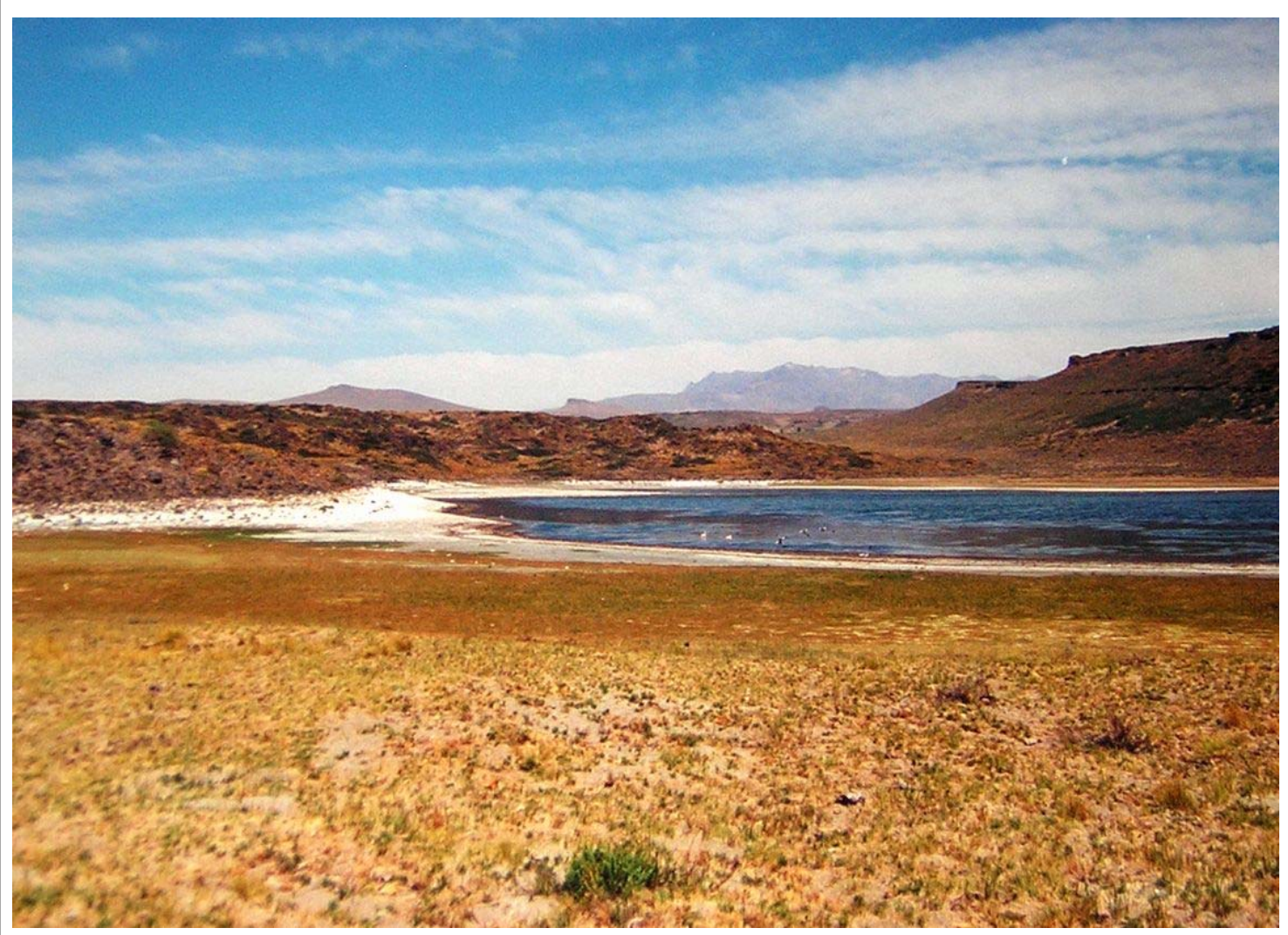

Figura 13: Laguna Verde, dentro del Parque Nacional Laguna Blanca (Neuquén). Ambiente natural patagónico de Atelognathus patagonicus y de Atelognathus praebasalticus preaebasalticus. 


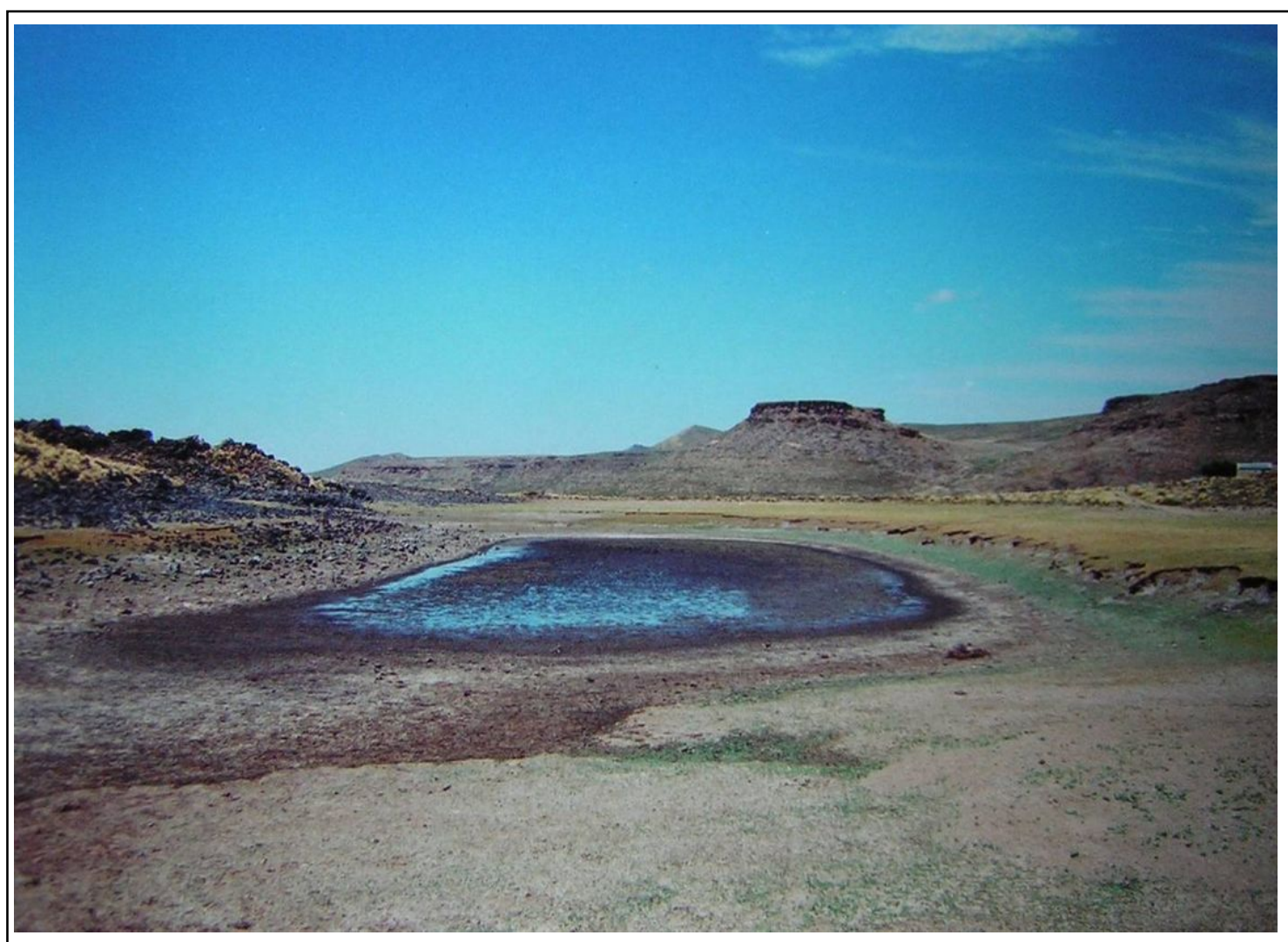

Figura 14: Laguna La Batea, dentro del Parque Nacional Laguna Blanca (Neuquén). Ambiente natural patagónico de Atelognathus patagonicus. 


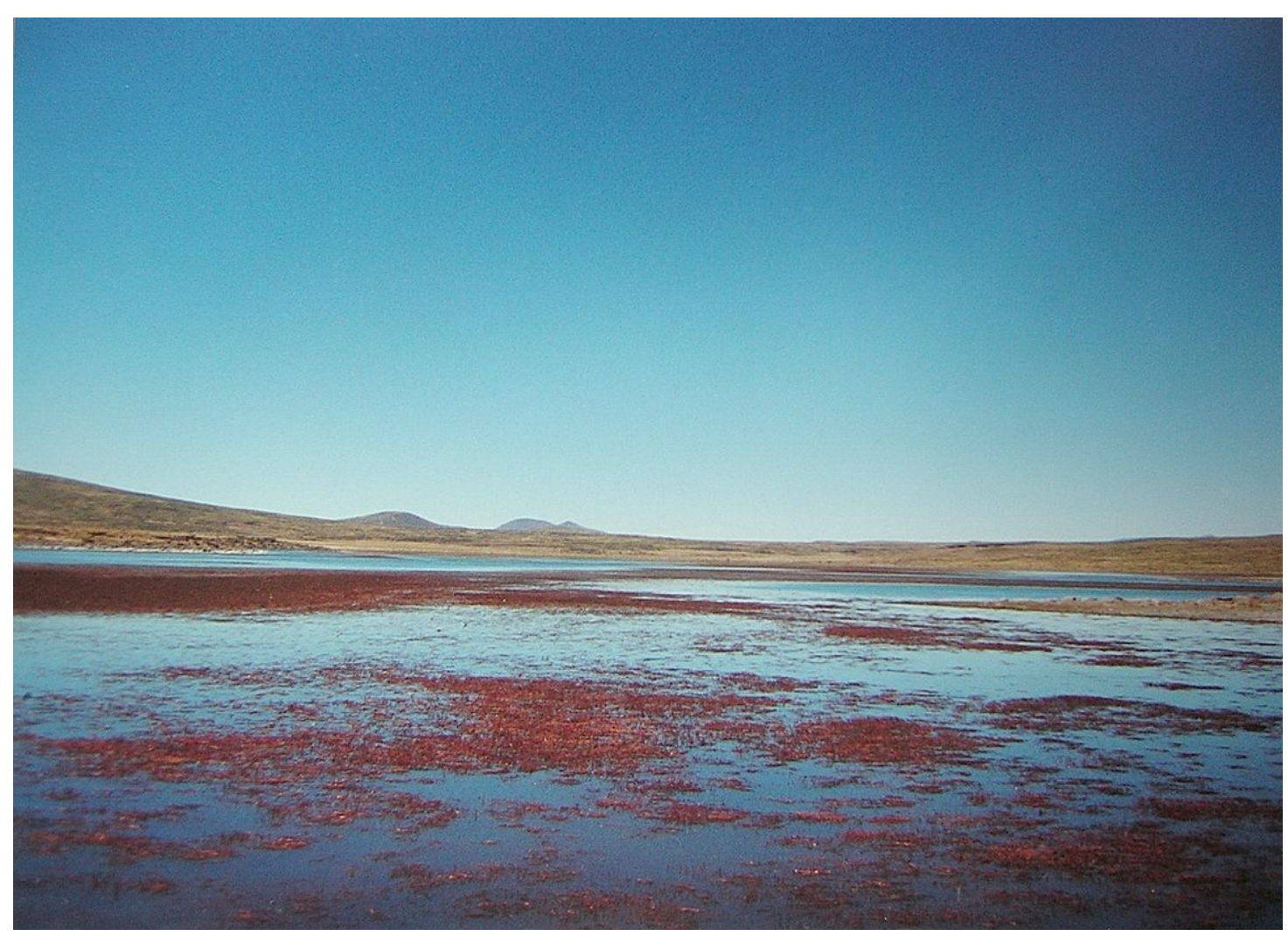

Figura 15: Laguna de los Flamencos, fuera del Parque Nacional Laguna Blanca (Neuquén). Ambiente natural patagónico de Atelognathus patagonicus. 


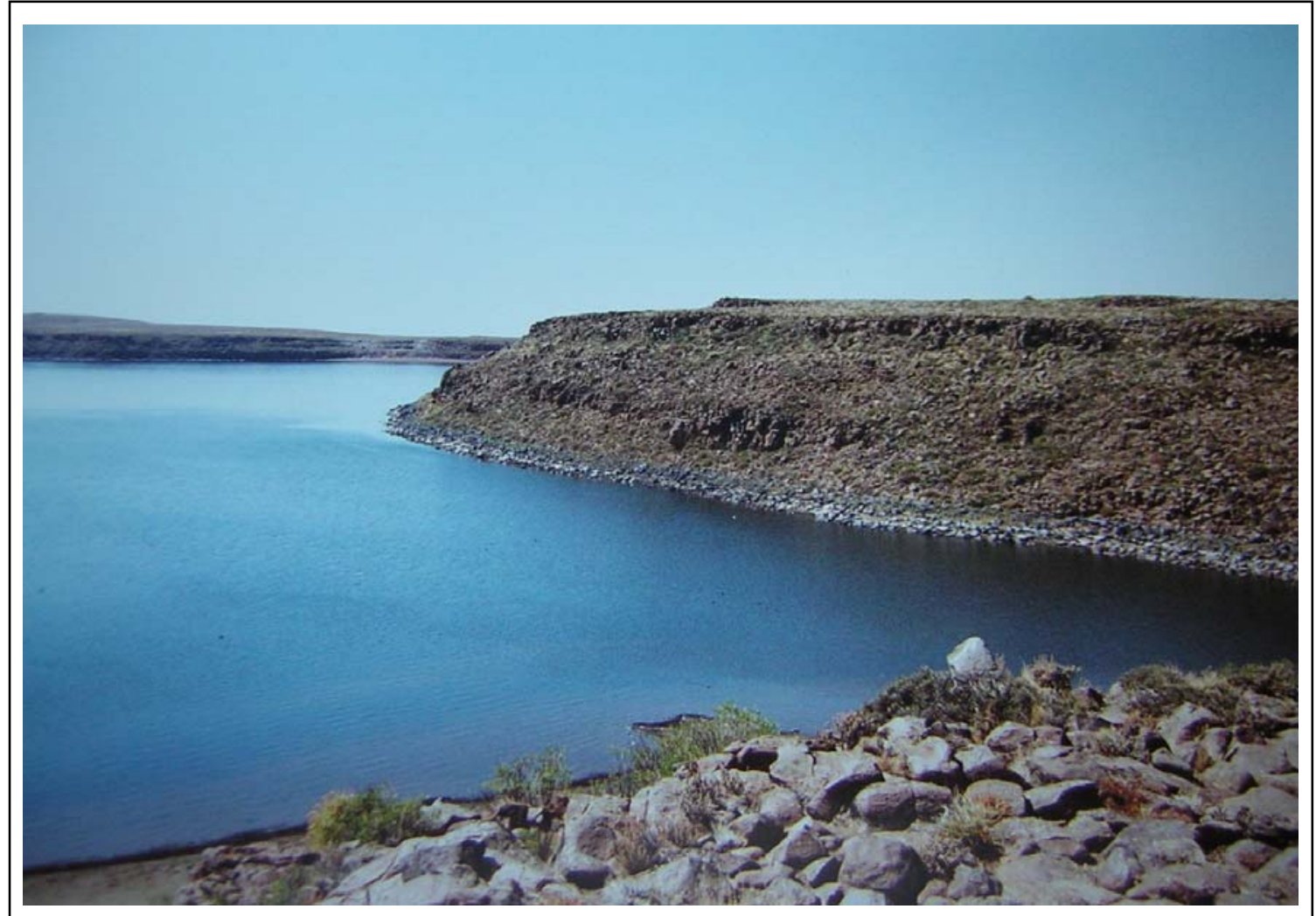

Figura 16: Laguna del Piojo en la Barda de Santo Tomás (Neuquén). Ambiente natural patagónico de Atelognathus praebasalticus dobeslawi. 


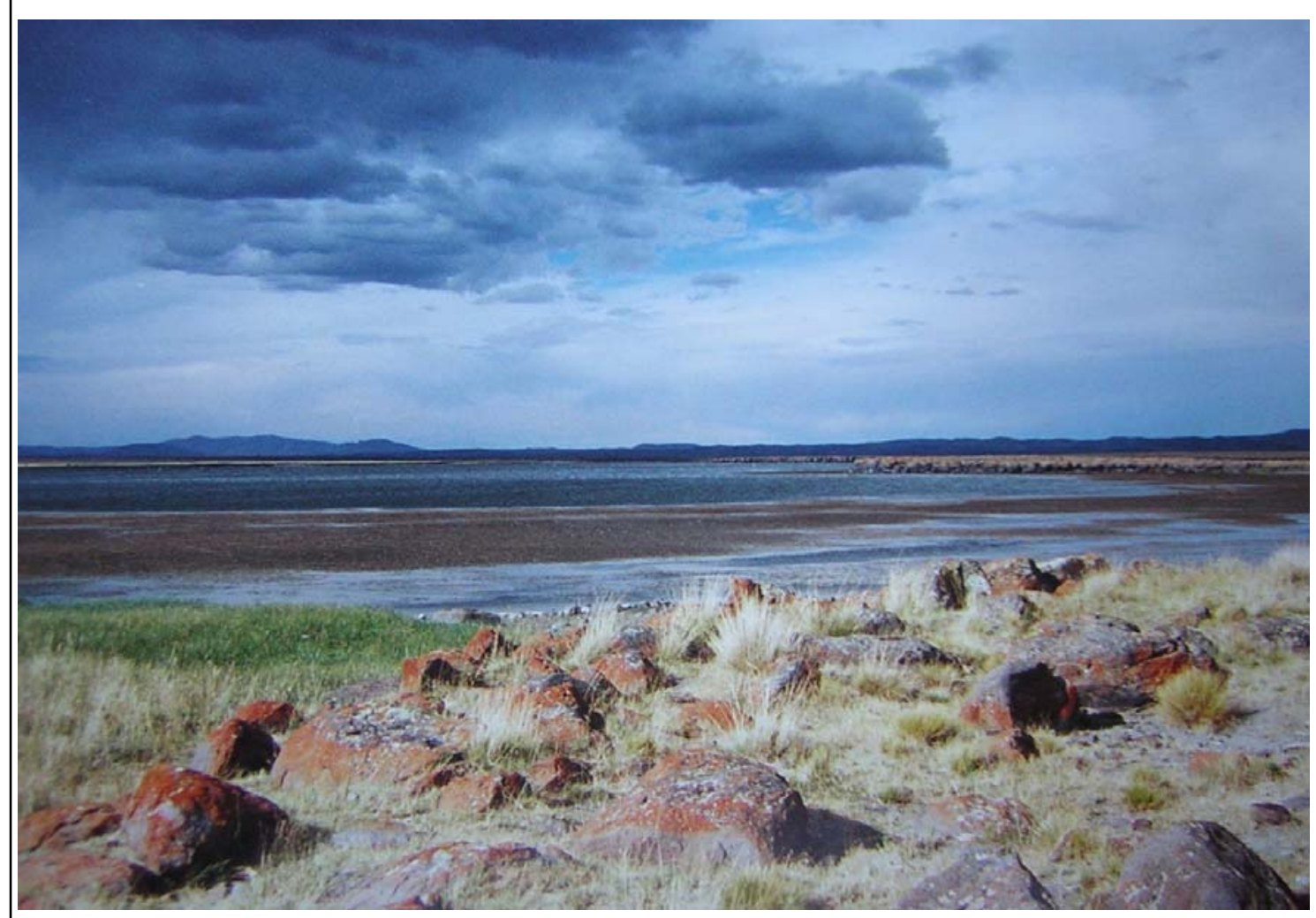

Figura 17: Laguna Overa al oeste de Catan Lil (Neuquén). Ambiente natural patagónico de Atelognathus praebasalticus luisi. 


\section{Captura y preservación del material colectado}

Se realizaron colectas de individuos de Atelognathus patagonicus (Figura 18) en siete lagunas del PNLB (Jabón, Antiñir, del Hoyo, del Molle, Verde, La Batea y del Overo) y cinco cuerpos de agua cercanos (de los Flamencos, del Tero, del Burro, Honda, Casa de Piedra); y de A. praebasalticus (Figura 19) en varias lagunas de la Provincia del Neuquén (lagunas del PNLB y cuerpos de agua cercanos, laguna de Casa de Piedra, laguna Overa y laguna del Piojo) durante las temporadas estivales 2008-2009, 2009-2010 y 2010-2011. También se utilizaron muestras obtenidas previamente por el grupo de trabajo. Los muestreos fueron realizados de forma manual tanto dentro como fuera de las lagunas (hasta $30 \mathrm{~m}$ de distancias perpendicular a la línea de costa). Los individuos colectados fueron sacrificados con una solución de benzocaína, fijados en formol al 10\% y conservados en alcohol etílico al 70\%. De cada espécimen preservado se tomaron muestras de tejido muscular o de hígado fijadas en alcohol etílico $96^{\circ}$ para los estudios moleculares. El material colectado y los tejidos utilizados en esta Tesis se encuentran depositados en la Colección Herpetológica del Centro Nacional Patagónico en el Laboratorio de Sistemática y Biología de Anfibios (CNP-LASBA). 

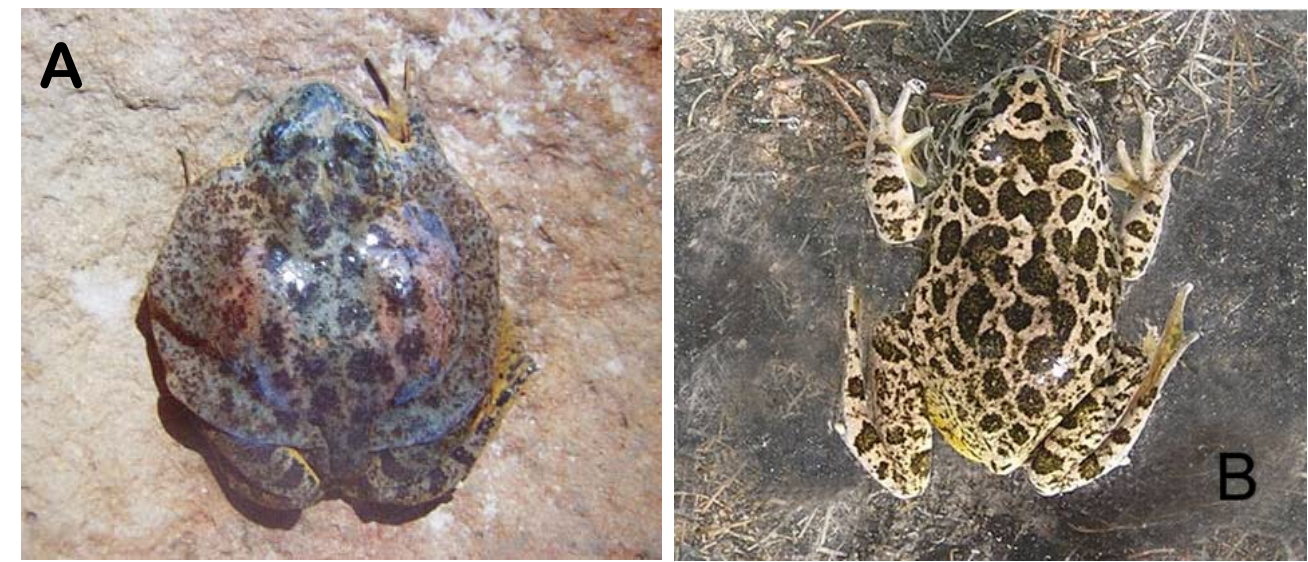

Figura 18: Atelognathus patagonicus. A)- Forma acuática de A. patagonicus (Laguna de los Flamencos). B)- Forma Litoral de A. patagonicus (Laguna la Batea).
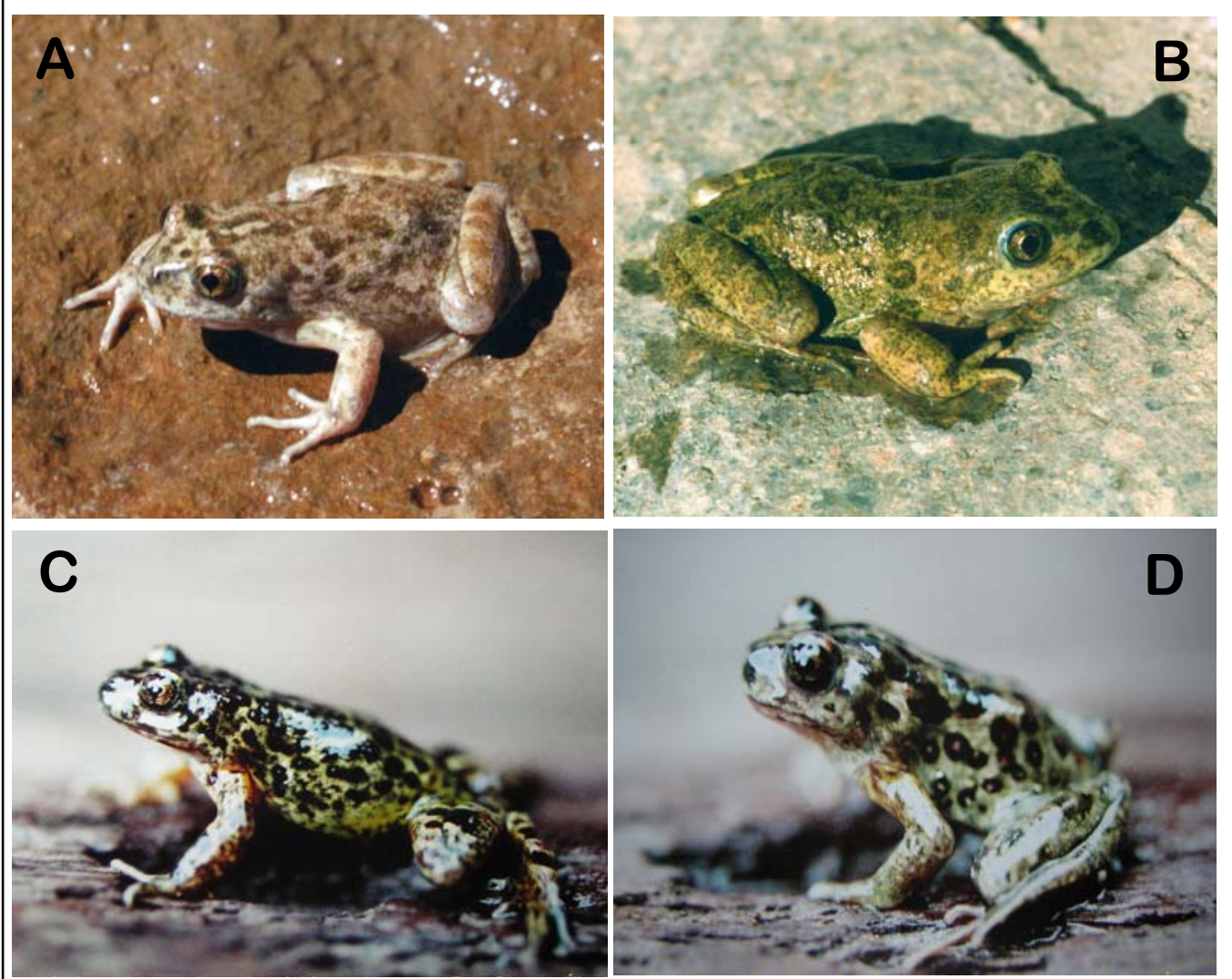

Figura 19: Atelognathus praebasalticus. A)- A. p. praebasalticus (Laguna Verde). B) A. p. agilis (Laguna Casa de Piedra). C)- A. p. luisi (Laguna Overa). A. p. dobeslawi (Laguna del Piojo). 
ADN

\section{Extracción de ADN}

Se realizó la extracción de ADN genómico total a partir de 185 muestras de tejido (hígado o músculo) siguiendo un protocolo adaptado de Sambrook \& Russell (2001). Para comprobar si la extracción de ADN fue efectiva, se corrió un gel de agarosa al 1\% coloreado en bromuro de etidio. El producto de extracción fue visualizado con luz ultravioleta en un transiluminador Vilber Lourmat.

\section{Amplificación y secuenciación del ADN}

Para el desarrollo de este trabajo se estudiaron porciones de dos genes mitocondriales (Figura 3): parte del gen que codifica para el citocromo b (Cit-b) y parte de la Región Control $(R C)$ mediante amplificación por reacción en cadena de la polimerasa (PCR, Polymerase Chain Reaction).

La amplificación de aproximadamente 1.200 pares de bases $(\mathrm{pb})$ de Cit- $b$ y $R C$ se realizó utilizando los pares de primers MVZ15-L (5'-GAACT AATGG CCCAC ACWWT ACGNA A-3')-MVZ16-H (5'-AA ATAGG AARTA TCAYT CTGGT TTRAT-3') y ControlWRev (5'-GACAT AYTAT GTATA ATCGA GCATT CA-3')-Control PH (5'-GTCCA TAGAT TCAST TCCGT CAG-3') respectivamente (Goebel et al., 1999). Las reacciones de amplificación (25 $\mu \mathrm{L})$ fueron preparadas con $10 \mathrm{mM}$ Tris- $\mathrm{HCl} \mathrm{pH} 9,0 ; 50 \mathrm{mM} \mathrm{KCl} ; 0,2 \mathrm{mM}$ de cada dNTP; 1,5 $\mathrm{mM} \mathrm{MgCl}_{2} ; 0,3 \mu \mathrm{M}$ de cada primer; 0,5 unidades de Taq DNA polimerasa (Invitrogen) y aproximadamente $50 \mathrm{ng}$ de ADN genómico. El producto de PCR fue obtenido usando un protocolo estándar que comienza con una desnaturalización inicial a $94^{\circ} \mathrm{C}$ por $2 \mathrm{~min}, 40$ ciclos de: $94^{\circ} \mathrm{C}$ por $30 \mathrm{~s}, 45^{\circ} \mathrm{C}$ por $45 \mathrm{~s} \mathrm{y} 72^{\circ} \mathrm{C}$ por $2 \mathrm{~min}$, y una extensión final a $72^{\circ} \mathrm{C}$ por 6 min. Los productos de PCR se visualizaron en geles de agarosa al $1 \%$ teñidos con bromuro de etidio y se purificaron utilizando el 
kit Geneclean III (MP Biomedicals). La reacción de secuenciación fue realizada usando el protocolo estándar de Big Dye Terminator v.3.1 (Applied Biosystems, Inc.). Se secuenciaron las dos hebras de ADN para cada gen con el fin de corroborar la calidad de las secuencias.

Edición y alineamiento de secuencias

Para realizar el ensamble de las dos hebras de los fragmentos de ADN obtenidas a partir de la secuenciación se utilizó el programa DNA Baser v.3 (Heracle BioSoft, Pitesti, Romania). El alineamiento de las secuencias fue realizado manualmente usando el programa BioEdit 7.0.9.0 (Hall 1999). 


\section{Análisis estadísticos}

Los análisis cualitativos y cuantitativos utilizados en esta tesis están orientados a tratar de resolver, en términos genéticos, la incertidumbre existente en la determinación específica y subespecífica que hay dentro y entre dos especies del género Atelognathus (A. patagonicus- A. praebasalticus). Dentro de la teoría de genética de poblaciones, que estudia los patrones y causas de la diversidad genética en las poblaciones, existen conceptos que descomponen la variación genética en diferentes factores. Hay gran cantidad de métodos descritos en la literatura sobre genética de poblaciones para estimar la diferenciación y la estructura genética. Las distintas medidas de estructura genética están relacionadas entre sí, y se basan en analizar las diferencias en las frecuencias alélicas. Las pruebas más sencillas simplemente comparan estadísticamente estas últimas. Otros métodos se basan en estimar la proporción de variación genética que se encuentra dentro y entre las poblaciones determinando la estructura genética poblacional de las mismas, usualmente empleando el estadístico $F_{\mathrm{ST}}$ o sus análogos, que permiten comparar de manera clara y cuantitativa la diferenciación existente entre poblaciones de distintas localidades geográficas de una misma especie. Estos estimadores tienen en principio la ventaja adicional de que pueden dar el estimado conjunto de la importancia de la deriva genética y el flujo génico. Por último, hay diferentes posibles medidas de distancia genética entre pares de poblaciones. La más difundida en la literatura es la distancia genética de Nei, que refleja el número de sustituciones nucleotídicas en el $\mathrm{ADN}$, y dado que como se ha usado ampliamente en diferentes grupos de organismos, permite comparaciones a distintos niveles (entre poblaciones, entre variedades o subespecies, entre especies). Adicionalmente se pueden utilizar las distancias genéticas entre pares de poblaciones para reconstruir sus genealogías graficando las distancias genéticas pareadas como función de la distancia geográfica que separa a las poblaciones, bajo el supuesto de que las diferencias genéticas se incrementan con la distancia que las separa, usualmente analizando la confiabilidad con una prueba de Mantel. 
Diversidad y estructura genética

Índices de Diversidad

La variabilidad genética o diversidad genética en sentido amplio es el componente más básico de la biodiversidad y se define como las variaciones heredables que ocurren en cada organismo, entre los individuos de una población y entre las poblaciones dentro de una especie. El resto de la biodiversidad se deriva de los procesos evolutivos que operan sobre esas variaciones. Cuanto mayor sea la diversidad genética, mayores probabilidades tienen las especies de sobrevivir a cambios en el ambiente. En general, cuando el tamaño de las poblaciones se reduce, aumenta la reproducción entre organismos emparentados (endogamia) y hay una reducción de la diversidad genética. En este trabajo se evaluó la diversidad genética intra e interpoblacional a partir de secuencias de Cit-b y $R C$ utilizando el programa Arlequin v3.1 (Excoffier et al., 2005). Los índices estimados fueron: diversidad haplotípica (h), medida como la probabilidad de que dos secuencias de ADN tomadas al azar sean diferentes; y diversidad nucleotídica $(\pi)$, medida como el número de nucleótidos diferentes por sitio entre dos secuencias de ADN tomadas al azar, la cual se ve afectada mayormente por los alelos que poseen mayor frecuencia y es independiente del tamaño muestral. Además se registró el número de sitios polimórficos (S) y el número de haplotipos $\left(\mathrm{n}_{\mathrm{h}}\right)$. Dado el escaso conocimiento que existe sobre los límites genéticos entre y dentro del complejo patagonicuspraebasalticus, se pusieron a prueba las diferencias entre poblaciones a partir de comparaciones pareadas de valores de $\Phi_{S T}$ (estimador de $F_{\mathrm{ST}}$ ). La distribución nula de los valores de $\Phi_{S T}$ pareados, bajo la hipótesis de que no existen diferencias genéticas entre las poblaciones, se obtuvieron comparando los haplotipos entre poblaciones a partir de 10.000 permutaciones. El valor de significancia (valor- $p$ ) de la prueba es la proporción de permutaciones que conduce a un valor de $\Phi_{S T}$ mayor o igual al observado. 
AMOVA

La estructura genética de la población se infirió mediante el uso del Análisis de la Varianza Molecular (AMOVA) (Excoffier et al, 1992). Este análisis incorpora información de divergencia haplotípica en formato de análisis de la varianza, derivada de una matriz de distancia genética entre todos los pares de haplotipos. El AMOVA produce estimaciones de los componentes de varianza y análogos de $F_{S T}$, designados aquí como $\Phi_{S T}$, reflejando la correlación entre la diversidad haplotípica y los diferentes niveles de subdivisión jerárquica.

En el AMOVA la varianza se descompone en: a) variación de los individuos dentro de las poblaciones $\left(\Phi_{S T}\right)$; b) variación de los individuos entre poblaciones dentro de los grupos $\left(\Phi_{S C}\right)$ y c) variación de individuos entre los grupos de poblaciones $\left(\Phi_{C T}\right)$. Para evaluar la significancia de estos agrupamientos, el método realiza 10.000 o más permutaciones no paramétricas de haplotipos, de individuos y de poblaciones. Luego de cada permutación se recalculan los estadísticos para comparar con la hipótesis nula de que no hay estructura poblacional.

En este trabajo de tesis se utilizó el criterio de proximidad geográfica para explorar la varianza molecular del complejo patagonicus-praebasalticus. 
Flujo génico

El flujo génico uniformiza a las poblaciones de una especie y contrarresta la diferenciación genética que pudiera ocurrir por el aislamiento geográfico (Slatkin, 1987). Este concepto se utiliza para indicar el movimiento que existe entre diferentes grupos que resulta en un intercambio genético (Hedrick, 2005); sin embargo, esto resulta muy difícil de cuantificar en poblaciones naturales. Por esta razón, se han utilizado medidas de estructuración genética, tales como el coeficiente $\Phi_{S T}$, para calcular el número de migrantes entre poblaciones. El modelo usado comúnmente para estimar flujo génico es el modelo de islas infinitas (infinite islands model) de Wright (1951) (Figura 20A). Este modelo considera condiciones en equilibrio entre un número infinito de islas o subpoblaciones de igual tamaño, que intercambian migrantes entre cualquiera de las islas con la misma probabilidad a una tasa constante. Las poblaciones pueden ser tratadas como réplicas y el modelo se puede caracterizar con dos parámetros: tamaño poblacional efectivo $(\mathrm{N})$ y tasa de migración (m). La importancia de la deriva génica es proporcional a $1 / \mathrm{N}$, mientras que la importancia del flujo génico es proporcional a $m$ (Slatkin, 1985). Por su parte, en el modelo de stepping-stone (Figura 20B y 20C) introducido por Kimura (1953), las poblaciones se localizan en una especie de enrejado de una, dos o tres dimensiones y los individuos solo pueden moverse entre poblaciones adyacentes.

Para estimar el flujo génico con un método indirecto usualmente se emplea la fórmula de Wright (1951), cuando $F_{S T}$ (aquí designado como $\Phi_{S T}$ ) llega al equilibrio entre deriva génica y migración en el modelo de islas infinitas.

$$
\Phi_{S T} \approx 1 /(2 N m+1) \text { para genoma haploide }
$$

De acuerdo con este modelo, el flujo génico entre las diferentes subpoblaciones puede ser estimado como:

$$
N m \approx\left(1-\Phi_{S T}\right) /\left(2 \Phi_{S T}\right) \text { para organismos haploides y ADNmt, }
$$


siendo $\mathrm{Nm}$ equivalente al número efectivo de migrantes por generación. En términos generales, se ha propuesto que un migrante por generación - $N m=1$ - es suficiente para contrarrestar los efectos de la deriva genética entre poblaciones (Wright, 1951; Slatkin, 1987); sin embargo, se recomienda considerar niveles mayores de flujo génico $(\mathrm{Nm}>5)$ para especies amenazadas (Mills y Allendorf, 1996).

A)

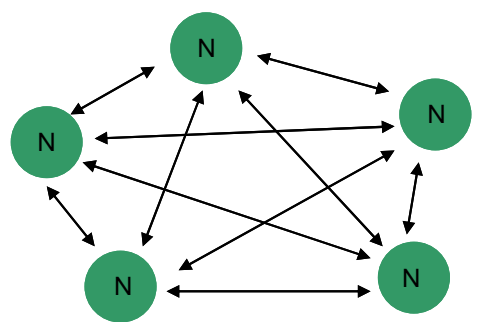

B)

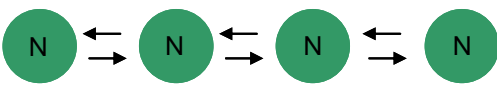

C)

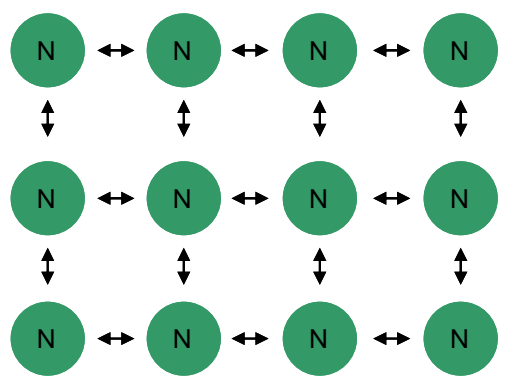

Figura 20. Modelos de flujo génico en poblaciones fragmentadas (modificado de Frankham et al., 2002). A) Modelo de islas, con intercambio recíproco de individuos en todas las poblaciones. B) Modelo de stepping-stone lineal, sólo las poblaciones adyacentes intercambian migrantes. C) Modelo de steppingstone bidimensional, las poblaciones vecinas intercambian migrantes. Cada flecha (bi o unidireccional) representa la tasa de migración $m$ existente entre un par de poblaciones en cada generación; $\mathrm{N}$ : número efectivode individuos de cada población. 


\section{Prueba de Mantel}

Con el fin de saber si una especie sigue un modelo de aislamiento por distancia, es decir, si existe una correlación entre las distancias geográficas y las distancias genéticas obtenidas para los distintos pares de poblaciones (Wright 1943), se hizo una comparación formal con una prueba de Mantel (1967). Dicha prueba se realizó con el programa Arlequin y consiste en asociar dos o más matrices mediante permutaciones que permiten obtener una distribución empírica nula del coeficiente de correlación. El programa usa valores pareados de $\Phi_{S T}$ para estimar tasa de migración $(\mathrm{Nm})$ y luego correlaciona este valor con la distancia geográfica entre poblaciones. El número efectivo de migrantes por generación $(\mathrm{Nm})$ fue estimado como $N m=\left(1-\Phi_{S T}\right) /\left(2 \Phi_{S T}\right)$. El test no paramétrico de Mantel (1967) considera la significancia estadística de esta correlación y determina si existe una relación lineal significativa entre el flujo génico y la distancia geográfica entre poblaciones. La matriz de distancias geográficas fue construida en base a las distancias en línea recta expresadas en kilómetros entre pares de localidades de acuerdo a mapas tomados de Google Earth 6.0.3 (Keyhole, Inc.). 
Historia demográfica

La historia demográfica de una población deja una huella en los genomas de sus representantes modernos. La reconstrucción de esta historia nos permite obtener información útil para interpretar diversos procesos de evolución y genética de población (Ho \& Shapiro 2011). Hay una variedad de métodos disponibles para estimar patrones demográficos usando datos de secuencias de ADN. En este trabajo la historia demográfica de las poblaciones del complejo patagonicus praebasalticus fue analizada mediante pruebas de neutralidad a partir de los estadísticos $D$ de Tajima (Tajima, 1989) y $F_{S}$ de $\mathrm{Fu}(\mathrm{Fu}, 1997)$ implementadas en Arlequin v3.1 (Excoffier et al., 2005), mediante distribuciones pareadas (mismatch distributions) utilizando el programa DNAsp (Rozas et al., 2003) y mediante el método skyline-plot (Pybus et al., 2000) implementado en Beast v. 1.6.2 (Drummond \& Rambaut, 2006).

\section{Pruebas de Neutralidad}

Estas pruebas conocidas bajo el nombre de "Test de Neutralidad" fueron desarrolladas para determinar si el polimorfismo contenido en un grupo de datos para un simple locus dentro de una especie se comporta bajo lo esperado por la teoría neutral (Kreitman 2000). Estos análisis parten de la idea de que las poblaciones han estado en equilibrio entre mutación y deriva genética durante un tiempo evolutivamente largo (Nei y Kumar 2000). El test de Tajima fue uno de los primeros en desarrollarse, y actualmente es uno de los más utilizados para estos tipos de análisis. Esta prueba compara diferencias entre dos estimadores del parámetro neutral: a) el número de sitios segregantes de la muestra (S) y b) la diversidad nucleotídica $(\pi)$, medida como el número de diferencias nucleotídicas entre dos pares de secuencias tomadas al azar. 
Valores positivos y negativos en los test de neutralidad, corresponden a desviaciones de lo esperado bajo la teoría neutral. Con valores significativamente positivos puede asumirse que se está frente a procesos de selección balanceadora, pero también puede indicar presencia de subdivisión poblacional. Valores significativamente negativos son consistentes con procesos de barridas selectivas, cuellos de botella y/o expansiones poblacionales recientes (Hartl 1999). Si las poblaciones sufren fuertes expansiones demográficas dejan de estar en equilibrio entre mutación y deriva genética, y los índices de estas pruebas de neutralidad tienden a tener valores significativamente negativos. Estos tests se calcularon con el programa Arlequin v3.1 (Excoffier et al., 2005). Para investigar las significancia de los estadísticos y calcular el valor de $p$ se utilizaron 1.000 permutaciones.

Distribución de diferencias pareadas (mismatch distributions)

Este análisis permite inferir si las poblaciones de una especie o la especie en su conjunto han experimentado una expansión de rango reciente o si se han mantenido estables. El programa asume como hipótesis nula una expansión poblacional y genera una distribución real de los datos. Cuando una población ha sufrido una rápida expansión poblacional, se espera observar en el análisis una distribución unimodal, mientras que cuando una población está subdividida o ha permanecido en equilibrio demográfico se espera que exhiba una distribución multimodal (Rogers y Harpending, 1992). El análisis se basa en tres parámetros: $\theta_{0}=$ $2 \mu N_{0}, \theta_{1}=2 \mu N_{1}$ y $\tau$. Donde $\mu$ es la tasa de mutación, $N_{0}$ es el tamaño poblacional antes de la expansión, $N_{1}$ es el tamaño poblacional después de la expansión, y $\tau$ es el tiempo desde la expansión en unidades mutacionales (Rogers y Harpending, 1992). En este trabajo se calcularon las diferencias apareadas (pairwise differences) entre todos los posibles pares de secuencias y se realizaron gráficos para visualizar la distribución del número de diferencias observadas entre pares de secuencias en la muestra o "mismatch distributions" utilizando 1.000 simulaciones coalescentes para 
poner a prueba la significancia del estadístico rg "raggedness", bajo el modelo de expansión poblacional. Las poblaciones que han sufrido gran expansión poblacional se espera que exhiban una distribución suave, unimodal y bajo valor de "raggedness", mientras que las poblaciones que se han mantenido estables se espera que exhiban una distribución más errática y multimodal (Harpending, 1994). Para poner a prueba si las distribuciones se ajustan a lo esperado en una población en expansión, se utilizó el estadístico $\mathrm{R}_{2}$ y su probabilidad asociada $(\mathrm{p}<0,05)$ (RamosOnsins y Rozas, 2002) con 1.000 réplicas. Este test se realizó con el programa DNAsp (Rozas et al., 2003).

\section{Skyline Plot}

Es una herramienta útil para estimar los patrones históricos del tamaño poblacional de una genealogía, sin necesidad de introducir restricciones previas sobre modelos demográficos (Ho \& Shapiro 2011). Este método y todas sus extensiones metodológicas propuestas posteriormente, está basado en la teoría de la coalescencia, la cual, como ya se expresó previamente, cuantifica las relaciones entre la genealogía de la secuencia de ADN y la historia demográfica de la población (Kingman 1982a,b). La reconstrucción de la historia demográfica implica la estimación de la genealogía y la inferencia del tamaño efectivo de la población $(\mathrm{Ne})$ en diferentes puntos a lo largo de la escala de tiempo genealógica. La base intuitiva del concepto de tamaño efectivo de la población propuesto por Sewall Wright está asociada al tamaño poblacional que es relevante en términos evolutivos, esto es, el número de individuos reproductivos, ya que son éstos los que contribuyen a la generación siguiente en términos demográficos y sobre todo genéticos (Wright, 1969; Hedrick, 2000). El skyline-plot implementado en BEAST v. 1.6.2 (Drummond \& Rambaut, 2006) utiliza procedimientos de muestreo de cadenas de Markov Monte Carlo (MCMC) para estimar la distribución a posteriori del tamaño poblacional efectivo a través del tiempo, a partir de una muestra de secuencias de nucleótidos, dado un 
modelo de sustitución de nucleótidos previamente especificado (Drummond et al., 2002). Aquí se utilizó el modelo de evolución de secuencias HKY obtenido a partir del programa jModelTest 0.1.1 (Posada 2008) para las dos especies en estudio ( $A$. patagonicus y A. praebasalticus) y para los dos genes analizados (Cit-b y RC). Los tiempo de divergencia y su intervalo de confianza fueron estimados utilizando un modelo de reloj relajado y con una distribución log-normal no correlacionada. Debido a que las tasas de mutación para las especies y genes aquí estudiados son desconocidas, se utilizaron tasas de 0,005 a 0,01 mutaciones/sitio/Ma tanto para Cit$b$ como para $R C$ (Mueller, 2006). El rendimiento del proceso de MCMC fue comprobado a partir de la estacionalidad de los datos y por los tamaños poblacionales efectivos obtenidos mediante el programa Tracer 1.3 (Rambaut \& Drummond, 2004). 
Relaciones intra e interespecíficas

\section{Red de haplotipos}

Una forma de representar las relaciones entre los haplotipos es por medio de redes de haplotipos o "networks". Posada y Crandall (2001) argumentan que las redes definidas como gráficos conectados por círculos, son las más apropiadas para representar las relaciones dentro de una especie, dado que las genealogías intraespecíficas no se disponen de manera jerárquica y muchos supuestos de los métodos tradicionales sobre construcción de árboles filogenéticos (e.g. árboles totalmente dicotómicos, complete linage sorting) no se cumplen cuando se realizan estudios intraespecíficos. En este trabajo se construyó una red de haplotipos para cada una de las regiones de ADN mitocondrial analizadas (Cit- $b ; R C)$, con una matriz de datos que incluyó a todos los individuos de todas las localidades muestreadas mediante el programa TCS (Phylogenetic network estimation using statistical parsimony) desarrollado por Clement et al. (2000). Este programa, basado en el método de Templeton et al. (1992) y conocido como parsimonia estadística, permite elaborar redes filogenéticas a partir de secuencias de ADN o de matrices de distancias nucleotídicas, estimando el máximo número de diferencias entre haplotipos como resultado de sustituciones individuales con un $95 \%$ de confianza. Posteriormente, conecta los haplotipos que difieren por un cambio, luego aquellos que difieren por dos y así sucesivamente, hasta que todos los haplotipos son incluidos. El resultado final es una red que permite estimar las relaciones entre todos los haplotipos con base en el número mínimo de mutaciones. Las conexiones entre los haplotipos representan eventos coalescentes por lo que pueden hacerse, a partir de la red de parsimonia y con base en los principios de coalescencia, las siguientes predicciones: i) los haplotipos con mayor frecuencia tienen alta probabilidad de ser alelos ancestrales, ii) los haplotipos que tienen múltiples conexiones muy probablemente son ancestrales, iii) dentro de la red, los haplotipos ancestrales están 
en el interior y los haplotipos nuevos tienen mayor probabilidad de ser periféricos ('terminales'), iv) se espera que los haplotipos ancestrales tengan una amplia distribución geográfica (básicamente porque los individuos que tienen esos haplotipos han tenido mucho tiempo para dispersarse), y v) se predice que los haplotipos con una única conexión estén unidos a haplotipos de la misma población, dado que han evolucionado recientemente y por lo tanto sin tiempo para dispersarse (Vázquez-Domínguez et al., 2009).

Árbol de haplotipos

Tradicionalmente los análisis filogenéticos han sido utilizados para reconstruir relaciones entre especies en estudios macroevolutivos. Sin embargo los métodos tradicionales de reconstrucción filogenética (e.g. métodos de distancias, máxima parsimonia, máxima verosimilitud y análisis bayesiano) pueden ser útiles para reconstruir árboles de genes e identificar distintos linajes dentro de una especie en estudios a niveles microevolutivos (Avise 2000).

Las relaciones filogenéticas entre los haplotipos del complejo patagonicus praebasalticus fueron reconstruidas utilizando un análisis de máxima parsimonia (MP) implementado en el programa TNT 1.1 (Golobof et al., 2008). Los árboles fueron enraizados según el criterio de grupo externo. Para ello se utilizaron secuencias de Cit-b de Atelognathus ceii y secuencias de $R C$ de $A$. salai. Los árboles de MP se obtuvieron a partir de 200 réplicas de búsqueda heurística mediante de secuencias de adición al azar y TBR (tree-bisection-reconnection branch swapping). El soporte de los nodos fue puesto a prueba mediante 1.000 réplicas de bootstrap. 
Distancias genéticas en el género Atelognathus

Las distancias genéticas entre secuencias permite estimar cuantitativamente la divergencia genética entre pares de taxa (Avise, 2004). Las distancias genéticas constituyen un elemento fundamental para el estudio de la evolución molecular y son útiles para las reconstrucciones filogenéticas y para estimar tiempos de divergencias (Nei \& Kumar, 2000). Las distancias genéticas entre dos secuencias dentro y entre poblaciones se estimaron mediante el programa MEGA versión 4 (Tamura et al., 2007) utilizando la proporción de sitios variables entre secuencias ( $p$-distance) (Nei \& Kumar, 2000). 


\section{RESULTADOS}

\section{El problema de las formas “acuática” y "litoral” de Atelognathus patagonicus}

Se exploró si las formas morfológicas de Atelognathus patagonicus descriptas por Cei y Roig (1968) constituyen un caso de polimorfismo o de plasticidad fenotípica. Con tal fin se construyó un red de haplotipos utilizando el programa TCS a partir de datos de ADN mitocondrial (Cit-b y $R C$ ). Se analizaron 85 individuos de A. patagonicus representando ambas formas morfológicas (acuática: $\mathrm{N}=60$; litoral: $\mathrm{N}=25$ ) provenientes de seis lagunas ubicadas dentro del Parque Nacional Laguna Blanca (del Molle, del Hoyo, La Batea, del Overo, Jabón y Antiñir) y de tres lagunas cercanas fuera de los límites del PNLB (del Burro, del Tero y de los Flamencos).

La red de haplotipos ${ }^{1}$ obtenida para Cit-b (Figura 21) exhibe un haplotipo dominante, presente en todas las lagunas, portado por individuos con morfotipo acuático así como por individuos con morfotipo litoral. Con $R C$ se obtuvieron sólo dos haplotipos ambos existentes en los dos morfotipos.

\footnotetext{
${ }^{1}$ Los rótulos de cada haplotipo representado aquí (H1, H2, H3, H4, H5, H6, H7) no se corresponden con los utilizados en los restantes apartados (Diversidad y estructura genética, Historia demográficca, Relaciones intra e interespecífica).
} 


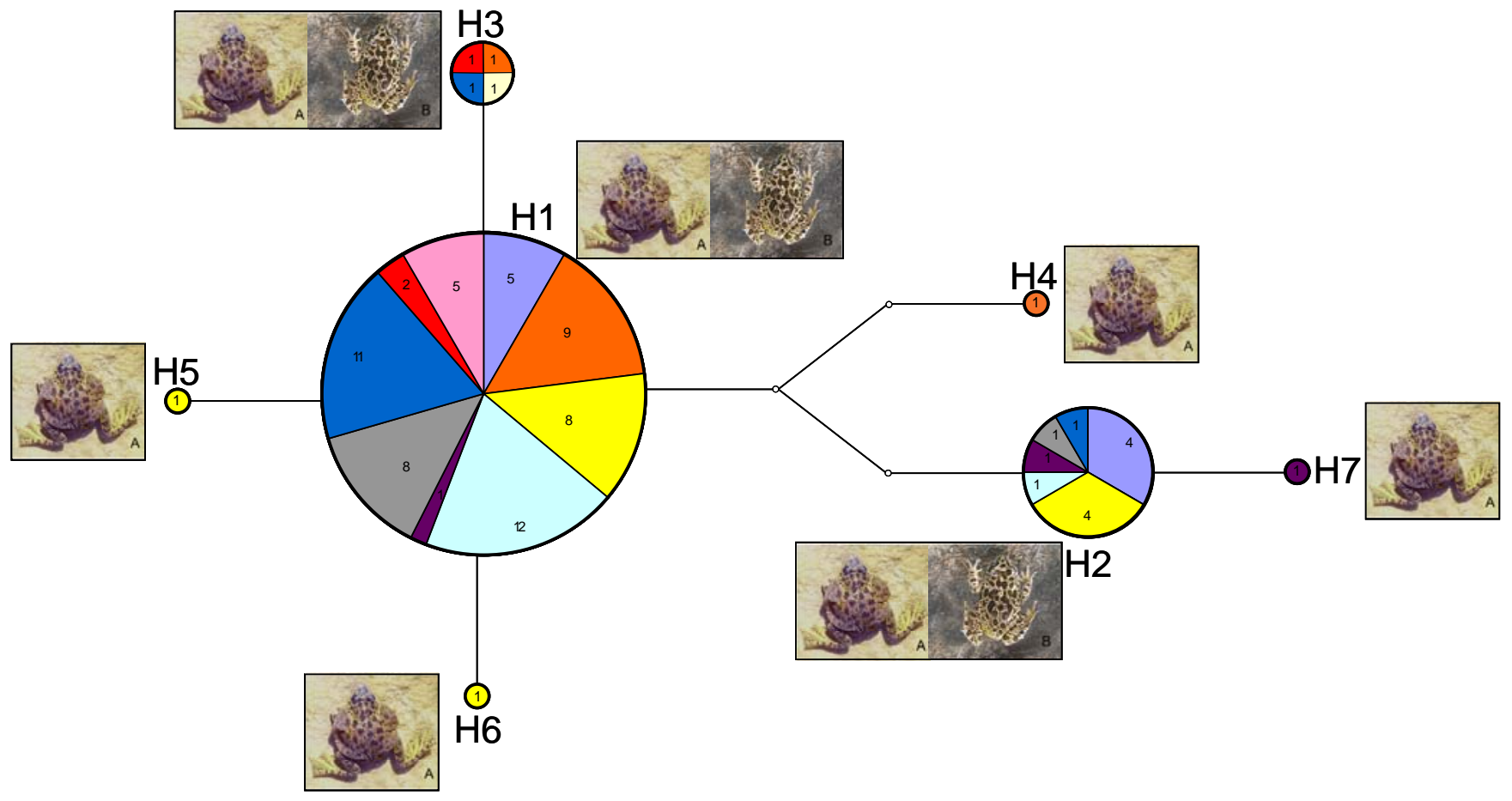

$\square$ Burro $\square$ Molle $\square$ Hoyo $\square$ Batea $\square$ Tero $\square$ Overo $\square$ Jabón $\square$ Antiñir $\square$ Flamencos

Figura 21: Red de haplotipos obtenida con el programa TCS a partir de secuencias de Cit-b del ADN mitocondrial. La figura muestra un red de siete haplotipos recuperados a partir de nueve poblaciones de Atelognathus patagonicus. Cada círculo representa un único haplotipo y el área de cada círculo es proporcional al número de individuos. Cada trozo de color dentro del círculo representa una laguna y el número mostrado es la cantidad de individuos de esa laguna que presenta ese haplotipo. Morfotipo acuático (fotografía A), morfotipo litoral (fotografía B). 


\section{Diversidad y estructura genética del complejo patagonicus-praebasalticus}

La diversidad y estructura genética del complejo patagonicus-praebaslticus fue analizada a nivel local (tratando cada laguna como una población independiente del resto) y a nivel regional (agrupando las lagunas por cercanía geográfica y tratando a cada grupo como una población) a partir de 653 pb y 581 pb de los genes mitocondriales $C i t-b$ y $R C$ respectivamente.

El segmento amplificado que corresponde al gen que codifica para Cit-b fue obtenido de 121 individuos asignados a Atelognathus patagonicus: 94 del Sistema Laguna Blanca (Sistema LB), la cual comprende lagunas ubicadas dentro del PNLB (lagunas del Molle, del Hoyo, del Overo, Jabón, Antiñir, Verde, La Batea) y fuera del PNLB (lagunas del Burro, del Tero, de los Flamencos); 19 individuos de laguna Honda, y 8 de la laguna de Casa de Piedra. De los 59 individuos asignados a $A$. praebasalticus se obtuvieron secuencias de nucleótidos de tres $A$. p. praebasalticus (laguna Verde del Sistema LB), 19 de A. p. agilis (laguna Casa de Piedra), 18 de $A$. p. dobeslawi (laguna del Piojo) y 19 a A. p. luisi (laguna Overa) (Tabla 3). El alineamiento de las secuencias de esta región del ADN mitocondrial (Cit-b) mostró 14 sitios variables que produjeron 13 haplotipos (Tabla 2). La red de haplotipos (Figura 22A) reveló un haplotipo más frecuente $(\mathrm{H} 4)$ compartido por individuos asignados a A. patagonicus, A. p. agilis y A. p. praebasalticus de 11 de las 14 lagunas muestreadas (lagunas del Sistema LB y laguna de Casa de Piedra). Los haplotipos H1, H2 y H10 también presentaron haplotipos compartidos por individuos provenientes de lagunas del Sistema LB y de la laguna de Casa de Piedra. El haplotipo H5 se encuentra separado del haplotipo H4 por cuatro cambios mutacionales y corresponde sólo a individuos asignados a $A$. p. dobeslawi de la laguna del Piojo. El haplotipo H7 se encuentra separado del haplotipo H4 por cinco cambios mutacionales y corresponde a individuos asignados a A. patagonicus de la laguna Honda y a $A$. p. luisi de la laguna Overa. Los haplotipos $\mathrm{H} 3, \mathrm{H} 6, \mathrm{H} 8, \mathrm{H}$, H11, H12 y H13 fueron exclusivos de alguna laguna en particular (Tabla 2, Figura 22A). La diversidad haplotípica (h) a nivel de poblaciones locales presentó un rango 
de variación que va desde valores muy bajos $(\mathrm{h}=0,0$ - laguna del Piojo-) a valores altos de diversidad ( $\mathrm{h}=0,833$ - laguna del Tero-). Por otro lado los valores de diversidad nucleotídica $(\pi)$ se presentaron en el rango de valores bajos $(\pi=0,0000)$ a valores moderados $(\pi=0,00384)$ (Tabla 3$)$.

A nivel regional con $C i t-b$ se observó que la diversidad haplotípica y nucleotídica fue mayor en las poblaciones de Casa de Piedra $(\mathrm{h}=0,71 ; \pi=0,0034)$ seguida por las poblaciones del Sistema LB $(\mathrm{h}=0,44 ; \pi=0,0017)$, luego las poblaciones de Honda/Overa $(\mathrm{h}=0,40 ; \pi=0,00059)$ y por último la población del Piojo $(\mathrm{H}=0,00 ; \pi=0,0000)$ (Tabla 4).

El segmento amplificado que corresponde a la Región Control $(R C)$ fue obtenido de 119 individuos de los cuales 90 fueron asignados a A. patagonicus: 72 correspondieron a individuos del Sistema LB, ocho individuos de la población de Casa de Piedra y 13 representantes de la laguna Honda; y 28 fueron asignados a $A$. praebasalticus: dos A. p. praebasalticus, laguna Verde - nueve A. p. agilis, laguna Casa de Piedra - nueve A. p. dobeslawi, laguna del Piojo - y ocho A. p. luisi, laguna Overa (Tabla 3). En este análisis se detectaron 17 sitios variables que produjeron siete haplotipos (Tabla 2). La red construida con estos datos $(R C)$ muestra un haplotipo más frecuente (H17) compartido por individuos asignados a $A$. patagonicus, A. p. agilis y A. p. praebasalticus de todas las lagunas del Sistema LB. El haplotipo H15 se encuentra separado del H17 por 14 cambios mutacionales y corresponde a individuos asignados a $A$. patagonicus de la laguna Honda y a $A$. $p$. luisi de la laguna Overa. El haplotipo H14 se encuentra separado del H17 por 13 cambios mutacionales y corresponde a ranas determinadas como A. p. agilis de la laguna de Casa de Piedra y A. p. dobeslawi de la laguna del Piojo (Figura 22B). A nivel local la diversidad haplotípica (h) varió entre 0,00 (en las poblaciones de lagunas Antiñir, del Tero y del Piojo) y 0,73 (en la población de la laguna Honda). La diversidad nucleotídica $(\pi)$ presentó un rango de 0,0000 (poblaciones de las lagunas Antiñir, del Tero y del Piojo) a 0,0116 (en la población de A. p. agilis de Casa de Piedra) (Taba 3). 
A nivel regional, con $R C$, la diversidad haplotípica fue mayor en la población del Grupo Honda/Overa $(\mathrm{h}=0,63)$ seguido por el Grupo de Casa de Piedra $(\mathrm{h}=$ 0,52), luego por el Grupo del sistema LB $(\mathrm{h}=0,47)$ y por último el Grupo del Piojo con nula diversidad haplotípica $(\mathrm{h}=0,00)$. La diversidad nucleotídica $(\pi)$ para $R C$ varió entre 0,00081 en el Sistema LB a 0,011 en el Grupo de Casa de Piedra. Un valor intermedio se obtuvo para el Grupo de Honda/Overa $(\pi=0,0012)$ y nulo para el Grupo Piojo ( $\pi=0,0000)$ (Tabla 4). 
Tabla 2: Número de individuos por haplotipo/por laguna para ambos marcadores moleculares (Cit-b y $R C$ ).

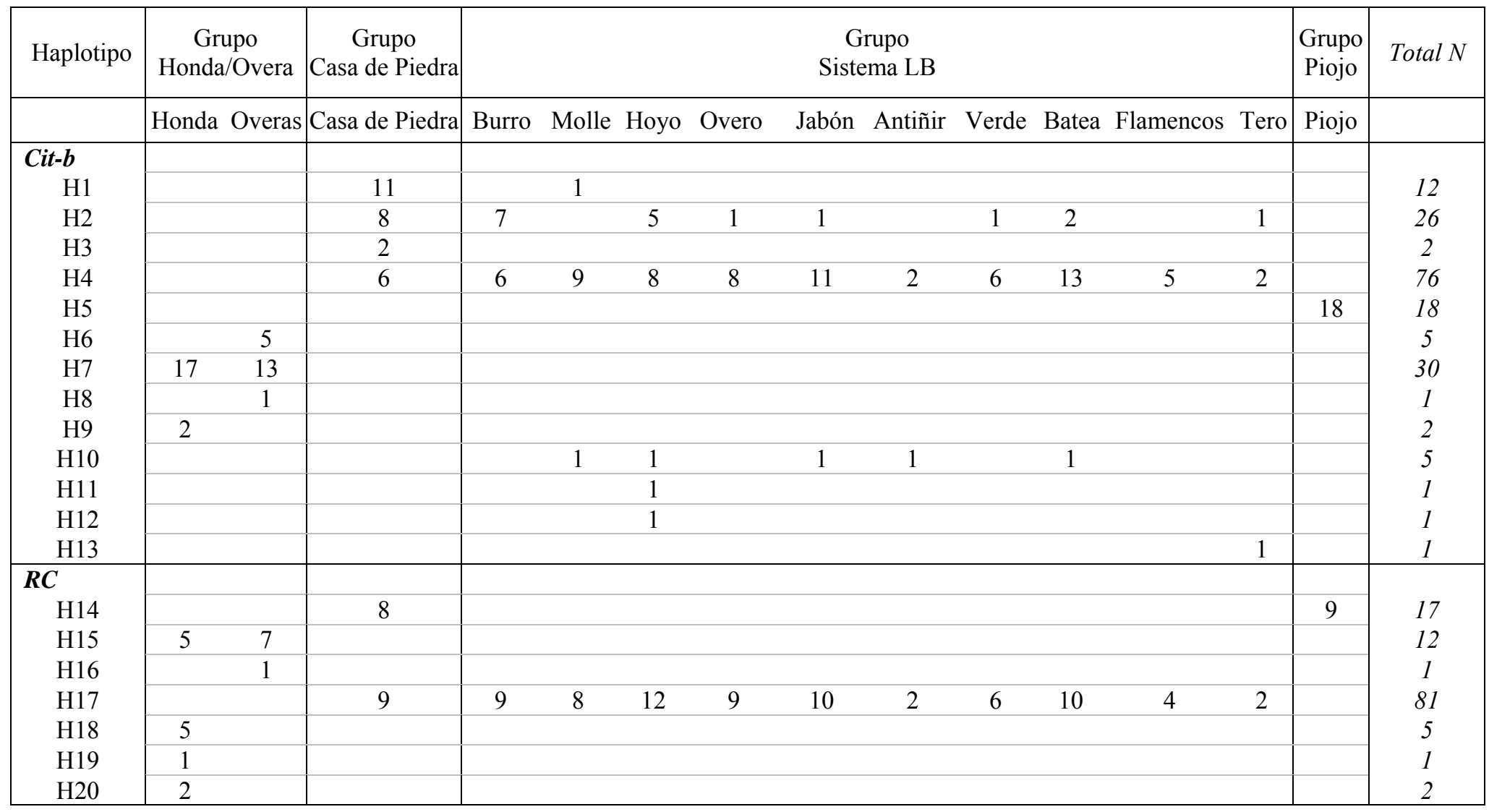


Tabla 3: Índices de diversidad genética para cada una de las poblaciones estudiadas. $\mathrm{N}$ : tamaño muestral, $\mathrm{n}_{\mathrm{h}}$ : número de haplotipos, $\mathrm{h}$ : diversidad haplotídica, $\pi$ : diversidad nucleotídica, S: número de sitios polimórficos.

\begin{tabular}{|c|c|c|c|c|c|c|c|c|c|c|c|c|}
\hline \multirow[t]{2}{*}{ Grupos regionales } & \multirow[t]{2}{*}{ Especie } & \multirow[t]{2}{*}{ Sitios de muestreo } & \multicolumn{5}{|c|}{$C i t-b$} & \multicolumn{5}{|c|}{$R C$} \\
\hline & & & $\mathrm{N}$ & $\mathrm{n}_{\mathrm{h}}$ & $\mathrm{h}$ & $\pi$ & $\mathrm{S}$ & $\mathrm{N}$ & $\mathrm{n}_{\mathrm{h}}$ & $\mathrm{h}$ & $\pi$ & $\mathrm{S}$ \\
\hline \multirow{11}{*}{ Sistema LB } & A. patagonicus & Burro & 13 & 2 & 0,538 & $2,48^{-3}$ & 3 & 9 & 2 & 0,222 & $3,83^{-4}$ & 1 \\
\hline & A. patagonicus & Molle & 11 & 3 & 0,345 & $1,11^{-3}$ & 4 & 8 & 2 & 0,428 & $7,38^{-4}$ & 1 \\
\hline & A. patagonicus & Hoyo & 16 & 5 & 0,683 & $2,68^{-3}$ & 6 & 12 & 2 & 0,530 & $9,14^{-4}$ & 1 \\
\hline & A. patagonicus & Overo & 9 & 2 & 0,222 & $1,02^{-3}$ & 3 & 9 & 2 & 0,555 & $9,57^{-4}$ & 1 \\
\hline & A. patagonicus & Jabón & 13 & 3 & 0,294 & $9,45^{-4}$ & 4 & 10 & 2 & 0,466 & $8,04^{-4}$ & 1 \\
\hline & A. patagonicus & Antiñir & 3 & 2 & 0,666 & $1,02^{-3}$ & 1 & 2 & 1 & 0,000 & 0,00 & 0 \\
\hline & A. patagonicus & Verde & 4 & 1 & 0,000 & 0,00 & 0 & 3 & 2 & 0,666 & $1,14^{-3}$ & 0 \\
\hline & A.p.praebasalticus & Verde & 3 & 2 & 0,666 & $3,07^{-3}$ & 3 & 3 & 2 & 0666 & $1,14^{-3}$ & 1 \\
\hline & A.patagonicus & Batea & 16 & 3 & 0,341 & $1,26^{-3}$ & 4 & 10 & 2 & 0,466 & $8,04^{-4}$ & 1 \\
\hline & A.patagonicus & Flamencos & 5 & 1 & 0,000 & 0,00 & 0 & 4 & 2 & 0,500 & $8,62^{-4}$ & 1 \\
\hline & A.patagonicus & Tero & 4 & 3 & 0,833 & $3,84^{-3}$ & 4 & 2 & 1 & 0,000 & 0,00 & 0 \\
\hline \multirow{2}{*}{ Casa de Piedra } & A. patagonicus & Casa de Piedra & 8 & 3 & 0,750 & $3,78^{-3}$ & 5 & 8 & 2 & 0,535 & $1,12^{-2}$ & 12 \\
\hline & A.p. agilis & Casa de Piedra & 19 & 4 & 0,725 & $3,43^{-3}$ & 5 & 9 & 2 & 0,555 & $1,16^{-2}$ & 12 \\
\hline \multirow{2}{*}{ Honda/Overa } & A. patagonicus & Honda & 19 & 2 & 0,198 & $3,05^{-4}$ & 1 & 13 & 4 & 0,730 & $1,63^{-3}$ & 3 \\
\hline & A.p. luisi & Overa & 19 & 4 & 0,555 & $7,89^{-4}$ & 2 & 8 & 2 & 0,250 & $4,31^{-4}$ & 1 \\
\hline Piojo & A. p. dobeslawi & Piojo & 18 & 1 & 0,000 & 0,00 & 0 & 9 & 1 & 0,000 & 0,00 & 0 \\
\hline
\end{tabular}




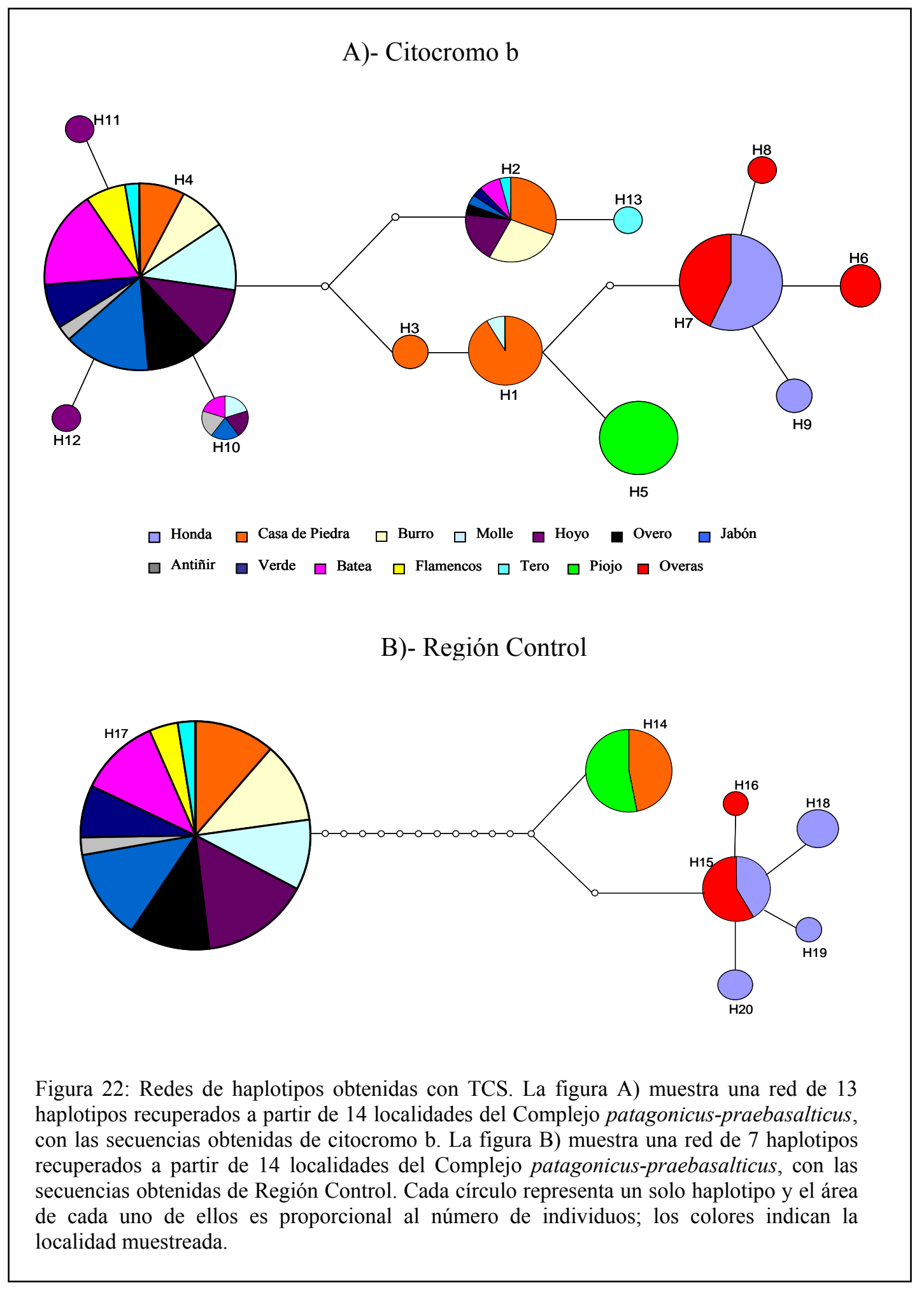


Tabla 4: Índices de diversidad genética para cada uno de los grupos regionales. N: tamaño muestral, $\mathrm{n}_{\mathrm{h}}$ : número de haplotipos, $\mathrm{h}$ : diversidad haplotídica, $\pi$ : diversidad nucleotídica.

\begin{tabular}{|l|cccc|cccc|}
\hline & \multicolumn{5}{|c|}{$C i t-b$} & \multicolumn{5}{c|}{$R C$} \\
\hline & $\mathrm{N}$ & $\mathrm{n}_{\mathrm{h}}$ & $\mathrm{h}$ & $\pi$ & $\mathrm{N}$ & $\mathrm{n}_{\mathrm{h}}$ & $\mathrm{h}$ & $\pi$ \\
\hline Honda/Overa & 38 & 5 & 0,40 & $5,0^{-4}$ & 21 & 5 & 0,63 & $1,2^{-3}$ \\
Casa de Piedra & 27 & 4 & 0,71 & $3,4^{-3}$ & 17 & 2 & 0,52 & $1,1^{-2}$ \\
Sistema LB & 97 & 7 & 0,44 & $1,7^{-3}$ & 72 & 2 & 0,47 & $8,0^{-4}$ \\
Piojo & 18 & 1 & 0,00 & 0,00 & 9 & 1 & 0,00 & 0,00 \\
\hline
\end{tabular}

Comparaciones pareadas

A nivel de poblaciones locales, los valores de $\Phi_{S T}$ obtenidos a partir de las comparaciones pareadas realizadas con $C i t-b$ (Tabla 5), variaron desde $-0,295(\approx 0)$ hasta 0,983 (entre las lagunas Verde y del Tero y las lagunas del Piojo y Antiñir respectivamente). Cuando se analiza la región $C i t-b$, los valores de significancia de dichas comparaciones (Tabla 6) ponen en evidencia que los individuos de las lagunas del Piojo, Overa y Honda son significativamente diferentes entre sí y diferentes al resto de las ranas de las lagunas comprendidas dentro del área de estudio. La población de $A$. patagonicus de la laguna de Casa de Piedra no presenta diferencias significativas (Tabla 6) con la población simpátrica de $A$. p. agilis, aunque esta última resultó ser significativamente diferente a la mayoría de las poblaciones de $A$. patagonicus (excepto a la población de la laguna del Tero y a la de Casa de Piedra) y a todas las poblaciones de $A$. praebasalticus. No se observaron diferencias significativas entre la población de A. patagonicus y $A$. p. praebasalticus de laguna Verde (Tabla 6).

A nivel regional, los valores de $\Phi_{S T}$ obtenidos a partir de las secuencias de Cit-b, variaron entre 0,332 (entre el grupo de Sistema LB y el grupo Casa de Piedra) 
y 0,918 (entre el grupo de Honda/Overa y el grupo Piojo) y todos los grupos resultaron significativamente diferentes entre sí (Tabla 7).

El mismo análisis con $R C$ mostró una variación que osciló entre $-0,50(\approx 0)$ y 1,00 (Tabla 5). Los valores de significancia de estas comparaciones (Tabla 6) muestran que la población de la laguna del Piojo es significativamente diferente del resto de las poblaciones estudiadas, con excepción de la población de A. p. agilis que habita la laguna Casa de Piedra. No se encontraron diferencias significativas entre las poblaciones de laguna Honda y laguna Overa (Tabla 6), como se evidenció con Cit$b$, pero sí que esas ranas son significativamente diferentes del resto de las poblaciones comprendidas en el sistema lagunar bajo estudio. No se observaron diferencias significativas entre la población de A. patagonicus y A. p. praebasalticus de laguna Verde (Tabla 6). Algunas de las poblaciones de A. patagonicus del Sistema Laguna Blanca mostraron diferencias significativas entre lagunas sin evidenciar un patrón claro (Tabla 6).

A nivel regional (con $R C$ ), los valores de $\Phi_{S T}$ obtenidos variaron entre 0,414 (entre el grupo de Piojo y el grupo Casa de Piedra) y 0,966 (entre el grupo Piojo y el grupo Sistema LB) y todos los grupos resultaron significativamente diferentes entre sí (Tabla 7). 
Tabla 5: Comparaciones pareadas realizadas a partir del estimador $\Phi_{S T}$ usando como modelo de sustitución lo propuesto por Jukes \& Cantor. Arriba de la diagonal valores de $\Phi_{S T}$ obtenidos a partir de los análisis realizados con $R C$ y por debajo se presentan los valores de $\Phi_{S T}$ para $C i t-b$.

\begin{tabular}{|c|c|c|c|c|c|c|c|c|c|c|c|c|c|c|c|c|}
\hline & \multicolumn{2}{|c|}{$\begin{array}{l}\text { Grupo Regional } \\
\text { Honda/Overa }\end{array}$} & \multicolumn{2}{|c|}{$\begin{array}{l}\text { Grupo Regional } \\
\text { Casa de Piedra }\end{array}$} & \multicolumn{11}{|c|}{$\begin{array}{l}\text { Grupo Regional } \\
\text { Sistema LB }\end{array}$} & \multirow{2}{*}{$\begin{array}{c}\begin{array}{c}\text { Grupo } \\
\text { Regional } \\
\text { Piojo }\end{array} \\
\text { Piojo } \\
\end{array}$} \\
\hline & Overa & Honda & $\begin{array}{c}\begin{array}{c}\text { Casa de Piedra } \\
\text { (A. patagonicus })\end{array} \\
\end{array}$ & $\begin{array}{c}\text { Casa de Piedra } \\
\text { (A.p.agilis) }\end{array}$ & Burro & Molle & Hoyo & Overo & Jabón & Antiñir & $\begin{array}{c}\text { Verde } \\
\text { (A. patagonicus) }\end{array}$ & $\begin{array}{c}\text { Verde } \\
\text { (A.p.praebasalticus) } \\
\end{array}$ & Batea & Flamencos & Tero & \\
\hline Overa & 0,000 & 0,151 & 0,633 & 0,531 & 0,981 & 0,974 & 0,966 & 0,967 & 0,970 & 0,983 & 0,972 & 0,972 & 0,970 & 0,974 & 0,982 & 0,971 \\
\hline Honda & 0,152 & 0,000 & 0,671 & 0,579 & 0,949 & 0,944 & 0,943 & 0,940 & 0,943 & 0,937 & 0,931 & 0,931 & 0,943 & 0,934 & 0,932 & 0,879 \\
\hline $\begin{array}{l}\text { Casa de Piedra } \\
\text { (A. patagonicus) }\end{array}$ & 0,621 & 0,675 & 0,000 & $-0,062$ & 0,299 & 0,347 & 0,357 & 0,312 & 0,318 & 0,141 & 0,107 & 0,107 & 0,318 & 0,159 & $-0,012$ & 0,590 \\
\hline $\begin{array}{l}\text { Casa de Piedra } \\
\text { (A.p. agilis) }\end{array}$ & 0,568 & 0,594 & $-0,056$ & 0,000 & 0,492 & 0,504 & 0,535 & 0,492 & 0,504 & 0,328 & 0,322 & 0,322 & 0,504 & 0,365 & 0,242 & 0,375 \\
\hline Burro & 0,742 & 0,782 & 0,119 & 0,206 & 0,000 & 0,537 & 0,119 & 0,148 & $-0,004$ & 0,786 & $-0,067$ & $-0,067$ & $-0,004$ & $-0,130$ & $-0,321$ & 0,990 \\
\hline Molle & 0,818 & 0,872 & 0,227 & 0,358 & 0,367 & 0,000 & 0,108 & 0,065 & 0,252 & $-0,170$ & 0,116 & 0,116 & 0,252 & 0,269 & 0,542 & 0,984 \\
\hline Hoyo & 0,710 & 0,745 & 0,097 & 0,238 & 0,027 & 0,110 & 0,000 & $-0,105$ & $-0,068$ & 0,289 & $-0,243$ & $-0,243$ & $-0,068$ & $-0,128$ & 0,061 & 0,975 \\
\hline Overo & 0,832 & 0,890 & 0,212 & 0,346 & 0,258 & $-0,030$ & 0,010 & 0,000 & $-0,068$ & 0,242 & $-0,251$ & 0,251 & $-0,068$ & $-0,124$ & 0,086 & 0,977 \\
\hline Jabón & 0,837 & 0,886 & 0,284 & 0,399 & 0,334 & $-0,042$ & 0,065 & $-0,086$ & 0,000 & 0,464 & $-0,273$ & 0,273 & $-0,111$ & $-0,204$ & $-0,093$ & 0,980 \\
\hline Antiñir & 0,851 & 0,926 & 0,174 & 0,340 & 0,314 & $-0,105$ & 0,031 & 0,000 & $-0,076$ & 0,000 & 0,368 & 0,368 & 0,464 & 0,529 & 1,000 & 1,000 \\
\hline $\begin{array}{l}\text { Verde } \\
\text { (A. patagonicus) }\end{array}$ & 0,870 & 0,946 & 0,215 & 0,358 & 0,337 & $-0,125$ & 0,049 & $-0,116$ & $-0,130$ & 0,111 & 0,000 & $-0,500$ & $-0,273$ & $-0,387$ & $-0,200$ & 0,989 \\
\hline $\begin{array}{l}\text { Verde } \\
\text { (A.p.praebasalticus) }\end{array}$ & 0,794 & 0,873 & $-0,073$ & 0,114 & $-0,148$ & 0,102 & $-0,235$ & $-0,067$ & 0,042 & 0,000 & 0,111 & 0,000 & $-0,273$ & $-0,387$ &,- 200 & 0,989 \\
\hline Batea & 0,809 & 0,852 & 0,246 & 0,374 & 0,269 & $-0,013$ & 0,024 & $-0,088$ & $-0,063$ & $-0,051$ & $-0,089$ & $-0,062$ & 0,000 & $-0,204$ & $-0,093$ & 0,980 \\
\hline Flamencos & 0,875 & 0,948 & 0,256 & 0,382 & 0,366 & $-0,089$ & 0,081 & $-0,077$ & $-0,095$ & 0,189 & 0,000 & 0,189 & $-0,056$ & 0,000 & $-0,263$ & 0,988 \\
\hline Tero & 0,773 & 0,838 & 0,008 & 0,136 & $-0,144$ & 0,330 & $-0,064$ & 0,207 & 0,309 & 0,188 & 0,285 & $-0,295$ & 0,222 & 0,347 & 0,000 & 1,000 \\
\hline Piojo & 0,920 & 0,967 & 0,734 & 0,600 & 0,848 & 0,928 & 0,816 & 0,946 & 0,938 & 0,932 & 1,000 & 0,945 & 0,907 & 1,000 & 0,909 & 0,000 \\
\hline
\end{tabular}


Tabla 6: Matriz de significancia de los valores $p$ obtenidos a partir de las comparaciones pareadas calculadas con el estadístico $\Phi_{S T}$ para $C i t-b$ (debajo de la diagonal) y $R C$ (arriba de la diagonal).

\begin{tabular}{|c|c|c|c|c|c|c|c|c|c|c|c|c|c|c|c|c|}
\hline & \multicolumn{2}{|c|}{$\begin{array}{l}\text { Grupo Regional } \\
\text { Honda/Overa }\end{array}$} & \multicolumn{2}{|c|}{$\begin{array}{l}\text { Grupo Regional } \\
\text { Casa de Piedra }\end{array}$} & \multicolumn{11}{|c|}{$\begin{array}{l}\text { Grupo Regional } \\
\text { Sistema LB }\end{array}$} & \multirow{2}{*}{$\begin{array}{c}\begin{array}{c}\text { Grupo } \\
\text { Regional } \\
\text { Piojo }\end{array} \\
\text { Piojo } \\
\end{array}$} \\
\hline & Overa & Honda & $\begin{array}{c}\text { Casa de Piedra } \\
\text { (A. patagonicus })\end{array}$ & $\begin{array}{c}\text { Casa de Piedra } \\
\text { (A.p.agilis })\end{array}$ & Burro & Molle & Ноyо & Overo & Jabón & Antiñir & $\begin{array}{c}\text { Verde } \\
\text { (A. patagonicus) }\end{array}$ & $\begin{array}{c}\text { Verde } \\
\text { (A.p. praebasalticus) }\end{array}$ & Batea & Flamencos & Tero & \\
\hline Overa & & - & + & + & + & + & + & + & + & + & + & + & + & + & + & + \\
\hline Honda & + & & + & + & + & + & + & + & + & + & + & + & + & + & + & + \\
\hline $\begin{array}{l}\text { Casa de Piedra } \\
\text { (A. patagonicus) }\end{array}$ & + & + & & - & - & + & + & + & + & - & - & - & + & - & - & + \\
\hline $\begin{array}{l}\text { Casa de Piedra } \\
\text { (A.p. agilis) }\end{array}$ & + & + & - & & + & + & + & + & + & - & - & - & + & - & - & - \\
\hline Molle & + & + & - & + & + & & - & - & - & - & - & - & - & - & - & + \\
\hline Hoyo & + & + & - & + & - & - & & - & - & - & - & - & - & - & - & + \\
\hline Overo & + & + & - & + & - & - & - & & - & - & - & - & - & - & - & + \\
\hline Jabón & + & + & + & + & + & - & - & - & & - & - & - & - & - & - & + \\
\hline Antiñir & + & + & - & + & - & - & - & - & - & & - & - & - & - & - & + \\
\hline $\begin{array}{l}\text { Verde } \\
\text { (A. patagonicus) }\end{array}$ & + & + & - & + & - & - & - & - & - & - & & - & - & - & - & + \\
\hline $\begin{array}{l}\text { Verde } \\
\text { (A.p.praebasalticus) }\end{array}$ & + & + & - & - & - & - & - & - & - & - & - & & - & - & - & + \\
\hline Flamencos & + & + & - & + & - & - & - & - & - & - & - & - & - & & - & + \\
\hline Tero & + & + & - & - & - & - & - & - & - & - & - & - & - & - & & + \\
\hline Piojo & + & + & + & + & + & + & + & + & + & + & + & + & + & + & + & \\
\hline
\end{tabular}


Tabla 7: Comparaciones pareadas realizadas a partir del estimador $\Phi_{S T}$ usando como modelo de sustitución lo propuesto por Jukes \& Cantor. Arriba de la diagonal (en rojo) valores de $\Phi_{S T}$ obtenidos a partir de los análisis realizados con $R C$ y por debajo (en azul) se presentan los valores de $\Phi_{S T}$ para Cit-b. Los asteriscos (*) indican comparaciones significativas.

\begin{tabular}{lcccc}
\hline \multicolumn{4}{c}{ Grupo Regional } \\
\hline & Honda/Overa & Casa de Piedra & Sistema LB & Piojo \\
\hline Honda/Overa & 0,0000 & $0,6133^{*}$ & $0,9584^{*}$ & $0,8826^{*}$ \\
Casa de Piedra & $0,3324^{*}$ & 0,0000 & $0,6389^{*}$ & $0,4149^{*}$ \\
Sistema LB & $0,5679^{*}$ & $0,7857^{*}$ & 0,0000 & $0,9663^{*}$ \\
Piojo & $0,6060^{*}$ & $0,7370^{*}$ & $0,9186^{*}$ & 0,0000 \\
\hline
\end{tabular}

\begin{abstract}
AMOVA
En el análisis de la varianza molecular las poblaciones fueron agrupadas, por proximidad geográfica en cuatro grupos: Grupo Sistema LB: poblaciones del Sistema Laguna Blanca (lagunas del Burro, del Molle, del Hoyo, del Overo, Jabón, Antiñir, Verde, La Batea, de los Flamencos y del Tero), Grupo Casa de Piedra: laguna de Casa de Piedra, Grupo Honda/Overa: lagunas Honda y Overa; y Grupo Piojo: laguna del Piojo.

Para ambos genes el componente de la varianza entre grupos fue elevado (Cit$b: 66,70 \% ; R C: 86,21 \%$ ). El resto de la variación fue de 3,21\% para Cit-b y -0,64\% para $R C$ entre poblaciones dentro de los grupos; y de 30,09\% (Cit-b) y 14,43\% (RC) dentro de las poblaciones. Los componentes de la varianza y los índices de fijación $\Phi_{S T}$ se presentan en la Tabla 8.
\end{abstract}


Tabla 8: Análisis jerárquico de la varianza molecular (AMOVA) tomando en cuenta cuatro grupos: Grupo 1: poblaciones del Sistema Laguna Blanca (lagunas del Burro, del Molle, del Hoyo, del Overo, Jabón, Antiñir, Verde, la Batea, de los Flamencos y del Tero), Grupo 2: laguna de Casa de Piedra, Grupo 3: lagunas Overa y Honda; y Grupo 4: laguna del Piojo.

\begin{tabular}{|c|c|c|c|c|}
\hline & \multicolumn{2}{|c|}{$C i t-b$} & \multicolumn{2}{|c|}{$R C$} \\
\hline $\begin{array}{l}\text { Fuente de } \\
\text { Variación }\end{array}$ & $\begin{array}{l}\text { Porcentaje de } \\
\text { variación }\end{array}$ & $\begin{array}{c}\text { Índice de fijación } \\
(\text { valor } p)\end{array}$ & $\begin{array}{l}\text { Porcentaje de } \\
\text { variación }\end{array}$ & $\begin{array}{c}\text { Índice de fijación } \\
(\text { valor } p)\end{array}$ \\
\hline $\begin{array}{l}\% \text { varianza entre } \\
\text { grupos }\end{array}$ & 66,70 & $\begin{array}{c}\Phi_{C T}=0,667 \\
(0,003)\end{array}$ & 86,21 & $\begin{array}{c}\Phi_{C T}=0,862 \\
(0,000)\end{array}$ \\
\hline $\begin{array}{l}\text { \% varianza entre } \\
\text { poblaciones } \\
\text { dentro de los } \\
\text { grupos }\end{array}$ & 3,21 & $\begin{array}{c}\Phi_{S C}=0,096 \\
(0,000)\end{array}$ & $-0,64$ & $\begin{array}{c}\Phi_{S C}=-0,046 \\
(0,000)\end{array}$ \\
\hline $\begin{array}{l}\% \text { Varianza } \\
\text { dentro de las } \\
\text { poblaciones }\end{array}$ & 30,09 & $\begin{array}{c}\Phi_{S T}=0,699 \\
(0,000)\end{array}$ & 14,43 & $\begin{array}{c}\Phi_{S T}=0,855 \\
(0,000)\end{array}$ \\
\hline
\end{tabular}

\section{Flujo Génico}

A nivel de poblaciones locales, los resultados obtenidos a partir de la estimación de flujo génico entre las poblaciones estudiadas (Tabla 9) reveló con Cit$b$, que entre las poblaciones del Sistema LB los valores de número efectivo de migrantes fueron muy altos $(N m>>1)$, lo que evidencia alto flujo génico entre ellas. El mismo resultado se observó entre las poblaciones simpátricas $A$. patagonicus - $A$. p. agilis (laguna de Casa de Piedra) y A. patagonicus - A. p. praebasalticus (laguna Verde). El valor de $N m$ más bajo $(0,016)$ fue observado entre la población de la laguna Honda y la laguna del Piojo. Entre la laguna Overa y la laguna Honda el valor de $N m$ fue moderado $(2,771)$.

A nivel regional, el valor más alto observado entre los grupos, utilizando las secuencias de $C i t-b$, fue entre el grupo de Casa de Piedra y el grupo del Sistema LB $(\mathrm{Nm}=1,004)$ y el valor más bajo observado fue entre los grupos de Honda/Overa y Piojo $(N m=0,044)($ Tabla 10$)$.

El mismo análisis realizado para $R C$ mostró resultados semejantes, tanto a nivel local (Tabla 9) como a nivel regional (Tabla 10). 
Resultados

Tabla 9: Matriz de valores $\mathrm{M}(\mathrm{M}=N m)$ a nivel de poblaciones locales. Cit- $b$ en azul (debajo de la diagonal) y $R C$ en rojo (arriba de la diagonal).

\begin{tabular}{|c|c|c|c|c|c|c|c|c|c|c|c|c|c|c|c|c|}
\hline & \multicolumn{2}{|c|}{$\begin{array}{c}\text { Grupo Regional } \\
\text { Honda/Overa }\end{array}$} & \multicolumn{2}{|c|}{$\begin{array}{l}\text { Grupo Regional } \\
\text { Casa de Piedra }\end{array}$} & \multicolumn{11}{|c|}{$\begin{array}{l}\text { Grupo Regional } \\
\text { Sistema LB }\end{array}$} & \multirow{2}{*}{$\begin{array}{c}\begin{array}{c}\text { Grupo } \\
\text { Regional } \\
\text { Piojo }\end{array} \\
\text { Piojo }\end{array}$} \\
\hline & Overa & Honda & $\begin{array}{l}\text { Casa de Piedra } \\
\text { (A. patagonicus) }\end{array}$ & $\begin{array}{l}\text { Casa de Piedra } \\
\text { (A.p.agilis) }\end{array}$ & Burro & Molle & Hoyo & Overo & Jabón & Antiñir & $\begin{array}{c}\text { Verde } \\
\text { (A. patagonicus) }\end{array}$ & $\begin{array}{c}\text { Verde } \\
\text { (A. p. praebasalticus) }\end{array}$ & Batea & Flamencos & Tero & \\
\hline Overa & 0,000 & 2,805 & 0,289 & 0,441 & 0,009 & 0,013 & 0,017 & 0,016 & 0,015 & 0,008 & 0,014 & 0,014 & 0,015 & 0,013 & 0,009 & 0,014 \\
\hline Honda & 2,771 & 0,000 & 0,244 & 0,362 & 0,026 & 0,029 & 0,030 & 0,031 & 0,029 & 0,033 & 0,036 & 0,036 & 0,029 & 0,034 & 0,036 & 0,068 \\
\hline $\begin{array}{l}\text { Casa de Piedra } \\
\text { (A. patagonicus) }\end{array}$ & 0,304 & 0,240 & 0,000 & muy alto & 1,169 & 0,939 & 0,898 & 1,098 & 1,071 & 3,032 & 4,141 & 4,141 & 1,071 & 2,640 & $\begin{array}{l}\text { muy } \\
\text { alto }\end{array}$ & 0,346 \\
\hline $\begin{array}{l}\text { Casa de Piedra } \\
\text { (A.p. agilis) }\end{array}$ & 0,380 & 0,340 & muy alto & 0,000 & 0,516 & 0,490 & 0,434 & 0,514 & 0,491 & 1,023 & 1,049 & 1,049 & 0,491 & 0,868 & 1,565 & 0,833 \\
\hline Burro & 0,173 & 0,138 & 3,695 & 1,920 & 0,000 & 0,429 & 3,680 & 2,863 & $\begin{array}{l}\text { muy } \\
\text { alto }\end{array}$ & 0,135 & muy alto & muy alto & $\begin{array}{l}\text { muy } \\
\text { alto }\end{array}$ & $\begin{array}{l}\text { muy } \\
\text { alto }\end{array}$ & $\begin{array}{l}\text { muy } \\
\text { alto }\end{array}$ & 0,004 \\
\hline Molle & 0,111 & 0,072 & 1,700 & 0,894 & 0,860 & 0,000 & 4,090 & 7,136 & 1,481 & $\begin{array}{l}\text { muy } \\
\text { alto }\end{array}$ & 3,804 & 3,804 & 1,481 & 1,358 & 0,421 & 0,007 \\
\hline Hoyo & 0,203 & 0,171 & 4,632 & 1,596 & 17,873 & 4,022 & 0,000 & $\begin{array}{l}\text { muy } \\
\text { alto }\end{array}$ & $\begin{array}{l}\text { muy } \\
\text { alto }\end{array}$ & 1,224 & muy alto & muy alto & $\begin{array}{l}\text { muy } \\
\text { alto }\end{array}$ & $\begin{array}{l}\text { muy } \\
\text { alto }\end{array}$ & 7,636 & 0,012 \\
\hline Overo & 0,100 & 0,061 & 1,855 & 0,943 & 1,431 & $\begin{array}{l}\text { muy } \\
\text { alto }\end{array}$ & 49,370 & 0,000 & $\begin{array}{l}\text { muy } \\
\text { alto }\end{array}$ & 1,565 & muy alto & muy alto & $\begin{array}{l}\text { muy } \\
\text { alto }\end{array}$ & $\begin{array}{l}\text { muy } \\
\text { alto }\end{array}$ & 5,294 & 0,011 \\
\hline Jabón & 0,097 & 0,063 & 1,255 & 0,750 & 0,996 & $\begin{array}{l}\text { muy } \\
\text { alto }\end{array}$ & 7,118 & $\begin{array}{l}\text { muy } \\
\text { alto }\end{array}$ & 0,000 & 0,576 & muy alto & muy alto & $\begin{array}{l}\text { muy } \\
\text { alto }\end{array}$ & $\begin{array}{l}\text { muy } \\
\text { alto }\end{array}$ & $\begin{array}{l}\text { muy } \\
\text { alto }\end{array}$ & 0,010 \\
\hline Antiñir & 0,087 & 0,039 & 2,371 & 0,967 & 1,090 & $\begin{array}{l}\text { muy } \\
\text { alto }\end{array}$ & 15,248 & 5438,4 & $\begin{array}{l}\text { muy } \\
\text { alto }\end{array}$ & 0,000 & 0,857 & 0,857 & 0,576 & 0,444 & 0,000 & 0,000 \\
\hline $\begin{array}{l}\text { Verde } \\
\text { (A. patagonicus) }\end{array}$ & 0,074 & 0,028 & 1,824 & 0,893 & 0,981 & $\begin{array}{l}\text { muy } \\
\text { alto }\end{array}$ & 9,543 & $\begin{array}{l}\text { muy } \\
\text { alto }\end{array}$ & $\begin{array}{l}\text { muy } \\
\text { alto }\end{array}$ & 4,000 & 0,000 & muy alto & $\begin{array}{l}\text { muy } \\
\text { alto }\end{array}$ & $\begin{array}{l}\text { muy } \\
\text { alto }\end{array}$ & $\begin{array}{l}\text { muy } \\
\text { alto }\end{array}$ & 0,005 \\
\hline $\begin{array}{l}\text { Verde } \\
\text { (A.p.praebasalticus) }\end{array}$ & 0,129 & 0,072 & muy alto & 3,852 & $\begin{array}{l}\text { muy } \\
\text { alto }\end{array}$ & 4,396 & $\begin{array}{l}\text { muy } \\
\text { alto }\end{array}$ & $\begin{array}{l}\text { muy } \\
\text { alto }\end{array}$ & 11,137 & $\begin{array}{c}973,99 \\
5\end{array}$ & 4,000 & 0,000 & $\begin{array}{l}\text { muy } \\
\text { alto }\end{array}$ & $\begin{array}{l}\text { muy } \\
\text { alto }\end{array}$ & $\begin{array}{l}\text { muy } \\
\text { alto }\end{array}$ & 0,005 \\
\hline Batea & 0,117 & 0,086 & 1,529 & 0,835 & 1,352 & $\begin{array}{l}\text { muy } \\
\text { alto }\end{array}$ & 19,717 & $\begin{array}{l}\text { muy } \\
\text { alto }\end{array}$ & $\begin{array}{l}\text { muy } \\
\text { alto }\end{array}$ & $\begin{array}{l}\text { muy } \\
\text { alto }\end{array}$ & muy alto & muy alto & 0,000 & $\begin{array}{l}\text { muy } \\
\text { alto }\end{array}$ & $\begin{array}{l}\text { muy } \\
\text { alto }\end{array}$ & 0,010 \\
\hline Flamencos & 0,070 & 0,027 & 1,448 & 0,808 & 0,862 & $\begin{array}{l}\text { muy } \\
\text { alto }\end{array}$ & 5,619 & $\begin{array}{l}\text { muy } \\
\text { alto }\end{array}$ & $\begin{array}{l}\text { muy } \\
\text { alto }\end{array}$ & 2,142 & muy alto & 2,142 & $\begin{array}{l}\text { muy } \\
\text { alto }\end{array}$ & 0,000 & $\begin{array}{l}\text { muy } \\
\text { alto }\end{array}$ & 0,005 \\
\hline Tero & 0,146 & 0,095 & 59,020 & 3,170 & $\begin{array}{l}\text { muy } \\
\text { alto }\end{array}$ & 1,010 & $\begin{array}{l}\text { muy } \\
\text { alto }\end{array}$ & 1,906 & 1,117 & 2,154 & 1,249 & muy alto & 1,745 & 0,937 & 0,000 & 0,000 \\
\hline Piojo & 0,043 & 0,016 & 0,181 & 0,333 & 0,088 & 0,038 & 0,112 & 0,028 & 0,032 & 0,008 & 0,000 & 0,028 & 0,051 & 0,000 & 0,049 & 0,000 \\
\hline
\end{tabular}


Tabla 10: Matriz de valores $\mathrm{M}(\mathrm{M}=\mathrm{Nm})$ a nivel regional. Cit $-b$ en azul (debajo de la diagonal) y $R C$ en rojo (arriba de la diagonal).

\begin{tabular}{lcccc}
\hline \multicolumn{4}{c}{ Grupo Regional } \\
\hline & Honda/Overa & Casa de Piedra & Sistema LB & Piojo \\
\hline Honda/Overa & 0,000 & 0,315 & 0,021 & 0,066 \\
Casa de Piedra & 0,324 & 0,00 & 0,282 & 0,705 \\
Sistema LB & 0,178 & 1,004 & 0,000 & 0,017 \\
Piojo & 0,044 & 0,380 & 0,136 & 0,000 \\
\hline
\end{tabular}

\section{Prueba de Mantel}

El coeficiente de correlación calculado con el test de Mantel entre las matrices de distancia geográfica (Tabla 11) y de distancia genética obtenidas bajo el modelo de Jukes \& Cantor (Tabla 5$)$ fue positivo y significativo $(p<0,05)$ tanto para $C i t-b$ como para $R C\left(\mathrm{r}_{C i t-b}=0,94 \mathrm{y}_{R C}=0,85\right.$; respectivamente) (Figura 23). 
Tabla 11: Distancias geográficas aproximadas (en línea recta) en kilómetros.

\begin{tabular}{|c|c|c|c|c|c|c|c|c|c|c|c|c|c|c|}
\hline & Honda & $\begin{array}{c}\text { Casa de } \\
\text { Piedra }\end{array}$ & Burro & Molle & Ноуо & Overo & Jabón & Antiñir & Verde & Batea & Flamencos & Tero & Piojo & Overa \\
\hline Honda & 0 & & & & & & & & & & & & & \\
\hline Casa de Piedra & 36,34 & 0 & & & & & & & & & & & & \\
\hline Burro & 50,55 & 14,02 & 0 & & & & & & & & & & & \\
\hline Molle & 61,23 & 25,16 & 11,21 & 0 & & & & & & & & & & \\
\hline Ноуо & 60,92 & 25,24 & 11,53 & 1,43 & 0 & & & & & & & & & \\
\hline Overo & 60,60 & 24,51 & 10,82 & 1,14 & 0,85 & 0 & & & & & & & & \\
\hline Jabón & 65,34 & 29,48 & 15,26 & 5,34 & 6,35 & 6,38 & 0 & & & & & & & \\
\hline Antiñir & 64,44 & 28,46 & 14,34 & 3,51 & 4,17 & 4,40 & 2,33 & 0 & & & & & & \\
\hline Verde & 62,35 & 26,25 & 12,03 & 2,71 & 4,27 & 3,92 & 3,23 & 2,98 & 0 & & & & & \\
\hline Batea & 59,95 & 23,48 & 9,22 & 3,50 & 4,90 & 4,19 & 6,07 & 5,56 & 2,89 & 0 & & & & \\
\hline Flamencos & 72,97 & 37,13 & 22,99 & 11,80 & 12,11 & 12,58 & 8,12 & 8,43 & 11,06 & 13,89 & 0 & & & \\
\hline Tero & 50,41 & 14,14 & 0,80 & 11,18 & 11,43 & 10,73 & 15,28 & 14,31 & 12,01 & 9,12 & 23,6 & 0 & & \\
\hline Piojo & 45,75 & 61,95 & 72,63 & 85,04 & 84,54 & 84,81 & 87,77 & 87,85 & 85,38 & 81,74 & 95,84 & 74,94 & 0 & \\
\hline Overa & 12,43 & 48,55 & 64,68 & 73,61 & 74,55 & 73,69 & 79,19 & 77,32 & 74,68 & 72,93 & 85,03 & 63,60 & 39,35 & 0 \\
\hline
\end{tabular}




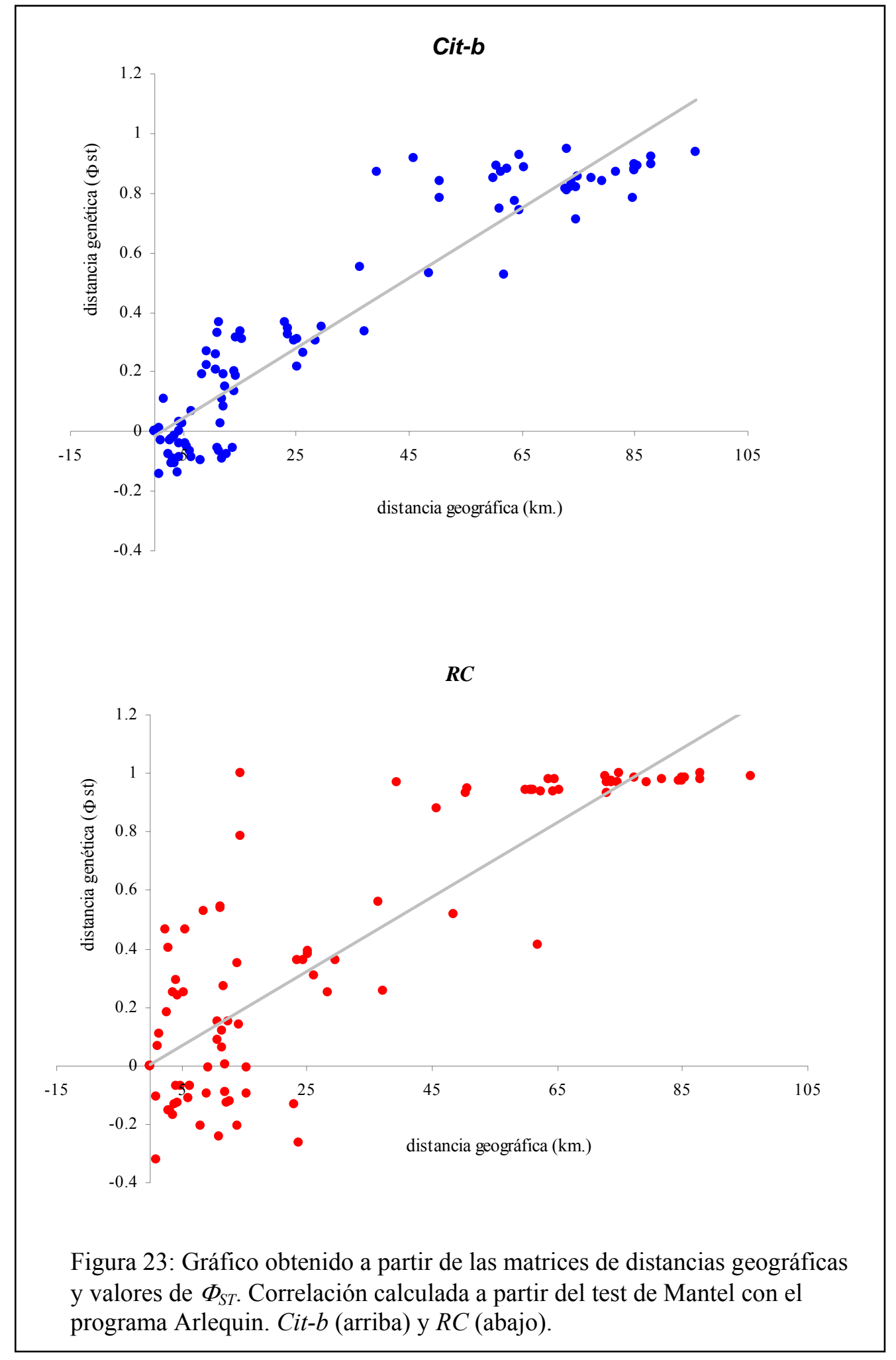




\section{Historia Demográfica}

\section{Pruebas de Neutralidad}

A nivel de poblaciones locales, no se encontraron desviaciones de la neutralidad usando el índice $F_{S}$ de $\mathrm{Fu}$, el cual es considerado una buena prueba para detectar expansión poblacional (Ramos-Onsins \& Rozas 2002). Sin embargo el estadístico $D$ de Tajima fue negativamente significativo en tres de las 14 poblaciones estudiadas (del Molle, del Overo y Jabón) (Tabla 5). A nivel regional estas pruebas no resultaron significativas en ninguno de los grupos.

Para $R C$ los estadísticos de $\mathrm{Fu}\left(F_{S}\right)$ y Tajima $(D)$ calculados fueron no significativos en todos los casos, tanto a nivel de poblaciones locales (Tabla 12) como a nivel regional (Tabla 13).

Tabla 12: Valores de la prueba de Tajima $(D)$ y de la prueba de $\mathrm{Fu}\left(F_{S}\right)$ a nivel de poblaciones locales. *: $p<0,05$.

\begin{tabular}{|c|c|c|c|c|c|c|}
\hline \multirow[t]{2}{*}{ Grupos Regionales } & \multirow[t]{2}{*}{ Especie } & \multirow[t]{2}{*}{ Sitios de muestreo } & \multicolumn{2}{|c|}{$C i t-b$} & \multicolumn{2}{|c|}{$R C$} \\
\hline & & & $D$ & $F_{S}$ & $D$ & $\overline{F_{S}}$ \\
\hline \multirow{2}{*}{ Honda/Overa } & A.p. luisi & Overa & $-0,240$ & $-0,196$ & $-1,054$ & $-0,181$ \\
\hline & A. patagonicus & Honda & $-0,562$ & $-0,054$ & $-0,058$ & $-0,627$ \\
\hline \multirow{7}{*}{ Casa de Piedra } & A. patagonicus & Casa de Piedra & 1,260 & 2,050 & 1,957 & 7,753 \\
\hline & A.p. agilis & Casa de Piedra & 1,746 & 2,042 & 2,416 & 8,523 \\
\hline & A. patagonicus & Burro & 2,121 & 3,789 & $-1,088$ & $-0,263$ \\
\hline & A. patagonicus & Molle & $-1,711 *$ & $-0,018$ & 0,333 & 0,536 \\
\hline & A. patagonicus & Ноуо & $-0,110$ & $-0,026$ & 1,381 & 1,152 \\
\hline & A. patagonicus & Overo & $-1,512 *$ & 1,317 & 1,401 & 1,015 \\
\hline & A. patagonicus & Jabón & $-1,774 *$ & $-0,169$ & 0,819 & 0,818 \\
\hline \multirow[t]{6}{*}{ Sistema LB } & A. patagonicus & Antiñir & 0,000 & 0,200 & 0,000 & 0,000 \\
\hline & A. patagonicus & Verde & 0,000 & 0,000 & 0,000 & 0,200 \\
\hline & A. p. praebasalticus & Verde & 0,000 & 1,609 & 0,000 & 0,200 \\
\hline & A. patagonicus & Batea & $-0,987$ & 0,585 & 0,819 & 0,818 \\
\hline & A. patagonicus & Flamencos & 0,000 & 0,000 & $-0,612$ & 0,171 \\
\hline & A. patagonicus & Tero & 1,365 & 0,461 & 0,000 & 0,000 \\
\hline Piojo & A.p. dobeslawi & Piojo & 0,000 & 0,000 & 0,000 & 0,000 \\
\hline
\end{tabular}


Tabla 13: Valores de la prueba de Tajima $(D)$ y de la prueba de $\mathrm{Fu}\left(F_{S}\right)$ a nivel regional. Cit$b$ en azul (debajo de la diagonal) y $R C$ en rojo (arriba de la diagonal).

\begin{tabular}{lcccc}
\hline \multicolumn{4}{c}{ Grupo Regional } \\
\hline & Honda/Overa & Casa de Piedra & Sistema LB & Piojo \\
\hline Honda/Overa & 0,000 & 0,315 & 0,021 & 0,066 \\
Casa de Piedra & 0,324 & 0,00 & 0,282 & 0,705 \\
Sistema LB & 0,178 & 1,004 & 0,000 & 0,017 \\
Piojo & 0,044 & 0,380 & 0,136 & 0,000 \\
\hline
\end{tabular}

Distribución de diferencias pareadas

A nivel de poblaciones locales, el análisis de distribuciones de diferencias pareadas o "mistmach distributions" con Cit-b, sugiere una historia de expansión poblacional sólo para la población de la laguna Honda reflejando una distribución unimodal y un bajo número de diferencias pareadas $(\mathrm{k}=0,199)$ con un valor de estadístico de "raggedness" de 0,402 ( $p>0,05)$ ajustándose al modelo de expansión espacial y expansión demográfica reciente (Figura 24). El resto de las poblaciones reflejan una historia demográfica estable, con distribuciones bimodales que no se ajustan a la hipótesis de expansión poblacional.

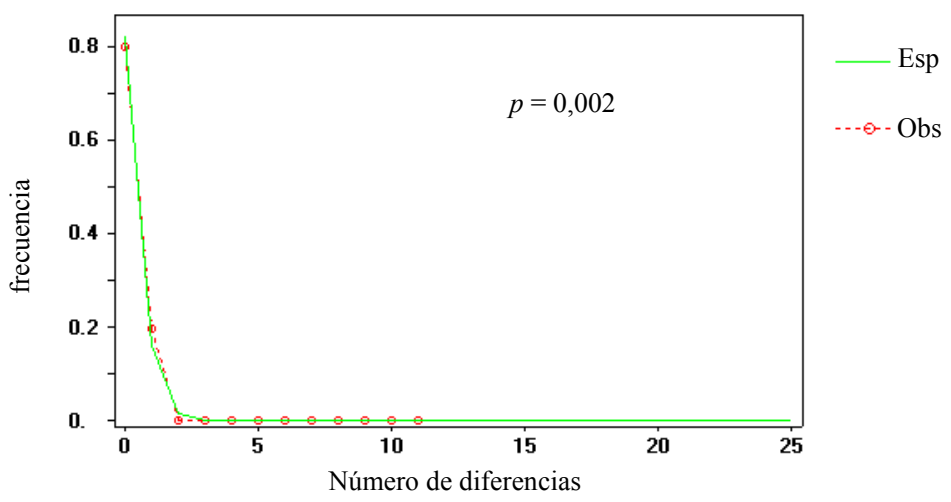

Figura 24: Cit-b. Distribuciones pareadas o "mismatch distributions" para la población de la laguna Honda. La frecuencia esperada está basada en el modelo de expansión poblacional con un $\theta_{0}=0, \theta_{1}=1.000, \tau_{\mathrm{Honda}}=0,199$. 
A nivel regional, el análisis de distribuciones de diferencias pareadas o “mistmach distributions" con Cit- $b$, reveló una distribución bimodal para las poblaciones del grupo Sistema LB (Figura 25A) y Grupo Casa de Piedra (Figura 25B), lo que estaría indicando una historia demográfica estable para estas poblaciones. A pesar de esto, en ambos casos no pudo ser rechazada la hipótesis nula de expansión poblacional, siendo el índice de "raggedness" de $r g_{\text {SistemaLB }}=0,348$ ( $p$ $>0,05)$ y $r g_{\text {CasaDePiedra }}=0,239(p>0,05)$, respectivamente. En ambos casos se observó un bajo ajuste a lo esperado bajo el modelo de expansión espacial y expansión demográfica reciente. Para el grupo Honda/Overa se obtuvo una distribución unimodal (Figura 25C) con un valor del estadístico de "raggedness" no significativo $\left(r g_{\text {Honda/Overa }}=0,187 ; p>0,05\right)$ y un buen ajuste según lo esperado bajo el modelo de expansión espacial y expansión demográfica reciente. El tiempo relativo $(\tau)$ desde la expansión poblacional (medido en unidades mutacionales) para el grupo Honda/Overa fue de 0,390. Para el grupo Piojo no pudo realizarse el análisis ya que resultó imposible calcular los parámetros demográficos debido a que su población no presenta varianza genética.

Los análisis realizados a partir de la $R C$ arrojaron resultados semejantes. A nivel de poblaciones locales no se detectó expansión poblacional en ningún caso. A nivel regional, sólo para el grupo Honda/Overa se observó una curva unimodal y un buen ajuste al modelo de expansión poblacional reciente (Figura 26B).

Los valores del parámetro $\tau$, el cual describe el tiempo relativo desde la expansión geográfica del rango (en unidades mutacionales), fueron: $\tau_{C i t-b}=1,729 \mathrm{y}$ $\tau_{R C}=0,895$ para el grupo Casa de Piedra; $\tau_{C i t-b}=0,390$ y $\tau_{R C}=0,752$ para el grupo Honda/Overa; $\tau_{C i t-b}=0,192$ para el grupo Sistema LB, cuyo valor de $\tau$ para $R C$ no pudo ser calculado debido a la falta de variabilidad genética en este caso.

Para el grupo Piojo no pudo realizarse el análisis ya que resultó imposible calcular los parámetros demográficos debido a la falta de varianza genética en la $R C$. 
A)

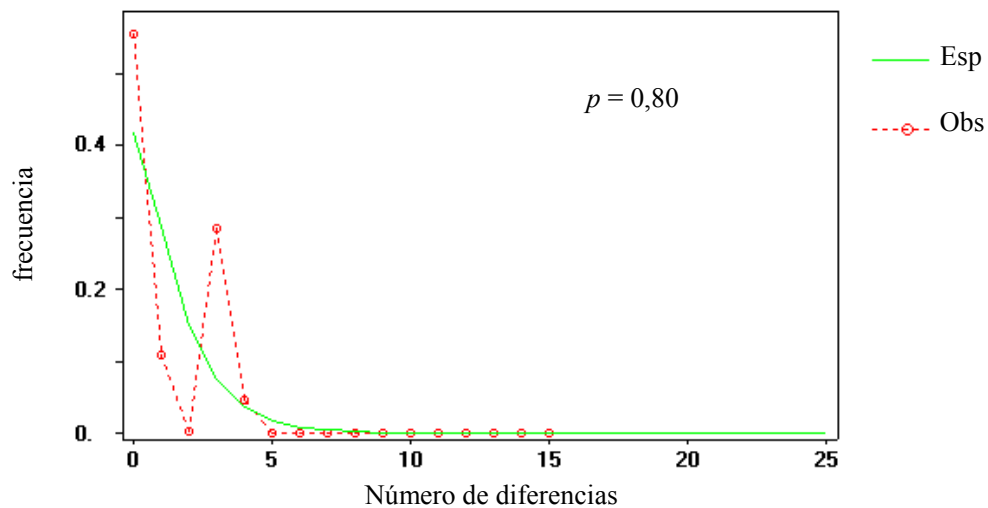

B)

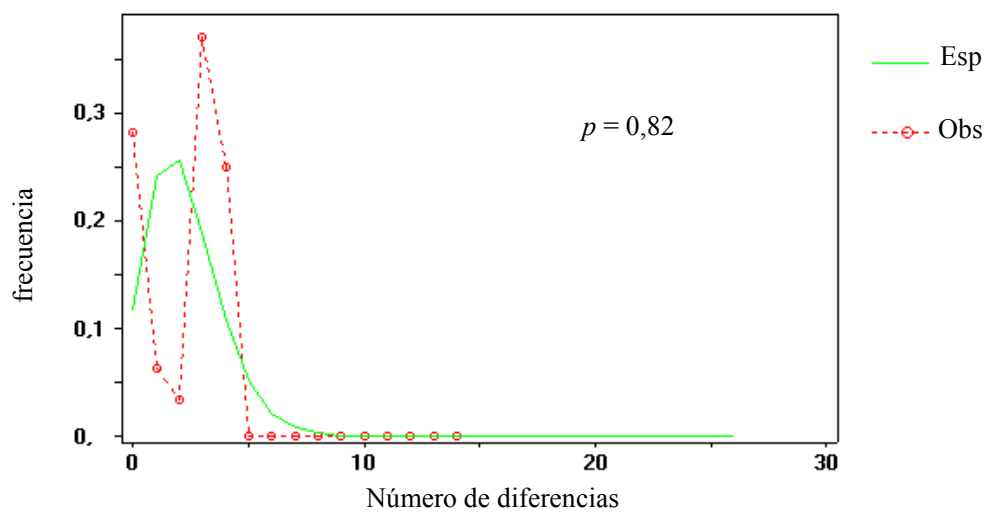

C)

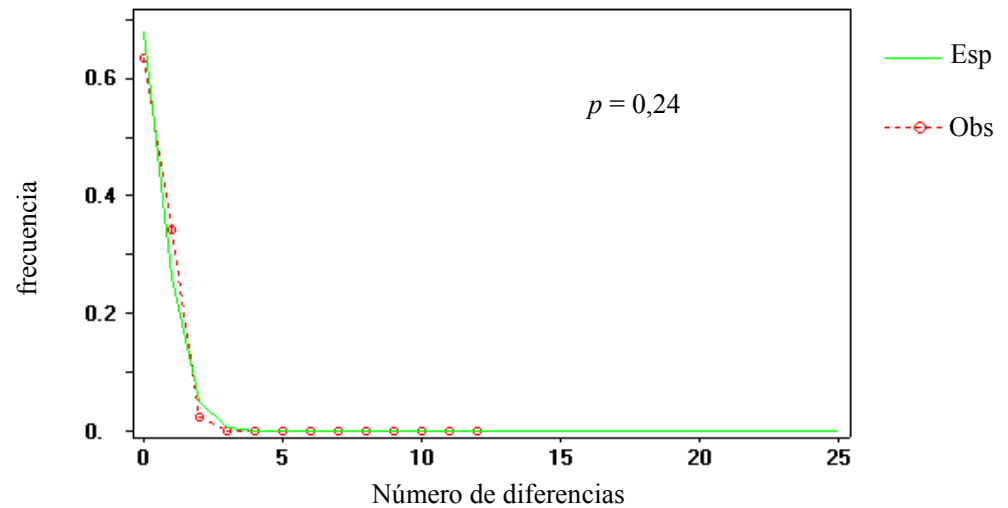

Figura 25: Cit-b. Distribuciones pareadas o "mismatch distributions". A)- Grupo Sistema LB: poblaciones del PNLB y lagunas cercanas. B)- Grupo Casa de Piedra: población de laguna Casa de Piedra. C)- Grupo Honda/Overa: población de laguna Overas y laguna Honda. La frecuencia esperada está basada en el modelo de expansión poblacional con un $\theta_{0}=0, \theta_{1}=1.000, \tau_{\text {Honda/Overa }}=0,390$. 
A)

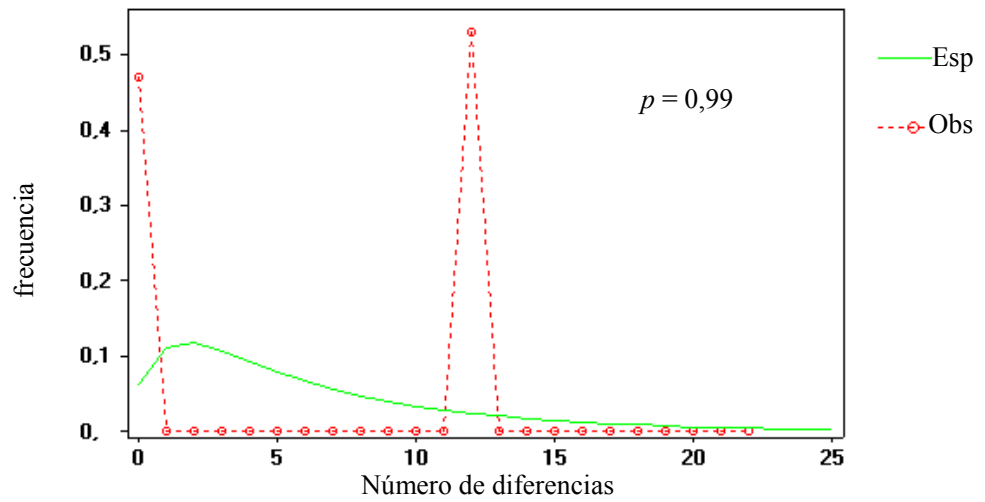

B)

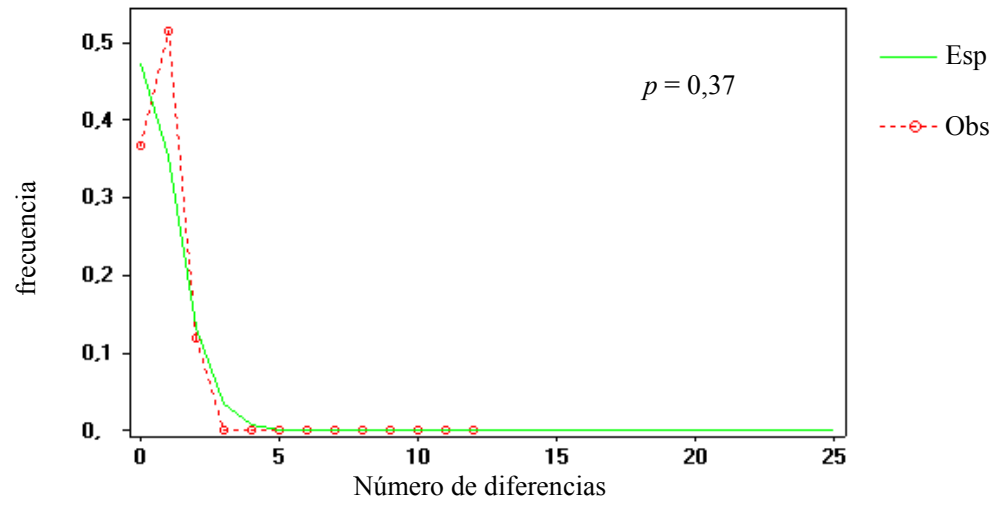

Figura 26: $R C$. Distribuciones pareadas o "mismatch distributions". A)- Grupo Casa de Piedra: población de laguna Casa de Piedra. B)- Grupo Honda/Overa: población de laguna Overas y laguna Honda. La frecuencia esperada está basada en el modelo de expansión poblacional con un $\theta_{0}=1, \theta_{1}=1.000, \tau_{\text {Honda/Overa }}=0,752$.

\section{Skyline Plot}

Los análisis realizados a partir de este método no evidenciaron, en ningún caso y a ningún nivel, cambios en los tamaños poblacionales. 


\title{
Relaciones intra e interespecíficas
}

\author{
Árboles de Haplotipos
}

Los árboles de máxima parsimonia que establecen las relaciones filogenéticas a partir del análisis de los haplotipos del complejo patagonicus-praebasalticus obtenidos del estudio de las secuencias del gen Cit- $b$ revelan una topología similar a los establecidos a partir del estudio de la $R C$. Estos análisis recuperaron el clado Honda + Overa (Figuras 27 y 28) con un valor de soporte de las ramas (bootstrap support) de $78 \%$ y $89 \%$, para $C i t-b$ y $R C$ respectivamente. Este clado incluye la población de laguna Honda (individuos determinados a priori como A. patagonicus por Cuello et al., 2009) y los de laguna Overa (descriptos originariamente como $A$. $p$. luisi, Cei 1972). Si bien no hay resolución para el resto de los haplotipos, se observa en el consenso estricto de seis árboles obtenidos con las secuencias de nucleótidos de Cit-b (Figura 27), que los ejemplares de Casa de Piedra comparten haplotipos con las poblaciones del Sistema LB. Mientras que, en el único árbol obtenido con las secuencias de $\mathrm{ADN}$ de la $R C$ (Figura 28), se visualiza que la población de Casa de Piedra comparte haplotipos con el Sistema LB y con la población de la laguna del Piojo. 


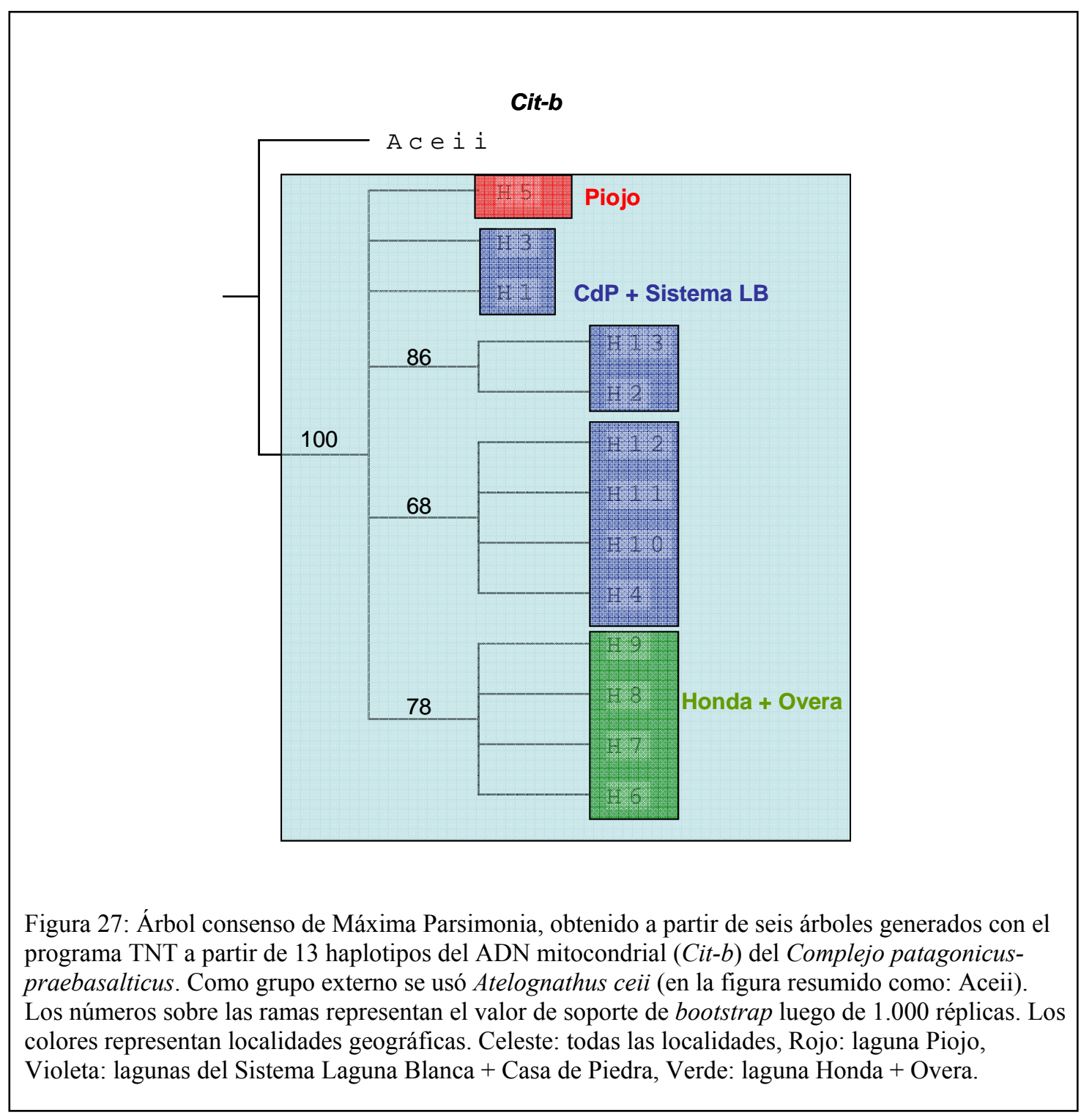




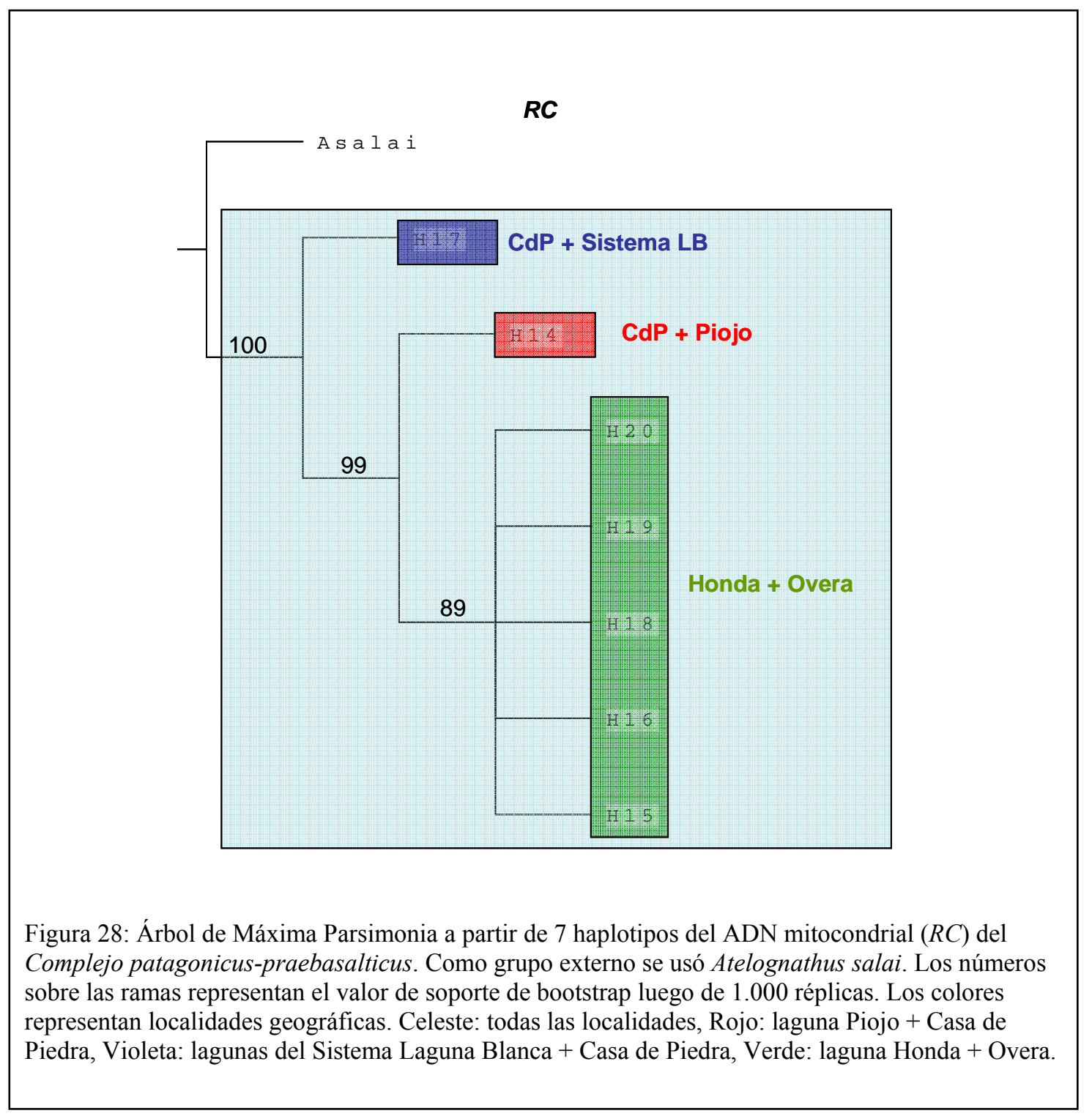


Distancias genéticas en el Género Atelognathus

Los análisis de distancias genéticas revelaron que existe una gran similitud entre todas las poblaciones del complejo patagonicus-praebasalticus. Este resultado es evidente incluso entre los individuos de la laguna del Piojo y las del Sistema LB, cuyos valores de distancia genética no superaron el 0,8\%. En este análisis se incluyeron otras especies de Atelognathus (A. reverberii, A. ceii, A. solitarius, A. salai y $A$. nitoi), algunas de Batrachyla (B. taeniata, B. fitzroya y B. leptopus), así como se incluyó también a Chaltenobatrachus grandisonae y a Hylorina sylvatica. Los valores de distancias no corregidas ( $p$-distance) obtenidos entre A. salai y las poblaciones del complejo patagonicus-praebasalticus variaron en un rango de $0,7 \%$ y $1 \%$, valores semejantes a los obtenidos entre las comparaciones de algunas poblaciones del complejo patagonicus-praebasalticus. A. nitoi y A. ceii presentaron valores más altos de divergencia genética, que variaron entre $1,1 \%$ a $1,5 \%$. $A$. reverberii y $A$. solitarius se diferenciaron genéticamente de las poblaciones del complejo patagonicus-praebasalticus con valores de distancia-p que variaron entre un 6 y 7 \%. Las comparaciones realizadas entre especies de Bartachyla mostraron que las distancias genéticas superaron el 1,3\%, aunque la mayoría mostró valores por encima del $16 \%$, porcentaje semejante al obtenido en las comparaciones entre Chaltenobatrachus grandisonae o Hylorina sylvatica y el resto de las especies incluidas en este análisis (Tabla 11). 
Tabla 11: Proporción de sitios variables (distancia-p) para secuencias de Cit-b del ADN mitocondrial. H: haplotipos número 1 a 13, G1: Grupo Sistema LB, G2: Grupo Casa de Piedra; G3: Grupo Overa/Honda, G4: El Piojo. En amarillo distancias menores a 0,5\%, en verde distancias que varían entre 0,5 $\%$ y $1 \%$, en fucsia entre $1 \%$ y $2 \%$, en celeste entre $2 \%$ y $10 \%$, en gris distancias mayores al $10 \%$.

\begin{tabular}{|c|c|c|c|c|c|c|c|c|c|c|c|c|c|c|c|c|c|c|c|c|c|c|c|}
\hline & \multicolumn{13}{|c|}{ HAPLOTIPOS DEL COMPLEJO patagonicus-praebasalticus } & \multicolumn{5}{|c|}{ Atelognathus } & \multicolumn{3}{|c|}{ Batrachyla } & \multirow{2}{*}{$\begin{array}{l}\text { Chalteno- } \\
\text { batrachus } \\
\text { grandisonaa }\end{array}$} & \multirow{2}{*}{$\begin{array}{c}\text { Hylorina } \\
\text { sylvatica }\end{array}$} \\
\hline & $\begin{array}{l}\mathrm{H} 1 \\
\text { G1 } \\
\text { G2 }\end{array}$ & $\begin{array}{l}\mathrm{H} 2 \\
\mathrm{G} 1 \\
\mathrm{G} 2\end{array}$ & $\begin{array}{l}\text { H3 } \\
\text { G2 }\end{array}$ & $\begin{array}{l}\mathrm{H} 4 \\
\mathrm{G} 1 \\
\mathrm{G} 2\end{array}$ & $\begin{array}{l}\mathrm{H} 5 \\
\text { G4 }\end{array}$ & $\begin{array}{l}\mathrm{H} 6 \\
\text { G3 }\end{array}$ & $\begin{array}{l}\mathrm{H} 7 \\
\mathrm{G} 3\end{array}$ & $\begin{array}{l}\text { H8 } \\
\text { G3 }\end{array}$ & $\begin{array}{l}\text { H9 } \\
\text { G3 }\end{array}$ & $\begin{array}{c}\mathrm{H} 10 \\
\mathrm{G} 1\end{array}$ & $\begin{array}{l}\text { H11 } \\
\text { G1 }\end{array}$ & $\begin{array}{c}\mathrm{H} 12 \\
\mathrm{G} 1\end{array}$ & $\begin{array}{c}\mathrm{H} 13 \\
\mathrm{G} 1\end{array}$ & reverberii & ceii & solitarius & salai & nitoi & taeniata & fitzroya & leptopus & & \\
\hline H1_G1_G2 & & & & & & & & & & & & & & & & & & & & & & & \\
\hline $\mathrm{H}_{2}^{2} \mathrm{G} 1{ }_{-} \mathrm{G} 2$ & 0.007 & & & & & & & & & & & & & & & & & & & & & & \\
\hline H3_G2 & 0.002 & 0.005 & & & & & & & & & & & & & & & & & & & & & \\
\hline H4_G1_G2 & 0.005 & 0.005 & 0.003 & & & & & & & & & & & & & & & & & & & & \\
\hline $\mathrm{H}_{5} \mathrm{G}_{4}$ & 0.002 & 0.008 & 0.003 & 0.007 & & & & & & & & & & & & & & & & & & & \\
\hline $\mathrm{H} 6-\mathrm{G} 3$ & 0.005 & 0.008 & 0.007 & 0.007 & 0.007 & & & & & & & & & & & & & & & & & & \\
\hline $\mathrm{H}_{7}{ }^{-} \mathrm{G} 3$ & 0.003 & 0.007 & 0.005 & 0.005 & 0.005 & 0.002 & & & & & & & & & & & & & & & & & \\
\hline H8_G3 & 0.005 & 0.008 & 0.007 & 0.007 & 0.007 & 0.003 & 0.002 & & & & & & & & & & & & & & & & \\
\hline H9_G3 & 0.005 & 0.008 & 0.007 & 0.007 & 0.007 & 0.003 & 0.002 & 0.003 & & & & & & & & & & & & & & & \\
\hline H10_G1 & 0.007 & 0.007 & 0.005 & 0.002 & 0.008 & 0.008 & 0.007 & 0.008 & 0.008 & & & & & & & & & & & & & & \\
\hline H11_G1 & 0.007 & 0.007 & 0.005 & 0.002 & 0.008 & 0.008 & 0.007 & 0.008 & 0.008 & 0.003 & & & & & & & & & & & & & \\
\hline H12_G1 & 0.007 & 0.007 & 0.005 & 0.002 & 0.008 & 0.008 & 0.007 & 0.008 & 0.008 & 0.003 & 0.003 & & & & & & & & & & & & \\
\hline H13_G1 & 0.007 & 0.000 & 0.005 & 0.005 & 0.008 & 0.008 & 0.007 & 0.008 & 0.008 & 0.007 & 0.007 & 0.007 & & & & & & & & & & & \\
\hline A_reverberii & 0.070 & 0.068 & 0.068 & 0.068 & 0.070 & 0.072 & 0.070 & 0.072 & 0.072 & 0.070 & 0.070 & 0.070 & 0.068 & & & & & & & & & & \\
\hline$A_{-}^{-} c e i i$ & 0.011 & 0.015 & 0.013 & 0.013 & 0.013 & 0.013 & 0.011 & 0.013 & 0.013 & 0.015 & 0.015 & 0.015 & 0.015 & 0.072 & & & & & & & & & \\
\hline A_solitarius & 0.068 & 0.067 & 0.067 & 0.067 & 0.068 & 0.070 & 0.068 & 0.070 & 0.070 & 0.068 & 0.068 & 0.068 & 0.067 & 0.010 & 0.070 & & & & & & & & \\
\hline$A_{-}$salai & 0.007 & 0.010 & 0.008 & 0.008 & 0.008 & 0.008 & 0.007 & 0.008 & 0.008 & 0.010 & 0.010 & 0.010 & 0.010 & 0.068 & 0.005 & 0.067 & & & & & & & \\
\hline A_nitoi & 0.008 & 0.011 & 0.010 & 0.010 & 0.010 & 0.010 & 0.008 & 0.010 & 0.010 & 0.011 & 0.011 & 0.011 & 0.011 & 0.068 & 0.003 & 0.067 & 0.002 & & & & & & \\
\hline B_taeniata & 0.184 & 0.182 & 0.186 & 0.186 & 0.184 & 0.181 & 0.182 & 0.184 & 0.184 & 0.184 & 0.187 & 0.187 & 0.182 & 0.184 & 0.182 & 0.186 & 0.181 & 0.179 & & & & & \\
\hline B_fitzroya & 0.174 & 0.173 & 0.176 & 0.174 & 0.174 & 0.174 & 0.173 & 0.174 & 0.174 & 0.176 & 0.176 & 0.174 & 0.173 & 0.164 & 0.182 & 0.161 & 0.178 & 0.179 & 0.164 & & & & \\
\hline B_leptopus & 0.178 & 0.176 & 0.179 & 0.178 & 0.178 & 0.178 & 0.176 & 0.178 & 0.178 & 0.179 & 0.179 & 0.178 & 0.176 & 0.169 & 0.182 & 0.166 & 0.178 & 0.179 & 0.168 & 0.013 & & & \\
\hline Ch_grandisonae & 0.178 & 0.174 & 0.179 & 0.179 & 0.178 & 0.173 & 0.174 & 0.174 & 0.176 & 0.181 & 0.178 & 0.179 & 0.174 & 0.168 & 0.184 & 0.160 & 0.179 & 0.181 & 0.202 & 0.178 & 0.179 & & \\
\hline H_sylvatica & 0.174 & 0.169 & 0.173 & 0.171 & 0.174 & 0.169 & 0.171 & 0.171 & 0.173 & 0.169 & 0.173 & 0.173 & 0.169 & 0.181 & 0.179 & 0.178 & 0.178 & 0.176 & 0.166 & 0.143 & 0.155 & 0.181 & \\
\hline
\end{tabular}




\section{DISCUSIÓN}

\section{Formas acuática y litoral de Atelognathus patagonicus}

La comparación de las secuencias nucleotídicas del Citocromo b del ADN mitocondrial entre los morfotipos litoral y acuático de Atelognathus patagonicus permitieron establecer una red haplotípica que muestra que estas formas comparten cinco haplotipos (H1, H2, H3, H8, H9), mientras que con Región Control comparten los únicos dos existentes. La presencia de haplotipos raros sólo en la forma acuática puede atribuirse a la diferencia en el tamaño muestral (acuática $\mathrm{N}=60$; litoral $\mathrm{N}=$ 25).

Los resultados obtenidos en esta Tesis apoyan la hipótesis de plasticidad fenotípica propuesta por Cuello et al. (2008). Estas autoras analizaron las relaciones entre los morfotipos y la profundidad y temperatura del agua de la laguna semipermanente La Batea, detectando que los cambios en el fenotipo eran consistentes con el nivel del agua y las condiciones limnológicas en general de la laguna. En estaciones secas sólo capturaron especímenes con morfotipo litoral y en estaciones húmedas, cuando la laguna alcanzaba su máximo nivel, capturaron con mayor frecuencia individuos con morfotipo acuático. Una situación intermedia observaron cuando el nivel de agua de la laguna comenzaba a decrecer, en cuyo caso capturaron ejemplares con morfotipo litoral, acuático e individuos que presentaban características de ambos morfotipos.

Los anfibios en general tienen baja vagilidad y alta filopatría (Seppä \& Laurila, 1999), características que estimulan la acumulación de diferencias morfológicas y genéticas (Blouin \& Brown, 2000; Camp et al., 2000; Miaud \& Merilä, 2001). La condición de plasticidad fenotípica reversible le permitiría a los individuos de $A$. patagonicus utilizar tanto el ambiente acuático como el terrestre, y de esa manera poder dispersarse cuando las condiciones ambientales sean propicias, 
a modo de preadaptación. Esto explicaría el alto flujo génico que hay entre las poblaciones de $A$. patagonicus resultando en la ausencia de diferencias genéticas significativas observadas en este estudio.

Si bien la plasticidad fenotípica debería ser puesta a prueba con experimentos de laboratorio, los resultados obtenidos por Cuello et al. (2008) y los alcanzados en el presente trabajo, sugirieren que las diferencias morfológicas encontradas entre los dos morfotipos de $A$. patagonicus son el resultado de una condición fenotípica reversible, y no debido a la existencia de dos especies crípticas, como propusieron inicialmente Cei \& Roig (1968), ni a la existencia de un polimorfismo equilibrado (Cei 1972). 
Diversidad y estructura genética del complejo patagonicus-praebasalticus

Las poblaciones del complejo patagonicus-praebasalticus distribuidas en distintas lagunas del noroeste y centro-oeste de la provincia del Neuquén evidencian, a nivel regional, un patrón en su variación genética. La alta diversidad haplotípica y baja diversidad nucleotídica encontradas en tres de los cuatro grupos analizados (Sistema LB, Casa de Piedra y Honda/Overa), tanto con Citocromo b como con Región Control, inducen a inferir que pudo producirse un rápido crecimiento poblacional a partir de una población ancestral pequeña. Esta etapa de crecimiento demográfico pudo haber sido suficientemente larga como para recuperar la variación haplotípica vía mutación, pero sin embargo demasiado breve como para acumular grandes divergencias en las secuencias (Grant \& Bowen, 1998). La población del grupo Piojo no presentó diversidad haplotípa y nucleotídica debido, probablemente, a una colonización reciente de algunos pocos individuos, tal vez provenientes de Casa de Piedra, con quienes comparten un haplotipo (H14) detectado en la red haplotípica obtenida a partir de las secuencias de la Región Control.

Tanto para $C i t-b$ como para $R C$ se obtuvo un único haplotipo más frecuente y ampliamente distribuido compartido, en ambos casos, por individuos determinados $a$ priori como A. patagonicus (del Sistema LB y de Casa de Piedra) y por dos subespecies de A. praebasalticus: A. p. praebasalticus (Sistema LB) y A. p. agilis (Casa de Piedra). Las comparaciones pareadas de los valores de $\phi_{S T}$ mostraron que no existen diferencias entre las poblaciones de A. patagonicus (Gallardo 1962) y A. $p$. praebasalticus. Además de la falta de diferenciación genética entre dichas poblaciones, también se ha observado que las diferencias morfológicas existentes entre los individuos de A. patagonicus de forma litoral y los individuos de A. p. praebasalticus son muy poco evidentes (obs. pers.). Estos resultados nos permiten sostener que estas poblaciones pertenecen a una misma especie.

Complementariamente esta afirmación se sostiene en los altísimos valores de flujo génico obtenidos al comparar a A. p. praebasalticus con distintas poblaciones de $A$. 
patagonicus, además de presentar haplotipos compartidos observados en la red de haplotipos.

Atelognathus p. agilis fue descripta como un microendemismo de la laguna de Casa de Piedra. Las diferencias genéticas entre estas ranas y las poblaciones de $A$. patagonicus del Sistema LB fueron significativas tanto para Región Control como para citocromo b. La única excepción a este patrón la constituye la población de $A$. patagonicus que habita simpátricamente con $A$. p. agilis en la laguna de Casa de Piedra, entre las que se evidencian altísimos valores de flujo génico y comparten haplotipos. A. patagonicus de Casa de Piedra no fue significativamente diferente genéticamente de otras poblaciones de $A$. patagonicus. Esta paradoja podría estar señalando un fenómeno incipiente de diferenciación de la población presente en la laguna de Casa de Piedra.

Los individuos provenientes de la laguna Honda habían sido determinados $a$ priori como A. patagonicus (Cuello et al., 2009). Los resultados aquí presentados ponen en evidencia que, genéticamente, estos anuros son significativamente diferentes a todas las otras poblaciones de $A$. patagonicus. Cuando se compararon estos anuros con los provenientes de la laguna Overa, determinados inicialmente como A. p. luisi, mediante la variabilidad del Cit-b se revelaron diferencias genéticas significativas, pero con $R C$ no se encontraron diferencias significativas entre ambas poblaciones. Además, para ambos genes, los niveles de flujo génico inferidos a partir de la tasa de migración $(\mathrm{Nm})$ fueron mayores a 1. Los anuros que habitan la laguna Honda entonces tendrían más afinidad con los A. p. luisi que con los A.patagonicus, si bien esta diferenciación no habría alcanzado aun un nivel que permita considerarlas como una especie distinta.

El análisis de diferencias pareadas de los valores de $\Phi_{S T}$ indica que los anuros de la laguna del Piojo, descriptos originalmente como A. p. dobeslawi, son significativamente diferentes a la mayoría de las poblaciones estudiadas. La excepción la constituye la población de $A$. p. agilis de la laguna de Casa de Piedra, analizada a partir de la variabilidad de la $R C$. Si bien los valores de flujo génico entre estas ranas y el resto de las poblaciones analizadas fueron en todas las comparaciones 
realizadas menores a 1 , se observa una tendencia a mostrar valores más altos con la población de Casa de Piedra - con la que comparten un haplotipo resultante del análisis con $R C$ - que con las restantes poblaciones analizadas. Esta observación los aproxima al taxón $A$. patagonicus.

El análisis de la varianza molecular (AMOVA) corrobora el patrón de diferenciación genética, evidenciando una clara estructuración poblacional del complejo patagonicus-praebasalticus. Se revelan cuatro grupos (Sistema de LB, Casa de Piedra, Honda+Overas y Piojo), aunque no se puede asegurar a partir de estos datos que se trate de unidades evolutivas independientes. Similares patrones de estructuración genética asosiada a la distancia geográfica han sido descriptos para otros anfibios (Rowe et al. 2000; Carnaval, 2002; Méndez et al. 2004).

Las pruebas de Mantel indicaron una correlación significativa y positiva entre la variación genética y las distancias geográficas, reflejando probablemente un modelo de aislamiento por distancia entre poblaciones del tipo stepping-stone (Kimura, 1953).

En este estudio se han obtenido topologías algo diferentes cuando la red de haplotipos fue construida a partir de las secuencias nucleotídicas de Cit- $b$ y $R C$. La red obtenida a partir de $C i t-b$ mostró mayor número de haplotipos que la resultante del análisis de la $R C$ (13 vs. 7, respectivamente) pero la red obtenida con $R C$ reveló mayor número de cambios (13) que separan al haplotipo más dominante del resto de los haplotipos (2 con Cit-b). Según las predicciones que proponen VázquezDomínguez et al. (2009) con referencia a la información aportada por las redes de haplotipos, el más frecuente y más ampliamente distribuido se considera el haplotipo ancestral. El resultado obtenido en este trabajo con ambas regiones del ADN mitocondrial estaría revelando que el haplotipo $\mathrm{H} 4$ de $C i t-b$ y el haplotipo $\mathrm{H} 17$ de $R C$ presentes en el Sistema LB corresponden a los haplotipos ancestrales del complejo patagonicus-preabasalticus.

Es ampliamente aceptado en la literatura que la Región Control del ADN mitocondrial presenta una tasa de sustitución de nucleótidos más alta y un mayor grado de polimorfismo intraespecífico que lo que se observa con citocromo b. Sin 
embargo hay numerosos ejemplos que demuestran que no en todos los casos esto se cumple (Roukonen \& Kvist 2002, Brehm et al., 2003, Zink \& Weckstein 2003, Samuels et al., 2005, Ujvari et al., 2005, Tang et al., 2006, Matsui et al., 2007). En el complejo patagonicus-praebasalticus la red de haplotipos muestra mayor variabilidad haplotípica con $C i t-b$ pero mayor variabilidad nucleotídica con $R C$. Probablemente la Región Control esté revelando episodios históricos más recientes que lo aportado por la variabilidad del Citocromo b. Esto también es inferido a partir de los tiempos relativos de expansión $(\tau)$ que se observaron en los análisis de distribuciones pareadas, mayores con Cit-b que con $R C$.

El patrón filogeográfico observado se asemeja a una categoría filogeográfica del tipo V. Es atribuible a esta categoría -conceptualmente intermedia entre las III y la IV- ya que las redes no presentaron grandes discontinuidades genéticas y los linajes no en todos los casos revelaron una distribución geográfica definida. Es característico de esta categoría filogeográfica la presencia de haplotipos ampliamente distribuidos como los observados en este estudio, junto con haplotipos estrechamente relacionados, exclusivos de una población o compartido por pocas poblaciones.

Los estudios de este tipo realizados con especies de anuros han arrojado resultados controversiales. Tradicionalmente se les atribuye a los miembros de este taxón una baja vagilidad y alta filopatría, atributos que, en ambientes altamente fragmentados, deberían conducir a que se encuentre una significativa estructuración genética poblacional. Sólo a modo de ejemplo, tal es el caso del hílido Pseudacris regilla de Baja California (Recuero et al. 2006). Contrariamente, ante semejantes condiciones de fragmentación ambiental, Litoria aurea, un anuro que se distribuye a lo largo de la costa sureste de Australia (Burns et al. 2007), presenta baja estructuración poblacional. Algo semejante se halló en el leptodactílido Insuetophrynus acarpicus (Méndez et al. 2006) de la región costera de Chile central. En nuestro caso, la alta estructuración genética paradógicamente acompañada de un alto flujo génico podría corresponderse con la ocurrencia esporádica de eventos de lluvia que uniformarían transitoriamente la anisotropía característica de cuerpos de agua dispersos en una matriz árida. El intercambio génico estaría maximizado bajo 
dichas condiciones en esta especie dada la capacidad de adoptar morfologías “litorales" más terrestres, constituyendo éste el vehículo de dispersión e intercambio genético. Como se verá en el apartado siguiente, también la fuerte variación observada en las cotas de algunos lagos y lagunas de la región en un pasado reciente estimula la visión de una orografía dinámica que podría ofrecer el escenario necesario para el desarrollo de esta hipótesis. 
Historia demográfica

Los resultados obtenidos al evaluar la historia demográfica de las poblaciones del complejo patagonicus-praebasalticus son en algunos casos contradictorios: a nivel local, en algunas poblaciones del Sistema LB (lagunas del Molle, del Overo y Jabón) se registraron índices significativamente negativos de Tajima (prueba de neutralidad), resultados consistentes con procesos de barridas selectivas, cuellos de botella y/o expansiones poblacionales recientes; sin embargo se trataría de fenómenos muy focalizados geográficamente, dado que el mismo análisis realizado a nivel regional indica que tales procesos demográficos no han tenido lugar en el Sistema LB.

Los análisis demográficos realizados a partir de las distribuciones de las diferencias pareadas (mismatch distributions) en los grupos Sistema LB y Casa de Piedra, revelaron curvas bimodales (curvas típicas de poblaciones estables) aunque no se pudo rechazar la hipótesis nula de expansión poblacional. Una vez más, estaríamos frente a una situación de ausencia de tales procesos demográficos significativos en la historia de esta parte del complejo lacustre.

Por otro lado, los índices de las pruebas de neutralidad no fueron significativos para el grupo Honda/Overa, resultado que estaría indicando que no hubo desviaciones respecto a la neutralidad. No obstante, con la prueba de distribución de las diferencias pareadas (mismatch distributions), no se pudo rechazar la hipótesis nula de expansión poblacional, evidenciada por una curva unimodal con buen ajuste al modelo de expansión poblacional. En este caso, podríamos estar frente a un evento expansivo reciente.

La población de la laguna del Piojo no presentó variabilidad como para estudiar su historia demográfica. Probablemente se trate de un sitio colonizado en un pasado muy reciente a partir de unos pocos individuos provenientes de Casa de Piedra, con quienes comparten un haplotipo revelado en la red de haplotipos obtenida a partir de las secuencias de Región Control. 
Según Rogers y Harpending (1992), un crecimiento poblacional reciente debería mostrarse en un único pico hacia la izquierda en el gráfico de las distribuciones de las diferencias pareadas, debido a una alta similitud (o incluso idéntica) en las secuencias. Los resultados obtenidos en este estudio son paradojales. Por una parte, sólo en el grupo Honda/Overa se obtuvo una curva con tales características. Además, los estadísticos de Tajima y de Fu fueron siempre no significativos, denotando ausencia de expansiones poblacionales. Pero el índice de raggedness fue en todos los casos estadísticamente no significativo, indicando expansión poblacional. Hipotetizando la existencia de un fenómeno reciente de expansión poblacional poco evidente, se estimaron los índices de $\tau$ (tiempo relativo de expansión poblacional medido en unidades mutacionales), que arrojaron valores bajos. Este último resultado abona la inferencia que, de haber existido, esa expansión poblacional debería haberse producido muy recientemente y a partir de una única población hipotética ancestral. Por ejemplo, podría especularse que la población del grupo Casa de Piedra se expandió primero, ya que presenta valores de $\tau$ mayores que el resto de los grupos $\left(\tau_{C i t-b}=1,729\right.$ y $\left.\tau_{R C}=0,895\right)$, hacia el Sistema LB y, en un episodio posterior, hacia el sureste entrando en contacto con la población de la laguna del Piojo. Esta información es congruente con la presencia de haplotipos compartidos para la Región Control entre ambas poblaciones. Posteriormente habría tenido lugar la expansión del grupo Honda/Overa con un $\tau_{C i t-b}=0,390$ y $\tau_{R C}=0,752$. Probablemente hayan ocurrido expansiones poblacionales desde y hacia las lagunas Overa y Honda en diferentes momentos de su historia evolutiva. Por último, mucho más recientemente, habría tenido lugar la expansión de las ranas del Sistema LB $\left(\tau_{C i t-}\right.$ $\left.{ }_{b}=0,192\right)$, tal vez asociada con expansiones locales de determinadas poblaciones dentro del mismo sistema de lagunas del Sistema LB, tal como lo revelan los índice de Fu y Tajima para las poblaciones de las lagunas del Molle, del Overo y Jabón del PNLB.

Los resultados obtenidos a partir del método de Skyline Plot, indican que todas las poblaciones, analizadas a nivel local y regionalmente, se han mantenido 
estables. Este resultado es nuevamente contradictorio con otros obtenidos en esta Tesis. Sin embargo estas contradicciones probablemente sean producto de cambios muy recientes en la estructura y distribución de una única población ancestral que ocupaba parte (reforzando la idea de expansiones poblacionales locales) o todo (abonando la teoría de cuellos de botellas y aislamiento) el sistema lacustre bajo estudio.

En Patagonia existen antecedentes de regresiones del nivel del agua de lagos y lagunas a través del tiempo. Stine y Stine (1990), basado en la datación por radiocarbono de las antiguas líneas costeras del Lago Cardiel (Santa Cruz), estimaron que en los últimos 10.000 años se habría producido una reducción de la profundidad del lago de 55m. Similares conclusiones para el mismo lago fueron obtenidas por Cusminsky et al. (2009). Estos autores, a partir del análisis de ensambles de ostrácodos, observaron que durante aproximadamente los últimos 15.500 años, el lago experimentó cambios drásticos en el nivel del agua. Para la Laguna Cari Lafquen, Río Negro, González Bonorino y Rabassa (1973) también reportaron una importante reducción del nivel del agua. Estos antecedentes, sumado a la observación personal de imágenes satelitales en las que se evidencian diferentes niveles de costas, sostienen la hipótesis de que la mayoría de las lagunas estudiadas en este trabajo han estado conectadas en el pasado reciente, tal vez en forma recurrente. 


\section{Relaciones intra e interespecíficas}

El árbol consenso de máxima parsimonia realizado con Cit-b (trece haplotipos) y el árbol obtenido con $R C$ (siete haplotipos) recuperaron un clado bien soportado formado por haplotipos de las poblaciones de las lagunas Honda y Overa (ubicadas al suroeste de la distribución del complejo patagonicus-praebasalticus). Probablemente estas poblaciones hayan pasado más tiempo aisladas del resto del complejo que las del Piojo con las de Casa de Piedra y éstas con las del Sistema LB.

Distancias genéticas en el género Atelognathus

Los análisis filogenéticos de ADN pueden orientar el reconocimiento de linajes genéticos parafiléticos o polifiléticos dentro de una especie (Fouquet et al., 2007). Un modo de identificar especies polifiléticas está basado en analizar la divergencia de las secuencias y los umbrales de las distancias genéticas. Vences \& Glaw (2005) sugirieron que un análisis de distancias genéticas realizado a partir de una base de datos de ADN constituye una herramienta útil para establecer la biodiversidad de anfibios. Si se definiera previamente un umbral, cualquier divergencia calculada entre pares de bases de dos secuencias determinadas podría aportar información acerca de si las mismas pertenecen a especies potencialmente diferentes. Sin embargo, debe tenerse en cuenta que, debido a introgresiones o muestreos incompletos, linajes muy divergentes pueden interpretarse como especies diferentes aunque no lo sean (Meyer \& Paulay 2005). Para ADN mitocondrial, la existencia de especies polifiléticas y parafiléticas parece ser mucho más frecuente que la generalmente reconocida (Funk et al., 2003). Los distintos genes mitocondriales (y nucleares) presentan tasas y patrones evolutivos muy disímiles que acotan su rango de aplicabilidad para resolver problemas en sistemática, biogeografía o ecología, aunque genes como $C i t-b$ y $R C$, por su variabilidad relativamente 
superior, son considerados ventajosos en estudios de sistemática molecular a bajos niveles jerárquicos taxonómicos (Pleguezuelos et. al., 2002).

Diferentes valores de distancia genética a nivel poblacional han sido reportados para diversos grupos de anfibios. Así por ejemplo para Cit-b Fouquet et al. (2010) reportaron distancias genéticas no corregidas ( $p$-distance) entre poblaciones de ranas endémicas de Nueva Zelanda (Leiopelma hochstetteri) del orden del 2,7\%. Tan \& Wake (1995) reportaron para Taricha torosa una divergencia poblacional entre el 0,6 - 2,5\%. Shaffer et al. (2004) obtuvieron tasas de divergencia intraespecíficas comprendidas entre 0 y $5 \%$ para cinco especies del género Rana. Mendez et al. (2006) a partir del gen Cit-b, realizaron una evaluación de la variabilidad genética y de las relaciones filogenéticas de las tres poblaciones de Insuetophrynus acarpicus conocidas, y encontraron que la proporción de sitios variables ( $p$-distances) para esta especie tiene un rango de 0,28\% - 1,84\%. En este trabajo, ninguna de las distancias genéticas obtenidas con $C i t-b$ para el complejo patagonicus-praebasalticus superó el 0,8\%. Entre las especies del género Atelognathus se observaron valores que variaron entre 0,7 y 7\%. Como se mencionó anteriormente, las distancias genéticas dependen de la historia evolutiva de cada grupo y probablemente de otros factores (e.g. ecológicos, etológicos, geomorfológicos, etc). Por ello las conclusiones que podrían derivarse a partir de la comparación de las distancias genéticas obtenidas en este estudio con otras descriptas en la literatura serían en el mejor de los casos relativas o meramente especulativas. 
Estado de Conservación del complejo patagonicus-praebasalticus

La genética de la conservación se originó poco tiempo después de haber surgido la biología de la conservación como disciplina, cuando se hicieron evidentes varios problemas genéticos asociados con las especies en peligro de extinción. Por ejemplo, se resaltó que la disminución de los tamaños poblacionales iba acompañada de la pérdida de diversidad genética y que la fragmentación de los hábitats afectaba la estructura poblacional. Desde el punto de vista evolutivo, se hizo entonces necesario entender los procesos de extinción de las especies (Simberloff, 1988, Eguiarte \& Pinero, 1990). Uno de los objetivos clave de la genética de la conservación es ayudar a establecer planes de conservación que minimicen la probabilidad de extinción evitando los problemas relacionados con tamaños efectivos pequeños. Entre éstos se destacan el efecto deletéreo de la endogamia (depresión por endogamia), la pérdida de diversidad y la habilidad para evolucionar en respuesta a los cambios ambientales, así como los efectos deletéreos que ocurren por la cruza entre individuos muy distintos (depresión por exogamia; Amos \& Balmford, 2001; Frankham et al., 2002). Los análisis genéticos también permiten estudiar el efecto de la fragmentación y la reducción del flujo génico en poblaciones estructuradas y el efecto de la acumulación y pérdida de mutaciones deletéreas. Por otro lado, desde la genética también se pueden aportar soluciones a problemas de tipo taxonómico, por ejemplo: establecer especies prioritarias para la conservación, resolver incertidumbres taxonómicas, definir unidades evolutivamente significativas y unidades de manejo e, idealmente, poder proteger los procesos evolutivos que mantienen la diversidad biológica (Moritz, 2002).

Atelognathus patagonicus se ha extinguido en su localidad tipo (Laguna Blanca). Se ha atribuido esa extinción a la introducción de peces. Por lo tanto sus restantes poblaciones han sido consideradas a principios de este siglo en Peligro de Extinción (Lavilla et al., 2000). A praebasalticus es considerada Vulnerable para cada una de sus subespecies (Lavilla et al., 2000). Ambas especies son consideradas "En Peligro de Extinción" por la IUCN (2006). 
El panorama que se presenta a través de este trabajo exige un replanteo de la situación de estos taxones. Los niveles de flujo génico entre todas las poblaciones del complejo patagonicus-praebasalticus detectados en este estudio indican que la situación taxonómica requiere ser revisada. En esa revisión sugerida se considera que no debieran, al menos en una primera aproximación, capturarse nuevos individuos, sino explorar la variabilidad en otros genes a partir de las colecciones ya disponibles. También debieran realizarse con ese mismo material estudios morfológicos complementarios de los realizados en las descripciones originales, dado que las considero limitadas por el escaso número de ejemplares estudiados oportunamente.

Por otra parte, es auspiciante para la conservación de las ranas del Sistema LB el hallazgo de fuentes complementarias de variabilidad en otras lagunas que podrían actuar como fuentes de eventuales repoblamientos, de modo natural o inducidos por el hombre a partir del desarrollo de planes de conservación y/o remediación ambiental. Ahora bien, debe destacarse que cualquier acción futura debe partir de una medida taxativa e inexcusablemente inmediata, consistente en la prohibición de introducción de peces en las lagunas neuquinas que circundan a las del Sistema LB. 


\section{CONCLUSIÓN}

Este trabajo constituye el primer estudio filogeográfico sobre el complejo patagonicus-praebasalticus del género Atelognathus, cuyas poblaciones habitan las lagunas del oeste neuquino.

Los resultados alcanzados en este estudio revelan que los morfotipos litoral y acuático de A. patagonicus son meras formas reversibles en un contexto de plasticidad fenotípica.

La diversidad alfa del complejo patagonicus-praebasalticus requiere ser reexaminada, realizándose un estudio multigénico. Transitoriamente, se propone considerar a Atelognathus praebasalticus (Cei \& Roig, 1968), incluyendo a todas sus subespecies nominadas, como sinónimo junior de Atelognathus patagonicus (Gallardo, 1962).

Es auspicioso para la conservación de las ranas pertenecientes al complejo patagonicus-praebasalticus los niveles de flujo génico detectados entre todas las poblaciones examinadas. Pero la extinción de ranas acaecida en Laguna Blanca es un hecho, y se ha atribuido la misma a la introducción de peces exóticos. Cualquier plan de conservación destinado a estos anuros nordpatagónicos debería contemplar la inexcusable supresión de nuevas introducciones de peces en las lagunas que aun no han sufrido este tipo de alteraciones antrópicas. Al mismo tiempo se debe trabajar en la determinación de núcleos fuente para eventuales repoblamientos de ranas en las lagunas que hayan perdido sus poblaciones locales. 


\section{REFERENCIAS BIBLIOGRÁFICAS}

Anderson, S., A.T. Bankier, H.G. Barrell, M.H.de Bruijn, A.R. Coulson., J. Drouin, J.C. Eperon, D.P. Nierlich, H.A. Roe, F. Sanger, P.H. Schreier, A.J. Smith, R. Staden \& I.G. Young. 1981. Sequence and organization of the human mitochondrial genome. Nature 290:457-464.

Anderson, S., M.R. de Bruijn, A.R. Coulson, J.C. Eperon, F. Sanger \& I.G. Young. 1982. Complete sequence of bovine mitochondrial DNA. Conserved features of the mammalian genome. J Mal. Rial. 156:683-7 17.

Amason, U., A. Gullberg, E. Johnsson \& C. Ledje. 1993. Ihe nucleotide sequence of the mitochondrial DNA molecule of the grey seal, Halichaerus grypus and a companson with mitochondrial sequences of other tite seals. $1 \mathrm{Mal}$. Evol. 37:312-322.

Amos W. \& A. Balmford. 2001. When does conservation genetics matter? Heredity 87:257-265.

Arnason, U., A. Gullberg \& B. Widegren. 1991. The complete nucleotide sequence of the mitochondrial DNA of the Fin whale, Balaenaptera physalus. J. Mal. Evol. 33:556-568.

Arnason, U. \& E. Johnsson. 1992. The complete mitochondrial DNA sequence of the Harbor seal, Phoca vitulina. J. Mol. Evol. 34:493-505.

Arnason, U. 1993. Secuencia completa del mtDNA de la ballena azul (Balaenaprera musculus) enviada directamente al GenBank. $\mathrm{N}^{\mathrm{o}}$ de acceso $\mathrm{x} 72204$.

Avise J.C., Neigel J.E. \& J. Arnold. 1984. Demographic influences on mitochondrial DNA lineage survivorship in animal populations. .J Mol. Evol. 20:99-105.

Avise, J.C., J. Arnold, R.M. Ball, E. Bermingham, T. Lamb, J.E. Neigel, C.A. Reeb \& N.C. Saunders. 1987. Intraspecific phylogeography: The mitochondrial DNA bridge between population genetic and systematics. Annu. Rev. Ecol. Syst., 18:489-522.

Avise, J.C. 2000. Phylogeography: The history and formation of species. Harvard University Press, Cambridge, Massachusetts. 
Avise, J.C. 2004. Molecular Markers, Natural History and Evolution (2nd Revised ed.). Sinauer Associates Inc.,U.S. 541 pp.

Avise, J. C. 2009. Phylogeography: retrospect and prospect. Journal of Biography 36:3-15.

Basso, N.G. 1998. A new telmatobiine leptodactylid frog of the genus Atelognathus from Patagonia. Herpetologica 54:44-52.

Basso, N.G., C.A. Úbeda, M.M. Bunge \& L.B. Martinazzo. 2011. A new genus of neobatrachian frog from southern Patagonian forests, Argentina and Chile. Zootaxa 3002:31-44.

Bibb, M.J., R.A. Van Etten, C.T. Wright, M.W. Walberg \& D.A. Clayton. 1981 Sequence and gene organization of mouse mitochondrial DNA.CeIl 26, 167180.

Blouin, M.S. \& S.T. Brown. 2000. Effects of temperature-induced variation in anuran larval growth rate on head width and leg length at metamorphosis. Oecologia 125:358-361.

Brehm, A., D.J. Harris, C. Alves, J. Jesus, F. Thomarat \& L. Vicente. 2003. Structure and evolution of the mitochondrial DNA complete control region in the lizard Lacerta dugesii (Lacertidae, Sauria). Journal of Molecular Evolution 56:4653.

Brown, W.M., M. George, Jr. \& A.C. Wilson. 1979. Rapid evolution of animal mitochondrial DNA. Proc. Natl. Acad. Sci. USA, 76:1967-1971.

Brown, G.G., G. Gadaleta, G. Pepr, C. Saccone, \& E. Sbisfi. 1986. Structural conservation and variation in the D-loop- containing region of vertebrate mitochondrial DNA. Journal of Molecular Biology 192:503-511.

Burns E.L., M.D.B. Eldridge, D.M. Crayn \& B.AHoulden. 2007. Low phylogeographic structure in a wide spread endangered Australian frog Litoria aurea (Anura: Hylidae). Conservation Genetics 8:17-32.

Cabrera, A.L. 1976. Regiones fitogeográficas argentinas. Enc. Arg. Agr. Jard. 2(1):185. 
Camp, C., J.L. Marshall \& R.M. Austin. 2000. The evolution of adult body size in black-bellied salamanders (Desmognathus quadramaculatus complex). Canadian Journal of Zoology 78:1,712-1,722.

Carnaval, A.C.O.Q. 2002. Phylogeography of Four Frog Species in Forest Fragments of Northeastern Brazil-A Preliminary Study. Integr.Comp.Biol., 42:913-921

Cei, J.M. 1972. Herpetología Patagónica. V. Las especies extra-cordilleranas alto patagónicas del género Telmatobius. Physis. Tomo XXXI, nº 83:431-449.

Cei, J.M. 1980. Amphibians of Argentina. Monitore zoológico Italiano, N.S., Monografía, 2:609 pp.

Cei J.M. \& V.G. Roig. 1966. Los caracteres biocenóticos de las lagunas basálticas del oeste de Neuquén. Bol. Est. Geogr. Univ. Nac. Cuyo XIII (51). Mendoza.

Cei, J.M. \& V. Roig. 1968. Telmatobinos de las Lagunas Basálticas de Neuquén (Anura, Leptodactylidae). Physis. Tomo XXVII, $\mathrm{n}^{\circ}$ 75:265-284.

Chang, Y.S. \& F.L. Huang. 1994. The complete nucleotide sequence and gene organization of carp (Cyprinus carpio) mitochondrial genome. J. Mol Evol. 38:138-155.

Chomyn, A., P. Mariottini, W.J. Cleeter, Cd Ragan, A. Matsuno-Yagi, Y.Hatefi, R.F. Doolittle \& G. Attardi. 1985. Six unidentified reading frames of human mitochondrial DNA encode components of the respiratory-chain NADH dehydrogenase. Nature 314:592-597.

Clement, M., D. Posada, K. Crandall. 2000. TCS: a computer program to estimate gene genealogies. Molecular Ecology 9:1657-1660.

Cuello, M.E., M.T. Bello, M. Kun \& C.A. Úbeda .2006. "Feeding habits and their implications for the conservation of the endangerd semiaquatic frog Atelognatus patagonicus (Anura, Neobatrachia) in a northwestern Patagonian pond." Phyllomedusa 5(1):67-76 .

Cuello, M.E., C.A. Úbeda \& M.T. Bello. 2008. Relationship between morphotypes of Atelognathus patagonicus (Anura, Neobatrachia) and environmental conditions: evidence and possible explanation. Phyllomedusa 7:35-44. 
Cuello, M.E., M.G. Perotti \& G.J. Iglesias. 2009. Dramatic decline and range contraction of the endangered Patagonian frog Atelognathus patagonicus (Anura, Leptodactylidae). Fauna \& Flora International 43(3):443-446.

Cusminsky, G., A. Schwalb, V. Markgraf, A. Gilli, D. Ariztegui \& F. Anselmetti. 2009. Ostracodes as indicators of Late Quaternary lake levels of Lago Cardiel, Southern Patagonia, Argentina. Simposio; 16 th International Symposium on Ostracoda. University of Brasilia.

De la Riva I., M.García-París \& G. Parra-Olea. 2010. Systematics of Bolivian frogs of the genus Telmatobius (Anura, Ceratophryidae) based on mtDNA sequences. Systematics and Biodiversity 8(1):49-61.

Desjardins, P. \& R. Morais. 1990. Sequence and organization of the chicken mitochondrial genome. A novel gene order in higher vertebrates. J Mol. Biol. 212:599-634.

Drummond, A. J., G. K. Nicholls, A. G. Rodrigo, and W.Solomon. 2002. Estimating mutation parameters, population history and genealogy simultaneously from temporally spaced sequence data. Genetics 161:1307-1320.

Drummond A.J. \& A. Rambaut. 2006. BEAST v1.4, Available from http://beast.bio.edsac.uk/.

Eguiarte, L. E. y D. Pinero. 1990. Genética de la conservación: leones vemos, genes no sabemos. Ciencias. Numero especial 4. Ecología y conservación en México: 34 -47 (reimpreso en Núñez-Farfán J. y L. E. Eguiarte (editores). La evolución biológica. Facultad de Ciencias, Instituto de Ecologia, UNAM, Conabio. Pp. 371-398).

Excoffier, L., P.E. Smouse \& J.M. Quattro. 1992. "Analysis of Molecular Variance Inferred From Metric Distances Among DNA Haplotypes: Application to Human Mitochondrial DNA Restriction Data." Genetics 131:479-491

Excoffier, L.; G. Laval \& S. Schneider. 2005. Arlequin ver. 3.0: An integrated software package for population genetics data analysis. Evolutionary Bioinformatics Online, 1:47-50. 
Fisher, R.A. 1932. Te genetical theory of natural selection. Oxford University Press, Londres.

Fouquet, A., A. Gilles, M. Vences, C. Marty, M. Blanc \& N.J Gemmell. 2007. Underestimation of species richness in neotropical frogs revealed by mtDNA analyses. PLoS ONE 2:e1109.

Fouquet, A., D.M. Green, B. Waldman, J.H. Bowsher, K.P. McBride \& N.J Gemmell. 2010. Phylogeography of Leiopelma hochstetteri reveals strong genetic structure and suggests new conservation priorities. Conserv Genet 11:907-919.

Frankham R., J.D. Ballou, \& D.A. Briscoe. 2002. Introduction to conservation genetics. Cambridge, Reino Unido.

Frost, D.R., T. Grant, J. Faivovich, R. Bain, A. Haas, C.F.B. Haddad, R.O. de Sá, A. Channing, M. Wilkinson, S.C. Donnellan, C.J. Raxworthy, J.A. Campbell, B.L. Blotto, P. Moler, R.C. Drewes, R.A. Nussbaum, J.D. Lynch, D. Green, W.C. Wheeler. 2006. The amphibian tree of life. Bulletin of the American Museum of Natural History 297:1-370.

Frost, D.R. 2011. Amphibian Species of the World: an Online Reference. Version 5.5 (31 January, 2011). Electronic Database accessible at http://research.amnh.org/vz/herpetology/amphibia/American Museum of Natural History, New York, USA.

Fu, Y.X. 1997. Statistical tests of neutrality of mutations against population growth, hitchhiking and background selection. Genetics 147:915-925.

Furlong, R.F. \& J.F.Y. Brookfield. 2001. Inference of past population expansion from the timing of coalescence events in a gene genealogy. Journal of theoretical biology 209:75-86.

Futuyma, D.J. 2009. Evolution. 2nd ed. Sinauer Associates, Sunderland, Massachusetts. 633 pages.

Gadaleta, G., G. Pepe, G. de Candia, C. Quagliaruiello, E. Sibisa, C. Saccone. 1989. The complete nucleotide sequence of the Rattus norvegicus mitocondrial 
genome: cryptic signals revealed by comparative analysis between vertebrates. J. Mol. Evol. 28:497-516.

Gallardo, J.M. 1962. Los géneros Telmatobius y Batrachophrynus (Amphibia, Leptodactylidae) en la Argentina. Neotropica 8:45-58.

Goebel, A.M., J.M. Donnelly \& M.E. Atz. 1999. PCR primers and amplification methods for $12 \mathrm{~S}$ ribosomal DNA, the control region, cytochrome oxidase I, and cytochrome $b$ in bufonids and other frogs, and an overview of PCR primers which have amplified DNA in amphibians successfully. Molecular Phylogenetics and Evolution 11:163-199.

Goloboff, P.A., J.S. Farris \& K.C. Nixon. 2008. TNT, a free program for phylogenetic analysis. Cladistics 24:774-786.

González Bonorino, F. \& J. Rabassa. 1973. La laguna Carri Lafquen Grande y el origen de los bajos patagónicos. Comentario. Revista Asociación Geológica Argentina XXVIII (3): 314.

Grant, W.S. \& B.W. Bowen. 1998. Shallow population histories in deep evolutionary lineages of marine fishes: insights from sardines and anchovies and lessons for conservation. Journal of Heredity 89:415-426.

Grant, T., D.R. Frost, J.P. Caldwell, R. Gagliardo, C.F.B. Haddad, P.J.R. Kok, D.B. Means, B.P. Noonan, W.E. Schargel \&W. Wheeler. 2006. Phylogenetic systematic of dart-poison frogs and their relatives (Amphibia: Athesphatanura: Dendrobatidae). Bull Am Mus Nat Hist 299:1-262.

Hall, T.A. 1999. BioEdit: a user-friendly biological sequence alignment editor and analysis program for Windows 95/98/NT. Nucleic Acids Symposium Series, 41:95-98.

Harding, R.M. 1996. New phylogenies: An introductory look at the coalescent, pp. 15-22. En: Harvey, P. H., A. J. Leigh Brown, J. Maynard Smith y S. Nee (eds.), New uses for new phylogenies, Oxford University Press, Nueva York.

Harpending, H. 1994. Signature of ancient population grhwth in a low-resolution mitochondrial DNA mismatch distributions. Human Biology 66:591-600. 
Hartl, D. L. 1999. A primer of population genetics (Third Edition). Sinauer Associates, Inc. Sunderland, Massachusetts, USA. 221 pp.

Hedrick, P.W. 2000. Genetics of Populations. Jones and Bartlett, Boston, MA, 553p.

Hein, J., M.H. Schierup \& C. Wiuf. 2005. Gene genealogies, variation and evolution: A primer in coalescent theory. Oxford University Press, Londres.

Ho, S.W. \& B. Shapiro. 2011. Skyline-plot methods for estimating demographic history from nucleotide sequences. Molecular Ecology 11:423-434.

IUCN 2011. IUCN Red List of Threatened Species. Version 2011.1.

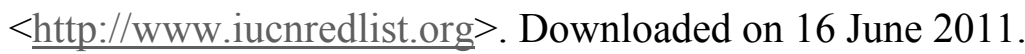

Janke, A., O. Feldmaier-Fuchs, K. Thomas, A. Von Haeseler \& S. Paabo. 1994. The marsupial mitochondrial genome and the evolution of placental mammals. Genetics 137:243-256.

Kimura, M. 1953. "Stepping-stone" model of population. Ann. Rep. Natl. Inst. Genet. Japan 3:62-63.

Kimura, M. 1968. Evolutionary rate at the molecular level. Nature 217, 624-626.

Kingman, J.F.C. 1982a. The coalescent. Stochastic Processes and their Applications, 13:235-248.

Kingman J.F.C. 1982b. On the genealogy of large populations. Journal of Applied Probability 19A:27-43.

Kreitman, M. 2000. Methods to detect selection in populations with applications to the human. Annual Reviews of Genomics and Human Genetics 1:539-59.

Kuhner M.K. 2008. Coalescent genealogy samplers: windows into population history. Trends Ecol. Evol. 24:86-93.

Lanteri, A.A. \& V.A. Confalonieri. 2000. Filogeografía: Objetivos, Métodos y Ejemplos en: Una perspectiva latinoamericana de la biogeografía. P4 Juan J. Morrone, Jorge Llorente Bousquets Ed.(s). México. UNAM, Facultad de Ciencias. 2003. VI, 307 P.

Lavilla, E.O, M.L. Ponssa, D. Baldo, N. Basso, A. Bosso, J. Céspedez, J.C. Chebez, J. Faivovich, L. Ferrari, R. Lajmanovich, J.A. Langone, P. Peltzer, C. Úbeda, M. Vaira \& F. Vera-Candioti. 2000. Categorización de los Anfibios de 
Argentina. En: E.O. Lavilla, E. Richard \& G.J. Scrocchi (eds.),

Categorización de los Anfibios y Reptiles de la República Argentina. Asoc.

Herpetol. Argentina. Pp: 11-34.

Lunt, D.H., L.E. Whipple \& B.C. Hyman. 1998. Mitochondrial DNA variable

Lumber tandem repeats (VNTRs): utility and problems in molecular ecology.

Molecular Ecology 7:1441-1455.

Lynch, J.D. 1971. Evolutionary relationships, osteology and zoogeography of leptodactyloid frogs. Univ. Kansas. Mus. Nat. Hist. Misc. Publ. 53:1-238.

Lynch, J. 1978. A re-assessment of the telmatobiine leptodactylid frogs of Patagonia. Occasional Papers of the Museum of Natural History The University of Kansas Lawrence, Kansas. 72:1-57.

Mantel, N. 1967. The detection of disease clustering and generalized regression approach. Cancer Research 27:209-220.

Matsui, M., A. Tominaga, T. Hayashi, Y. Misawa \& S. Tanabe. 2007. Phylogenetic relationships and phylogeography of Hynobius tokyoensis (Amphibia: Caudata) using complete sequences of cytochrome $b$ and control region genes of mitocondrial DNA. Molecular Phylogenetics and Evolution 44:204-216.

Méndez, M.A, E.R. Soto, C. Correa, A. Veloso, E. Vergara, M. Sallaberry \& P. Iturra. 2004. Morphological and genetic differentiation among Chilean populations of Bufo spinulosus (Anura: Bufonidae). Revista Chilena de Historia Natural, 77:559-567.

Méndez, M.A, F. Torres-Pérez, C. Correa, E.R. Soto, A. Veloso \& J. Armesto. 2006. Genetic differentiation of the endangered frog Insuetophrynus acarpicus (Anura: Leptodactylidae). Herpetological Journal, 16: 93-96

Meyer, C.P. \& G Paulay. 2005. DNA Barcoding: error rates based on comprehensive sampling. PLoS Biol. 3 (12): e422. doi:10.1371/journal.pbio.0030422.

Miaud, C. \& J. Merilä. 2001. Local adaptation or environmental induction? Causes of population differentiation in alpine amphibians. Biota 2:31-50.

Mills, L.S. \& F.W. Allendorf. 1996. The one-migrant-per-generation rule in conservation and management. Conservation Biology 10:1509-1518. 
Moritz C. 2002. Strategies to protect biological diversity and the evolutionary processes that sustain it. Syst. Biol. 51(2):238-254.

Mueller, R.L. 2006. Evolutionary Rates, Divergence Dates, and the Performance of Mitochondrial Genes in Bayesian Phylogenetic Analysis. Systematic Biology 55(2):289-300.

Nei, M. \& S. Kumar. 2000. Molecular Evolution and Phylogenetics. Oxford University Press, New York, 333 pp.

Noble, G.K. 1925. The integumentary, pulmonary, and cardiac modifications correlated with increased cutaneous respiration in the Amphibia: a solution of the "hairy frog" problem. Journal of morphology and Physiology 40:341-416.

Piñero, D., A. Barahona, L. Eguiarte, A. Rocha Olivares, R. Salas Lizana. 2008. La variabilidad genética de las especies: aspectos conceptuales y sus aplicaciones y perspectivas en México, en Capital natural de México, vol. I: Conocimiento actual de la biodiversidad. Conabio, México, pp. 415-435.

Pleguezuelos, J. M., R. Márquez \& M. Lizana, (eds.) 2002. Atlas y Libro Rojo de los Anfibios y Reptiles de España. Dirección General de Conservación de la Naturaleza-Asociación Herpetologica Española (2a impresión), Madrid, 587 pp.

Posada D. \& K.A. Crandall. 2001. Intraspecific gene genealogies: tress grafting into networks. Trends in Ecology \& Evolution 16:37-45.

Posada D. 2008. jModelTest: Phylogenetic Model Averaging. Molecular Biology and Evolution 25:1253-1256.

Plötner, J., F. Köhler, T. Uzzell, P. Beerli. 2007. Molecular Systematics of Amphibians.In Amphibian biology, Volume 7 (Eds. Heatwole, H., and M. Tyler). Surrey Beatty \& Sons. Chipping Norton, Australia. Pp. 2672-2756.

Pybus, O. G, A. Rambaut and P. H. Harvey. 2000. An integrated framework for the inference of viral population history from reconstructed genealogies. Genetics, 155, 1429-1437. 
Pyron, R.A., \& J.J. Wiens. 2011. A large-scale phylogeny of Amphibia with over 2,800 species, and a revised classification of extant frogs, salamanders, and caecilians. Molecular Phylogenetics and Evolution 61:543-583.

Rambaut, A. \& A. J. Drummond. 2004. Tracer, version 1.3. Institute of Evolutionary Biology, Edinburgh, UK. Website http://tree.bio.ed.ac.uk/software/.

Ramos-Onsins, S.E. \& J. Rozas. 2002. Statistical properties of new neutrality tests against population growth. Molecular Biology and Evolution 19:2092-2100.

Recuero, E., I. Martínez-Solano, G. Parra-Olea \& M. García-París. 2006. Phylogeography of Pseudacris regilla (Anura: Hylidae) in western North America, with a proposal for a new taxonomic rearrangement. Molecular Phylogenetics and Evolution 39:293-304.

Relyea, R.A. 2003. Predators come and predators go: the reversibility of predatorinduced traits. Ecology 84:1840-1848.

Ringuelet, R. 1958. Los Crustáceos Copépodos de las aguas continentales de la República Argentina. Sinopsis sistemática. Contribuciones Científicas de la Facultad de Ciencias Exactas, Físicas y Naturales, Universidad de Buenos Aires, Zoología 1:35-126.

Ringuelet, R. 1961. Rasgos fundamentales de la zoogeografía de la Argentina. Physis, 22 (63):151-170.

Roderick, G.K. 1996. Geographic structure of insect populations: Gene flow, phylogeography, and their uses. Annu. Rev. Entomol. 41:325-352.

Roe, B.A., M. Din-Pow, R.K. Wilson \& I.F. Wong. 1985. The complete nucleotide sequence of the Xenopus laevis mitochondrial genome. J. Biol. Chem. 260:9759-9774.

Rogers, A.R., \& H.C. Harpending. 1992. Population growth makes waves in the distributions of pairwise genetic differences. Molecular Biology and Evolution 9:552-569.

Roukonen, M. \& L. Kvist. 2002. Structure and evolution of the avian mitochondrial control region. Molecular Phylogenetics and Evolution 23:422-432. 
Rowe, G., T.J.C. Beebee \& T. Burke. 2000. A microsatellite analysis of natterjack toad (Bufo calamita) metapopulations. Oikos 88:641-651.

Rozas, J., J.C. Sánchez-Del Barrio, X. Messeguer \& R. Rozas. 2003. DNASP, DNA polymorphism analyses by the coalescent and other methods. Bioinformatics 19:2496-2497.

Ruíz Leal, A. 1966. Notas botánicas de dos breves viajes a Laguna Blanca (Neuquén) Bol. Est. Geogr. Univ. Nac. Cuyo XIII (51).

Sambrook, J. \& D. Russell. 2001. Molecular Cloning. A laboratory manual. 3rd. edition. Cold Spring Harbor Laboratory Press, New York.

Samuels, A.K., D.W. Weisrock, J.J. Smith, K.J. France, J.A. Walker, S. Putta \& S.R. Voss. 2005. Transcriptional and phylogenetic analysis of five complete ambystomatid salamander mitochondrial genomes. Gene 349:43-53.

Sbisà E., F. Tanzariello, A. Reyes, G. Pesole \& C. Saccone. 1997. Mammalian mitochondrial D-loop region structural analysis: identification of new conserved sequences and their functional and evolutionary emplications. Gene 205:125-140.

Schaal, B.A. \& K.M. Olsen. 2000. Gene genealogies and population variation in plants. Proc. Natl. Acad. Sci., USA, 97:7024-29.

Seppä, P. \& A. Laurila. 1999. Genetic structure of island populations of the anurans Rana temporaria and Bufo bufo. Heredity 82:309-317.

Shaffer, H.B., G.M. Fellers, S.R.Voss, J.C.Oliver \& G.B. Pauly. 2004. Species boundaries, phylogeography and conservation genetics of the redlegged frog (Rana aurora/draytonii) complex. Molecular Ecology 13:2667-2677.

Slatkin, M. 1985. Gene flow in natural populations. Annual Review of Ecology and Systematics 16:393-430.

Slatkin, M. 1987. Gene flow and the geographic structure of natural populations. Science 236: 787-792

Slatkin, M. 1993. Isolation by distance in equilibrium and non-equilibrium populations. Evolution 47:264-279. 
Slatkin, M. 1994. Gene flow and population structure. En: Ecological Genetics (ed Real LA). Pp. 3-18. Princeton University Press.

Simberloff, D. 1988. The contribution of population and community biology to conservation science. Ann. Rev. Ecol. Syst. 19:473-511.

Stine, S. \& Stine, M. 1990. A record from Lake Cardiel of climatic change in southern South America. Nature 345:705-708.

Taberlet, P. 1996. The use of mitochondrial DNA control region sequencing in conservation genetics. In: Molecular Genetic Approaches in Conservation. T.B. Smith \& R.K. Wayne (eds). New York: Oxford University Press, pp. 125-142.

Tajima, F. 1989. Statistical method for testing the neutral mutation hypothesis by AND polymorphism. Genetics 123:585-595.

Tamura K, J. Dudley, M. Nei \& S. Kumar. 2007. MEGA4: Molecular Evolutionary Genetics Analysis (MEGA) software version 4.0. Molecular Biology and Evolution 24:1596-1599. (Publication PDF at http://www.kumarlab.net/publications).

Tan, A.M. \& D.B Wake. 1995. MtDNA phylogeography of the California newt Taricha torosa (Caudata, Salamandridae). Molecular Phylogenetics and Evolution 4:383-394.

Tang, Q.G., H.Z. Liu, R. Mayden \& B.X. Xiong. 2006. Comparison of evolutionary rates in the mitochondrial DNA cytochrome $b$ gene and control region and their implications for phylogeny of the Cobitoidea (Teleostei: Cypriniformes). Molecular Phylogenetics and Evolution 39:347-357.

Templeton A.R, K.A Crandall \& C.F. Sing. 1992. A cladistic analysis of phenotypic associations with haplotypes inferred from restriction endonuclease mapping and DNA sequence data. III. Cladogram estimation. Genetics 132:619-633.

Tzeng, C.S., C.F. Hui, S.C. Shen \& P.C Huang. 1992. The complete nucleotide sequence of the Crossostoma lacustre mitochondrial genome: conservation and variations among vertebrates. Nucleic Acids Res. 20:4853-4858. 
Ujvari, B., T. Madsen \& M. Olsson. 2005. Discrepancy in mitochondrial and nuclear polymorphism in meadow vipers (Vipera ursinii) questions the unambiguous use of mtDNA in conservation studies. Amphibia-Reptilia 26:287-292.

Vázquez-Domínguez E., T.G. Susette Castañeda-Rico. 2009. Avances metodológicos para el estudio conjunto de la información genética, genealógica y geográfica en análisis evolutivos y de distribución. Revista Chilena de Historia Natural 82:277-297.

Vawter, L, .\& W. M. Brown. 1986. Nuclear and mitochondrial DNA comparisons reveal extreme rate variation in the niolecular clock. Science 234: 194-196.

Vences, M. \& F. Glaw. 2005. A new species of Mantidactylus from the east coast of Madagascar and its molecular phylogenetic relationships within the subgenus Guibemantis. Herpetological Journal 15:37-44.

Wakeley J. 2007. Coalescent Theory: An Introduction. New York: Roberts and Company Publishers.

Wright, S. 1931. Evolution in Mendelian populations. Genetics 16:97-101.

Wright, S. 1943. Isolation by distance. Genetics 28:114-138.

Wright, S. 1951. The genetical structure of populations. Annals of Eugenics 15:323354.

Wright, S. 1969. Evolution and Genetics of Populations, vol.2, The theory of gene frequencies. University of Chicago Press, Chicago.

Zink, R.M. \& J.D. Weckstein. 2003. Recent evolutionary history of the Fox Sparrows (Genus: Passerella). The Auk 120:522-527.

Zippel, K. C. 1997. Hairy frogs (Trichobatrachus robustus) in the field. Reptiles 5:68-73. 


\section{APÉNDICES}

Apéndice I

Protocolo de extracción de ADN genómico total

1- Cortar el tejido y colocarlo en un tubo de $1,5 \mathrm{ml}$.

2- Agregar $400 \mu \mathrm{l}$ de buffer de lisis y $12 \mu \mathrm{l}$ de proteinaza K.

3- Agitar con vortex y ponerlo en baño térmico a $56^{\circ} \mathrm{C}$ toda la noche.

4- Agitar con vortex y centrífugar.

5- Agregar a cada tubo $200 \mu \mathrm{l}$ de Fenol y $200 \mu \mathrm{l}$ de Cloroformo.

6- Agitar por inversión (hasta que se forma una emulsión).

7- Centrifugar 3 min a $15.000 \mathrm{~g}$.

8- Extraer con pipeta la parte superior sin tocar el fenol ni la interfase.

Precipitación con alcohol

1- Agregar $800 \mu \mathrm{l}$ de etanol absoluto.

2- Mezclar suavemente por inversión ( $\cong 50$ veces).

3- Dejar 45 min. (mínimo) en el freezer.

4- Centrifugar $15 \mathrm{~min}$ a $15.000 \mathrm{~g}$ y volcar el sobrenadante.

5- Agregar $500 \mu \mathrm{l}$ de etanol $70 \%$ y deja reposar 5 min (en hielo).

6- Centrifugar 15 min a $15.000 \mathrm{~g}$ y volcar el sobrenadante.

7- Secar el tubo sobre una servilleta y colocarlo en estufa por 20 min. a 37 ${ }^{\circ} \mathrm{C}$.

8- Resuspender en $10 \mu \mathrm{l}$ de buffer TE $1 \mathrm{X}$, dejar toda la noche en heladera o 2 hs. en baño a $56^{\circ} \mathrm{C}$. 
Apéndice II

En base a la descripción original de Gallardo (1962) y a observaciones personales de Cei y Roig (1968), las diagnosis de las especies del complejo patagonicus-praebasalticus especies pueden resumirse de la siguiente manera:

Atelognathus patagonicus

Anuro leptodactílido raniforme, con extremidades posteriores largas, y extremidades anteriores moderadas, no alcanzando las ingles con la punta del primer dedo, estiradas hacia atrás. La articulación tibiotarsal, estirando la extremidad hacia adelante, no alcanza el ojo, sino la región axilar o timpánica. Cabeza aguda de proyección casi triangular, inferior a $1 / 3$ de la longitud total del cuerpo; más ancha que larga o subigual. Canto rostral poco evidente. Distancia entre narina y ojo mayor que entre narina y hocico. Diámetro ocular casi igual al ancho del párpado superior. Distancia del ojo al hocico siempre mayor, o subigual, al diámetro ocular. Tímpano no visible, cubierto por pliegue cutáneo que se origina del ángulo de la boca. Dientes maxilares vestigiales, débiles de diferente desarrollo individual. Dientes vomerianos a veces vestigiales o ausentes, con crestas vomerianas sobresalientes. Lengua más ancha que larga sin escotadura posterior, libre posterior y lateralmente. Labio superior sobresaliente al inferior. Dedos de la mano libres $\left(3^{\circ}>4^{\circ}>2^{\circ}=1^{\circ}\right)$, con extremos redondeados. Tubérculos subarticulares evidentes; tubérculos subcarpales bien desarrollados, interno alargado y saliente, extremo subtriangular y más aplanado,y tubérculos pequeños en la base de los dedos. Fémur igual o poco más corto que la tiebia. Membrana interdigital muy desarrollada, llegando hasta el extremo de todos los dedos. Tubérculos metatarsales robustos, el interno alargado y el externo redondeado. Piel suave, lisa, fuertemente vascularizada, formando pliegues ondulantes en la región lateral y ventral del tronco y sobre los fémures (bagginess). Pigmentación dorsal de manchas confusas. Pigmentación ventral escasa. 
Tamaño de los adultos entre 26 y $42 \mathrm{~mm}$. Caracteres sexuales poco evidentes. No se evidencias diferencias sexuales en el tamaño. Color en vivo: fondo dorsal aceitunado-gris. Coloración ventral amarilla con matices anaranjados.

\section{Atelegnathus praebasalticus}

Cei y Roig (1968) describieron esta especie a parir de individuos colectados en laguna Tero y Burro (Zapala, Neuquén) cuya diagnosis se detalla a continuación:

Anuro leptodactílido raniforme, de tamaño modesto, esbelto. Extremidades posteriores largas, alcanzando con la articulación tibio-tarsal el borde posterior del ojo. La extremidad anterior es llega a la ingle con la punta del tercer dedo. Cabeza robusta, más de 1/3 del largo total del cuerpo, más larga que ancha con hocico redondeado, casi truncado. Proyección de la cabeza redondeada. Narinas muy próximas a la punta del hocico. Diámetro ocular mayor que el espacio interocular. Espacio interocular mayor o igual al párpado superior. Distancia entre ojo y hocico algo mayor, o subigual, al diámetro ocular. Distancia entre ojo y hocico algo mayor, o subigual al diámetro ocular. Tímpano bajo la piel pero no cubierto por pliegue cutáneo; un pliegue supratimánico desde el párpado hasta la axila. Dientes maxilares reducidos, débiles. Dientes vomerianos a presentes, relativamente desarrollados en dos pequeños grupos entre las coanas. Lengua subcircular libre posterior y lateralmente. Labio superior no sobresaliente al inferior. Dedos de la mano libres $\left(3^{\circ}>4^{\circ}>2^{\circ}=1^{\circ}\right)$, con extremos redondeados. Tubérculos subarticulares poco relevantes; tubérculos subarticulares poco relevantes; tubérculo metacarpal interno alargado; interno alargado y poco saliente. Fémur igual o subigual a la tiebia. Membrana interdigital escotada. Tubérculos subarticulares de los dedos del pie redondeados y suaves. Pliegue tarsal reducido a un simple borde cutáneo. Tubérculos metatarsales poco salientes, el interno más alargado y prominente. Piel suave, lisa, sin pliegues laterales o bagginess. Pigmentación dorsal de manchas esfumadas pero definidas, oscuras, simétricas, con bordes más claros; manchas interocular y bandas 
oscuras sobre fémur, tibia y antebrazos evidentes. Tamaño de los adultos entre 26 y $34 \mathrm{~mm}$. Caracteres sexuales poco evidentes. Color en vivo: fondo dorsal grisáceo con matices amarillentos o verdosos. Coloración ventral banquecina sin manchas (Cei y Roig, 1968).

Atelognathus praebasalticus ha sido subdividida en cuatro subespecies ( $A$. praebasalticus praebasalticus de laguna Blanca y lagunas cercanas, $A$. praebasalticus agilis de la Meseta de Casa de Piedra, A. praebasalticus luisi de laguna Overa y Catán Lil, A. praebasalticus dobeslawi de la laguna El Piojo, en la Barda de Santo Tomás (Cei, 1972).

- Atelognathus praebasalticus praebasalticus

Descripción: anuro leptodactílido raniforme, de tamaño modesto, esbelto. Extremidades posteriores largas, alcanzando con la articulación tibio-tarsal el borde posterior del ojo. La extremidad anterior estirada hacia atrás, llega a las ingles con la punta del $3^{\circ}$ dedo. Cabeza robusta, más de 1/3 del largo total del cuerpo, más ancha que larga, con hocico redondeado, casi truncado. Proyección de la cabeza redondeada. Narinas muy próximas a la punta del hocico (índices distancia ojo-narina/narina-hocico entre 1,45 y 3,50). Diámetro ocular mayor que el espacio interocular. Espacio interocular mayor o igual al párpado superior. Distancia entre ojo y hocico algo mayor o subigual al diámetro ocular. Tímpano bajo la piel pero no cubierto por pliegues cutáneos; un pliegue supratimpánico desde el párpado hasta la axila. Dientes maxilares reducidos, débiles; dientes vomerianos presentes, relativamente desarrollados, en dos pequeños grupos entre las coanas. Legua subcircular libre posterior y lateralmente. Labio superior no sobresaliente al inferior. Dedos de la mano libres, con extremos redondeados; orden de tamaño $3^{\circ}<4^{\circ}<2^{\circ}=1^{\circ}$. Tubérculos subarticulares poco relevantes; tubérculo metacarpal interno alargado. Fémur igual o subigual a la tibia. Membrana interdigital escotada. Tubérculos subarticulares de los dedos del pie 
redondeados y suaves. Pliegue tarsal reducido a un simple borde cutáneo.

Tubérculos metatarsales poco salientes, el interno más alargado y prominente.

Piel suave, lisa, sin pliegues laterales o bagginess. Pigmentación dorsal de manchas esfumadas pero definidas, oscuras, simétricas, con bordes más claros; manchas ineroculares y bandas oscuras sobre fémur, tibia y antebrazo evidentes.

\section{- Atelognathus praebasalticus agilis}

Diagnosis: Telmatobius semiterrestre de tamaño mediano, de extremidades posteriores y anteriores largas; fémur más largo que la tibia; dedos del pie con membrana interdigital escotada. Coloración grisácea con manchas oscuras y faz ventral finamente jaspeada.

Descripción: leptodactílido raniforme, de modesto tamaño. Cabeza mayor que 1/3 de la longitud del cuerpo, aplanada, más ancha que larga, con hocico obtuso. Narices muy próximas a la punta del hocico, más que en la forma nominal (índices: distancia ojo-nariz/ nariz-hocico:2,80 en 2 machos estudiados y entre 2,80-4,26 en 5 hembras. Diámetro ocular menor que el espacio interocular, que es mayor que el párpado superior. Distancia entre ojo y hocico netamente mayor que el diámetro ocular. Tímpano no visible; pliegue supratimánico desde el ojo a la axila, evidente. Dientes maxilares débiles; dientes vomerianos en dos grupos redondeados entre y a la altura del borde superior de las coanas. Lengua subcircuñar libre, posterior y lateralmente. Labio superior no sobresaliente. Extremidades posteriores largas, esbeltas: estiradas hacia delante pasando el ojo con la articulación tibio-tarsal en los machos, alcanzando el borde posterior en las hembras. Extremidades anteriores largas, alcanzando el coxis o pasando las ingles con la punta del $3^{\circ}$ dedo en ambos sexos. Fémur más largo que la tibia (índices entre 1,08 - 1,15, contra 0,87 - 1,00 en la forma nomina). Dedos de la mano libres; orden de longitud $3^{\circ}>4^{\circ}>2^{\circ}=1^{\circ}$. Tubérculos: subarticulares desarrollados, metacarpales y metatarsales robustos, los internos más alargados y 
sobresalientes. Membrana interdigital hasta $2 / 3$ de los dedos del pie. Piel lisa, sin láminas cutáneas, con placas glandulares pequeñas, poco evidentes. Pliegue discoidal ventral. Pigmentación dorsal: fondo grisáceo con manchas irregulares, algo simétricas, de bordes confusos, a veces con puntos centrales rojizos. Superficie ventral lisa, blanquecina, con fina pigmentación negruzca.

- Atelognathus praebasalticus luisi

Diagnosis: Telmatobius semiterrestre de tamaño mediano, con extremidades posteriores y anteriores cortas; fémur igual o subigual a la tibia, membrana de los dedos del pie poco escotada; coloración verdeoso-grisácea con manchas brillantes y pigmentación anaranjada axilar e inguinal; reticulación ventral sobre fondo amarillento.

Descripción: Leptodacílido raniforme, de aspecto robusto y de mediano tamaño. Cabeza 1/3 de la longitud del cuerpo, con hocico redondeado. Narices muy próximas a la punta del hocico (índices: distacias ojo-nariz/nariz-hocico 2,80-3,75 en 10 machos y 2,50-3,75 en 10 hembras). Diámetro ocular mayor que el espacio interocular que es igual al párpado superior. Distancia ojo-hocico mayor que el diámetro ocular. Tímpano no visible; débil pliegue supra-timánico entre ojo y axila. Dientes maxilares pocos desarrollados; dientes vomerianos en dos grupos cónicos prominentes entre las coanas y en su borde superior. Lengua libre, subcordiforme. Labio superior no sobresaliente. Extremidades posteriores cortas, alcanzando a penas la región post-timpánicas (machos) o la espalda (hembras) con la articulación tibiotarsal, estiradas hacia adelante. Extremidad anterior corta, no alcanzando o a penas alcanzando las íngles con la punta del $3^{\circ}$ dedo. Fémur igual o subigual a la tibia. Dedos de la mano libres: orden de longitud: $3^{\circ}>4^{\circ}>2^{\circ}=1^{\circ}$. Tubérculos: subarticulares desarrollados, metacarpales y metatarsales como en la forma nominal. Membrana interdigital ancha, más de 273 de los dedos del pie. Piel lisa, resbaladiza, sin relieves glandulares evidentes. Pliegue discoidal poco reconocible. Coloración dorsal 
aceitunado-grisácea o amaríllenlas con manchas oscuras redondeadas o alargadas, definidas a veces con puntos claros o rojizos en su área central. Manchas interoculares bien reconocibles, alargadas. Reticulaciones negras sobre fondo amarillento blanquecino o anaranjado en la región posterior del muslo: manchas efumadas amarillas o anaranjadas axilares o inguinales. Vientre amarillento blanquecino con matices púrpura y reticulaciones grisáceas; superficie inferior de los muslos granulosa, amarillenta. Bandas oscuras transversales netas, sobre las extremidades. En los ejemplares observados el patrón de coloración se hace más confuso, y el fondo más negruzco, desapareciendo los colores anaranjados y amarillos.

- Atelognathus praebasalticus dobeslawi

Diagnosis: Telmatobius semiterrestre, de tamaño mediano, esbelto, de extremidades anteriores y posteriores largas; fémur poco más largo que la tibia; narices terminales; membrana interdigital ancha; coloración amarillento grisácea con manchas oscuras y puntos centrales rojizos; pigmentos amarillos axilares e inguinales poco llamativos; reticulaciones ventrales evidentes.

Descripción: Leptodactílido raniforme, de tamaño mediano. Cabeza 1/3 de la longitud del cuerpo, más ancha que larga, con hocico truncado, prominente. Narices casi sobre la punta del hocico (índices: distancia ojo-nariz/nariz-hocico entre 3,00 y 4,00 en cuatro machos y 3,00-6,00 en diez hembras). Diámetro ocular igual o subigual al espacio interocular, que es mayor que el párpado superior. Distancia entre ojo y hocico mayor que el diámetro ocular. Tímpano no reconocible; pliegue supratimpánico poco evidente. Dientes maxilares fuertes, dientes vomerianos en dos grupos sobresalientes entre las coanas y en su región mediana. Lengua subcircular, libre. Labio superior sobresaliente. Extremidades posteriores largas, alcanzando con la articulación tibio-tarsal la parte posterior del ojo (en machos) o la parte anterior del tímpano (en hembras). Extremidades anteriores largas pasando las ingles con la 
punta del $3^{\circ}$ dedo. Fémur algo más largo que la tibia. Dedos de la mano libres, pero con borde cutáneo evidente; orden de longitud: $3^{\circ}>4^{0}>2^{\circ}>1^{\circ}$. Tubérculos:

subarticulares muy robustos y prominentes, metacarpales iguales o subyúgales, ovalados y sobresalientes, metatarsales fuertes, el exterior más desarrollado que el interior. Membrana interdigital de los pies ancha, hasta la punta de los dedos en los machos, algo escotada en las hembras. Piel lisa o finamente granulosa, con relieves o verrugas dorsales pequeñas, pigmentadascon área central clara: centralmente lisa, con granulaciones blanquecinas en los muslos. Pliegue discoidal ventral. Coloración: fondo dorsal amarillento, a veces grisáceo, con manchas oscuras algo efumadas, anastomosadas longitudinalmente o aisladas, circulares, con puntos claros centrales rojizos, los que se hacen más densos en los párpados que en la región cefálica. Manchas oscuras interoculares en forma de W, alargada. Coloración amarillenta axilar e inguinal, con manchas reticuladas. Superficie ventral blanquecina con pigmentación distribuidas según reticulaciones irregulares, espaciadas. Bandas oscuras en la superficie dorsal de las extremidades. 
Apéndice III

\section{ARLEQUIN}

El programa Arlequin (versión actual 2001), liberado en 1997, todavía es muy popular. Consiste en 'un ambiente de programa informático tipo explorador en genética de poblaciones, capaz de manejar grandes muestras de datos moleculares (RFLP, secuencias de ADN, microsatélites), mientras que conserva la capacidad de analizar datos genéticos convencionales (datos estándar de múltiples loci o los meros datos de frecuencia alélica).

Arlequin puede usar muchos tipos diferentes de datos, tales como datos moleculares y frecuencias genotípicas o haplotípicas, incluyendo datos codominantes o recesivos, pero no todavía datos dominantes. Los datos moleculares pueden ser entrados como secuencias de ADN, haplotipos de RFLP, perfiles de microsatélites o haplotipos de múltiples loci. El formato de datos se especifica en un archivo de entrada. El usuario puede crear un archivo de datos desde el principio, utilizando un editor de texto y palabras clave apropiadas, o utilizando el 'Project OutlineWizard'. Los datos pueden importarse de los archivos creados por otros programas, incluyendo MEGA, BIOSYS, GENEPOP y PHYLIP. Pueden existir datos ausentes o ambiguos. Existe un manual de usuario muy detallado, que incluye una gran cantidad de información teórica, fórmulas y referencias. Este programa tiene la capacidad de analizar una cantidad importante de datos y hay una opción "Batch Files" (archivo por tandas) disponible.

Autores: Laurent Excoffier, Stefan Schneider y David Roessli, Universidad de Ginebra, Suiza.

\section{DNASP}

El programa DnaSP, para el Polimorfismo de Secuencias de ADN, utiliza datos de secuencia de ADN. Este programa se usa ampliamente para el análisis de secuencias porque realiza todos los análisis necesarios $\mathrm{y}$, al mismo tiempo, es fácil de manejar. Se escribió exclusivamente para el sistema operativo Windows, pero puede 
ser ejecutado en un Macintosh mediante los emuladores SoftWindows o VirtualPC. DnaSP puede importar y exportar varios tipos de formatos de datos, incluyendo FASTA y NEXUS, lo cual es muy conveniente. Puede manejar grandes cantidades de secuencias largas, dependiendo de la memoria del computador. Los autores están trabajando actualmente en la versión 4. Está disponible en forma gratuita y se puede bajar del sitio en la Web. Aunque no hay manual disponible, hay un archivo de Ayuda incorporado en el programa. Además, en el sitio Web se incluye mucho material explicativo, así como numerosas referencias. Los autores han preparado varias publicaciones acerca del programa (por ejemplo, remitirse a las citas que aparecen a continuación).

Autores: Julio y Ricardo Rozas

MEGA

El programa MEGA (Molecular Evolutionary Genetics Analysis) ha sido ampliamente utilizado desde su creación en 1993. Ya salió MEGA4. Utiliza datos de secuencia de $\mathrm{ADN}$, secuencias de proteínas, y distancia evolutiva o de árboles filogénicos. El objetivo de los autores fue el de aprovechar los adelantos en la capacidad de los computadores y las interfases gráficas para proporcionar una 'plataforma de trabajo de análisis de datos genéticos que sea flexible y fácil de usar'. Aunque fue diseñado para el sistema operativo Windows, funciona bien en Macintosh con un emulador de Windows, una terminal Sun (con SoftWindows95) o Linux (con Windows por VMWare). Las versiones más recientes tienen muchas adiciones importantes, como la capacidad para importar datos de NEXUS o CLUSTAL W, tamaños ilimitados de series de datos y muchos otros.

Un libro escrito por Nei y Kumar (2000), los autores de ese programa, aporta información teórica acerca de los análisis estadísticos y la manera de interpretar los resultados de su programa informático y otros. Hay un manual exhaustivo disponible en línea (aunque no es fácil recorrer el formato), junto con una cartelera para que los usuarios interactúen entre sí.

Autores: Sudhir Kumar, Koichiro Tamura, Ingrid Jakobsen y Masatoshi Nei. 